Atmos. Chem. Phys., 3, 1301-1336, 2003

www.atmos-chem-phys.org/acp/3/1301/

\title{
Inorganic bromine in the marine boundary layer: a critical review
}

\author{
R. Sander ${ }^{1}$, W. C. Keene ${ }^{2}$, A. A. P. Pszenny ${ }^{3}$, R. Arimoto ${ }^{4}$, G. P. Ayers ${ }^{5}$, E. Baboukas ${ }^{1}$, J. M. Cainey ${ }^{6}$, P. J. Crutzen ${ }^{1}$, \\ R. A. Duce ${ }^{7}$, G. Hönninger ${ }^{8}$, B. J. Huebert ${ }^{9}$, W. Maenhaut ${ }^{10}$, N. Mihalopoulos ${ }^{11}$, V. C. Turekian $^{12}$, and \\ R. Van Dingenen ${ }^{13}$ \\ ${ }^{1}$ Air Chemistry Department, Max-Planck Institute of Chemistry, P.O. Box 3060, 55020 Mainz, Germany \\ ${ }^{2}$ Department of Environmental Sciences, University of Virginia, Charlottesville, VA 22903, USA \\ ${ }^{3}$ Center for Global Change Science, Massachusetts Institute of Technology, Cambridge, MA 02139, USA. Now at: Climate \\ Change Research Center, Institute for the Study of Earth, Oceans, and Space, University of New Hampshire, Durham, NH \\ 03824, and Mount Washington Observatory, P.O. Box 2310, North Conway, NH 03860, USA \\ ${ }^{4}$ CEMRC/New Mexico State University, 1400 University Drive, Carlsbad, NM 88220, USA \\ ${ }^{5}$ CSIRO Atmospheric Research, Private Bag No. 1, Aspendale 3195, Australia \\ ${ }^{6}$ Cape Grim Baseline Air Pollution Station, 159 Nelson Street, Smithton, Tasmania 7330, Australia \\ ${ }^{7}$ Depts. of Oceanography and Atmospheric Sciences, Texas A\&M University, TAMU-3146, College Station, TX 77843-3146, \\ USA \\ ${ }^{8}$ Institut für Umweltphysik, Universität Heidelberg, INF 229, 69120 Heidelberg, Germany. Now at: Meteorological Service of \\ Canada, 4905 Dufferin Street, Toronto, Ont. M3H 5T4, Canada \\ ${ }^{9}$ Department of Oceanography, University of Hawaii, 1000 Pope Road, Honolulu, HI 96822, USA \\ ${ }^{10}$ Ghent University, Department of Analytical Chemistry, Institute for Nuclear Sciences, Proeftuinstraat 86, B-9000 Gent, \\ Belgium \\ ${ }^{11}$ Environmental Chemical Processes Laboratory, Department of Chemistry, University of Crete, P.O. Box 1470, 71409 \\ Heraklion, Greece \\ ${ }^{12}$ National Academy of Sciences, 2101 Constitution Ave. NW, Washington, DC 20418, USA \\ ${ }^{13}$ European Commission, DG Joint Research Centre, Institute for Environment and Sustainability, T.P 290, I-21020 Ispra \\ (VA), Italy
}

\begin{abstract}
The cycling of inorganic bromine in the marine boundary layer $(\mathrm{mbl})$ has received increased attention in recent years. Bromide, a constituent of sea water, is injected into the atmosphere in association with sea-salt aerosol by breaking waves on the ocean surface. Measurements reveal that supermicrometer sea-salt aerosol is substantially depleted in bromine (often exceeding 50\%) relative to conservative tracers, whereas marine submicrometer aerosol is often enriched in bromine. Model calculations, laboratory studies, and field observations strongly suggest that the supermicrometer depletions reflect the chemical transformation of particulate bromide to reactive inorganic gases that influence the processing of ozone and other important constituents of marine air. Mechanisms for the submicrometer enrichments are not well understood. Currently available techniques cannot reliably quantify many $\mathrm{Br}$-containing compounds at ambient concentrations and, consequently, our understanding of inorganic $\mathrm{Br}$ cycling over the oceans and its global significance are uncertain. To provide a more coher-
\end{abstract}

Correspondence to: R. Sander

(sander@mpch-mainz.mpg.de) ent framework for future research, we have reviewed measurements in marine aerosol, the gas phase, and in rain. We also summarize sources and sinks, as well as model and laboratory studies of chemical transformations. The focus is on inorganic bromine over the open oceans outside the polar regions. The generation of sea-salt aerosol at the ocean surface is the major tropospheric source producing about $6.2 \mathrm{Tg} / \mathrm{a}$ of bromide. The transport of $\mathrm{Br}$ from continents (as mineral aerosol, and as products from biomass-burning and fossil-fuel combustion) can be of local importance. Transport of degradation products of long-lived Br-containing compounds from the stratosphere and other sources contribute lesser amounts. Available evidence suggests that, following aerosol acidification, sea-salt bromide reacts to form $\mathrm{Br}_{2}$ and $\mathrm{BrCl}$ that volatilize to the gas phase and photolyze in daylight to produce atomic $\mathrm{Br}$ and $\mathrm{Cl}$. Subsequent transformations can destroy tropospheric ozone, oxidize dimethylsulfide (DMS) and hydrocarbons in the gas phase and S(IV) in aerosol solutions, and thereby potentially influence climate. The diurnal cycle of gas-phase $\mathrm{Br}$ and the corresponding particulate $\mathrm{Br}$ deficits are correlated. Higher values of $\mathrm{Br}$ in the 
gas phase during daytime are consistent with expectations based on photochemistry. We expect that the importance of inorganic $\mathrm{Br}$ cycling will vary in the future as a function of both increasing acidification of the atmosphere (through anthropogenic emissions) and climate changes. The latter affects bromine cycling via meteorological factors including global wind fields (and the associated production of sea-salt aerosol), temperature, and relative humidity.

\section{Introduction}

Marchand (1852) reported what were probably the first atmospheric measurements of bromine (in rain). The next data were obtained more than 100 years later (Behne, 1953). Aerosol bromine was first measured by Duce et al. (1963) at Hawaii. Inorganic bromine compounds, especially $\mathrm{Br}, \mathrm{BrO}$, and $\mathrm{HOBr}$, are reactive and have the ability to destroy ozone catalytically. It is known that they contribute to the destruction of the stratospheric ozone layer (e.g. WMO, 1998). In addition, bromine may also affect ozone in the troposphere. Zafiriou (1974) was the first to notice that halogen atoms in the marine boundary layer $(\mathrm{mbl})$ would rapidly react with ozone. Summaries of these early results were presented by Duce and Hoffman (1976), Berg and Winchester (1978), Cicerone (1981), and Sturges and Harrison (1986b). Today, many new measurements are available which were made subsequent to these reviews. Several field experiments have shown the importance of tropospheric bromine chemistry in polar regions during spring (e.g. Barrie et al., 1988) and near salt lakes (e.g. Hebestreit et al., 1999). Apparently, reactions involving frozen sea water or solid salt crystals play a role there. However, the global role of marine bromine chemistry is still uncertain.

This review focuses on inorganic bromine chemistry over the open oceans, with emphasis on areas outside the polar regions. We have compiled atmospheric measurements of inorganic bromine in marine aerosol, rain drops, and the gas phase. We also review relevant model studies and laboratory measurements. Available data have been assembled and analyzed to gain insight concerning the physical and chemical processes that control inorganic bromine in the mbl. Specific questions that are addressed include:

- How does the chemical composition of the aerosol vary with particle size?

- How does it change with altitude and latitude?

- What are the diurnal and seasonal variations?

- Is particulate bromine in marine air correlated with ambient acids and sea-salt concentrations?

- Are there bromine sources in addition to sea salt?

\section{Measurement techniques, data quality and analysis}

\subsection{Aerosol measurements}

Particulate bromine as well as sea-salt reference species (e.g. $\mathrm{Na}, \mathrm{Mg}$ ) and crustal reference species (e.g. $\mathrm{Al}$ ) have been measured in marine air using several approaches. The most common techniques involve sampling aerosol over periods of hours to days either in bulk on a single filter (e.g. Kritz and Rancher, 1980) or as a function of size using either a 2-stage stacked filter unit (SFU) (e.g. Raemdonck et al., 1986) or inertial, multi-stage cascade impactors (CI) (e.g. Duce et al., 1965). Samples are then analyzed using various approaches including neutron activation analysis (NAA) for total $\mathrm{Br}, \mathrm{Na}, \mathrm{Mg}$, and $\mathrm{Al}$ (e.g. Arimoto et al., 1987), atomic absorption spectroscopy (AAS, also abbreviated AA) for total $\mathrm{Na}$ and $\mathrm{Mg}$ (e.g. Galloway et al., 1982), ion chromatography (IC) for $\mathrm{Br}^{-}, \mathrm{Na}^{+}$, and $\mathrm{Mg}^{2+}$ (e.g. Ayers et al., 1999), X-ray fluorescence (XRF) for total $\mathrm{Br}$ and $\mathrm{Na}$ (e.g. Sturges et al., 1985), and particle-induced X-ray emission (PIXE, also called proton-induced X-ray emission) for total Br, Na, and Mg (e.g. Andreae, 1982). Recently, several aerosol mass spectrometers have been developed to analyze the molecular (or molecular fragment) composition of single particles as a function of size (PALMS = particle analysis by laser mass spectrometry (Murphy et al., 1997); ATOFMS = aerosol time-of-flight mass spectrometry (Gard et al., 1998); AMS $=$ aerosol mass spectrometry (Jayne et al., 2000)).

Bromide $\left(\mathrm{Br}^{-}\right)$is the dominant form of inorganic bromine in sea water (Stumm and Brauner, 1975). It is therefore tempting to assume that all of the inorganic bromine in seasalt aerosol samples is also bromide. As described in more detail below, however, other brominated species may be associated with atmospheric aerosols. In addition, different analytical approaches quantify different pools of bromine. For example, NAA detects all chemical forms of bromine whereas IC detects only $\mathrm{Br}^{-}$. Consequently, reported measurements of total particulate bromine and particulate bromide may not be directly comparable. In this paper, we use the term 'bromine' and the symbol Br to denote the total of all bromine compounds. We only use 'bromide' if the ion $\mathrm{Br}^{-}$is meant specifically.

In addition to potential differences resulting from speciesspecific versus non-specific measurement techniques, several other factors can influence the comparability of the resulting data. The geometry of inlets and associated sampling rates impart an effective upper limit for the size of aerosols sampled by different devices. In addition, physical effects such as non-isokinetic flow at sampler inlets (e.g. Rader and Marple, 1988) or wall losses within inlets (e.g. Huebert et al., 1990) may introduce significant bias, particularly in the collection of supermicrometer aerosol from aircraft. Consequently, vertical profiles of sea-salt composition are very poorly constrained. Some cascade impactors may also experience significant internal losses of particles (e.g. Willeke, 1975). Fi- 
nally, the current generation of aerosol mass spectrometers is not capable of analyzing larger marine aerosol, which dominate the flux of atmospheric sea salt and related compounds. Reported data from these instruments are limited to the lower end of the sea-salt size distribution (less than about $3 \mu \mathrm{m}$ diameter). The above limitations in our ability to reliably characterize the upper end of marine aerosol size distributions contribute to the wide range in estimated fluxes of sea salt and associated compounds (e.g. Andreae, 1995; Graedel and Keene, 1995).

In certain techniques, such as NAA, XRF, and PIXE, the filter (or collection substrate) is normally analyzed together with the aerosol deposit. This calls for careful blank corrections. In some filter types, in particular Nuclepore ${ }^{\circledR}$ filters, the blank values of $\mathrm{Br}$ can be quite high and they can vary substantially from lot (batch) number to lot number. Blank filters of the same lot as used for the actual aerosol collections should therefore be analyzed. Failure to do so may have given rise to some erroneous (outlier) data in the literature.

Another concern is the possibility of a change in composition during the collection process. Mixing chemically distinct particles on sampling media (e.g. highly acidic sulfate aerosol with sea-salt aerosol on bulk filters) can lead to volatilization of $\mathrm{HCl}$ via acid displacement reactions. Fortunately, this is not the case for bromide because the effective solubility of $\mathrm{HBr}$ is much larger than that of $\mathrm{HCl}$. For recent paired measurements of particulate $\mathrm{Br}$ in size-segregated and bulk aerosol samples collected in coastal air at Hawaii, $\mathrm{Br}$ in bulk aerosol samples was found to be conservative (Keene, unpublished). However, gases such as $\mathrm{HOBr}$ and $\mathrm{O}_{3}$ in air streams may chemically interact with previously sampled aerosols on collection media (as they do in the atmosphere) during the relatively long exposure times (hours) required for most conventional measurement techniques. Such processes could cause significant post-collection artifacts. To our knowledge, the potential magnitudes of such bias in the measurement of particulate $\mathrm{Br}$ have not been evaluated experimentally.

Sampling locations and periods may not be regionally or temporally representative, respectively, thereby potentially compromising comparability among reported data. For instance, enhanced turbulence in coastal zones (surf) produces locally high concentrations of sea salt relative to off-shore locations. Sharp altitudinal gradients in sea salt (e.g. Blanchard et al., 1984) lead to substantial variability in measured concentrations as a function of sampling height. Since sea-salt aerosol production strongly depends on wind speed (Gong et al., 2002, 1997, and references therein), temporal variability in wind fields leads to large changes in sea-salt aerosol concentrations (e.g. Erickson et al., 1999). Finally, the relative amounts of sea salt and of acids and bases (both natural and anthropogenic) in the multiphase system vary as functions of proximity to and strengths of their respective upwind sources. Chemical interactions of this mixture together with ambient relative humidity control aerosol $\mathrm{pH}$ (Keene
Table 1. Concentrations of selected elements in sea water at $3.5 \%$ salinity (Wilson, 1975) and element ratios used to calculate enrichment factors

\begin{tabular}{|c|c|c|c|c|}
\hline \multirow[b]{2}{*}{$\mathrm{Cl}$} & \multicolumn{2}{|c|}{ based on mass } & \multicolumn{2}{|c|}{$\begin{array}{l}\text { based on amount } \\
\text { of substance }\end{array}$} \\
\hline & 19.35 & $\mathrm{~g} / \mathrm{kg}$ & 0.5459 & $\mathrm{~mol} / \mathrm{kg}^{*}$ \\
\hline $\mathrm{Br}$ & 0.0673 & $\mathrm{~g} / \mathrm{kg}$ & 0.000842 & $\mathrm{~mol} / \mathrm{kg}^{*}$ \\
\hline $\mathrm{Na}$ & 10.77 & $\mathrm{~g} / \mathrm{kg}$ & 0.4685 & $\mathrm{~mol} / \mathrm{kg}^{*}$ \\
\hline $\mathrm{Mg}$ & 1.290 & $\mathrm{~g} / \mathrm{kg}$ & 0.05306 & $\mathrm{~mol} / \mathrm{kg}^{*}$ \\
\hline $\mathrm{Ca}$ & 0.4121 & $\mathrm{~g} / \mathrm{kg}$ & 0.01028 & $\mathrm{~mol} / \mathrm{kg}^{*}$ \\
\hline $\mathrm{Br} / \mathrm{Na}$ & 0.00625 & $\mathrm{~kg} / \mathrm{kg}$ & 0.00180 & $\mathrm{~mol} / \mathrm{mol}$ \\
\hline $\mathrm{Br} / \mathrm{Cl}$ & 0.00348 & $\mathrm{~kg} / \mathrm{kg}$ & 0.00154 & $\mathrm{~mol} / \mathrm{mol}$ \\
\hline $\mathrm{Br} / \mathrm{Mg}$ & 0.0522 & $\mathrm{~kg} / \mathrm{kg}$ & 0.0159 & $\mathrm{~mol} / \mathrm{mol}$ \\
\hline $\mathrm{Br} / \mathrm{Ca}$ & 0.163 & $\mathrm{~kg} / \mathrm{kg}$ & 0.0819 & $\mathrm{~mol} / \mathrm{mol}$ \\
\hline $\mathrm{Cl} / \mathrm{Na}$ & 1.797 & $\mathrm{~kg} / \mathrm{kg}$ & 1.165 & $\mathrm{~mol} / \mathrm{mol}$ \\
\hline
\end{tabular}

* Note that this refers to $\mathrm{kg}$ of sea water and not to $\mathrm{kg}$ of solvent. It thus is not a molality.

and Savoie, 1998, 1999; Erickson et al., 1999; Keene et al., 2002) and related $\mathrm{pH}$-dependent processes involving particulate $\mathrm{Br}$ (e.g. Keene et al., 1998; Ayers et al., 1999).

\subsection{The enrichment factor $E F$}

Concentrations of aerosol bromine in the mbl can vary over a large range. The flux of sea-salt $\mathrm{Br}$ is mainly a function of wind speed, which drives the generation of sea-salt particles. Thus, it is often useful to interpret bromine data relative to conservative constituents of sea salt. Concentrations of selected elements in sea water are shown in Table 1. In the absence of significant mineral dust, $\mathrm{Na}$ and $\mathrm{Mg}$ are generally conservative tracers of sea salt in the mbl (e.g. Keene et al., 1986). They are major components of sea salt and stable ions that are not known to undergo chemical reactions in the atmosphere. However, at low concentrations typical of submicrometer marine aerosol, random analytical variability can lead to spurious departures from seawater composition.

Other constituents of sea-salt aerosol including $\mathrm{Ca}, \mathrm{K}$, and $\mathrm{Cl}$ have also been used as tracers of the sea-salt component. However, these tracers are often not conservative. For example, crustal dust contains significant $\mathrm{Ca}$ and $\mathrm{K}$; biomass burning emits particles enriched in $\mathrm{K}$; and $\mathrm{Cl}$ is displaced from acidified sea-salt aerosols as $\mathrm{HCl}$. In addition, for some techniques (e.g. AAS), the analytical resolutions for $\mathrm{Ca}$ and $\mathrm{K}$ are relatively lower than those for $\mathrm{Na}$ and $\mathrm{Mg}$. In some of the older Br data sets, paired measurements of $\mathrm{Na}$ or $\mathrm{Mg}$ were not reported. In such cases, other sea-salt tracers were used (see column 4 in Table 2), which makes the estimates of bromine enrichments less certain. In particular, several early papers used $\mathrm{Cl}$ as the reference species. In very remote regions where chlorine deficits relative to sea salt are typically low, errors will be small. However, in polluted regions where 
Table 2. Bromine depletions measured in marine aerosol samples

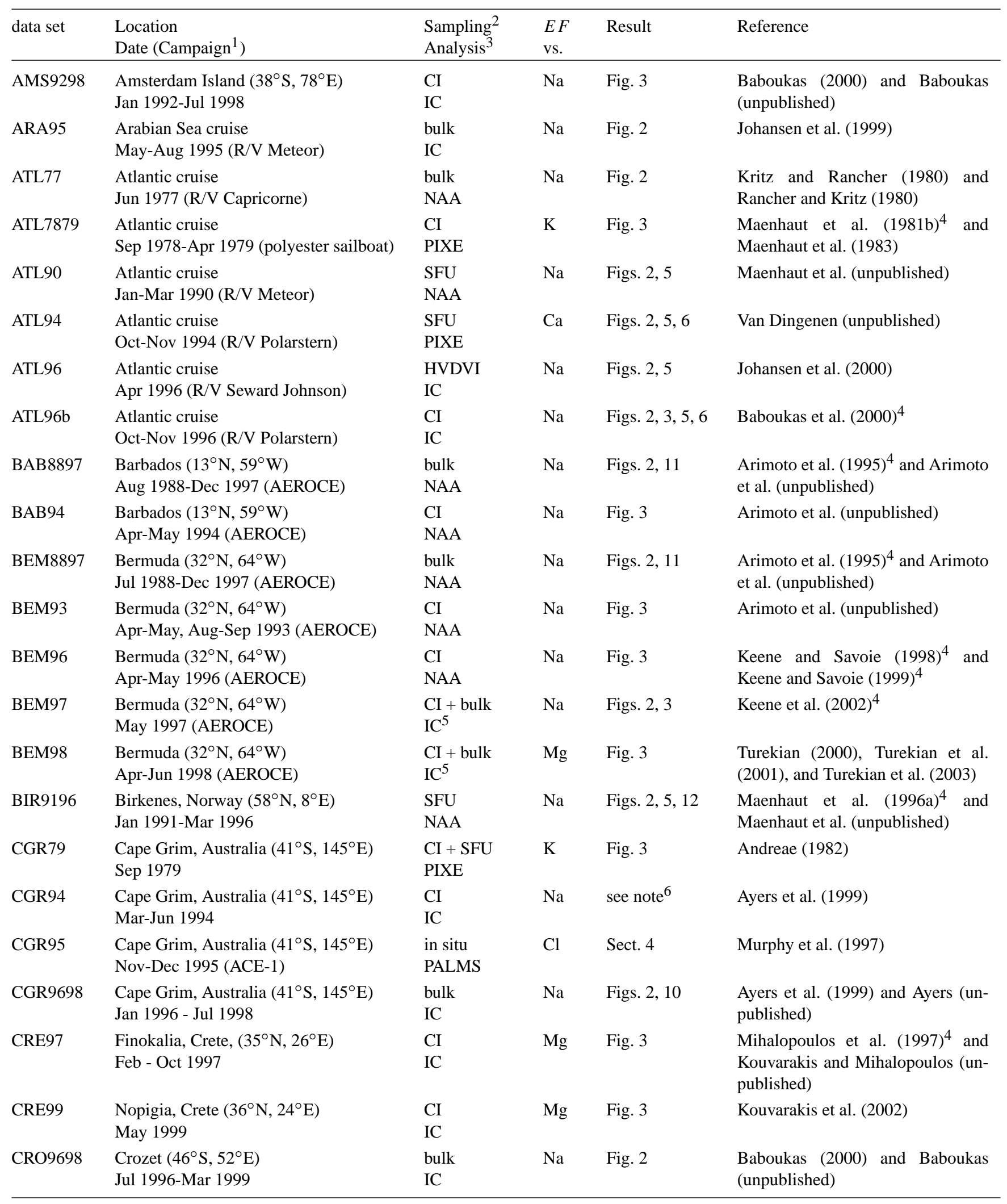


Table 2. (continued)

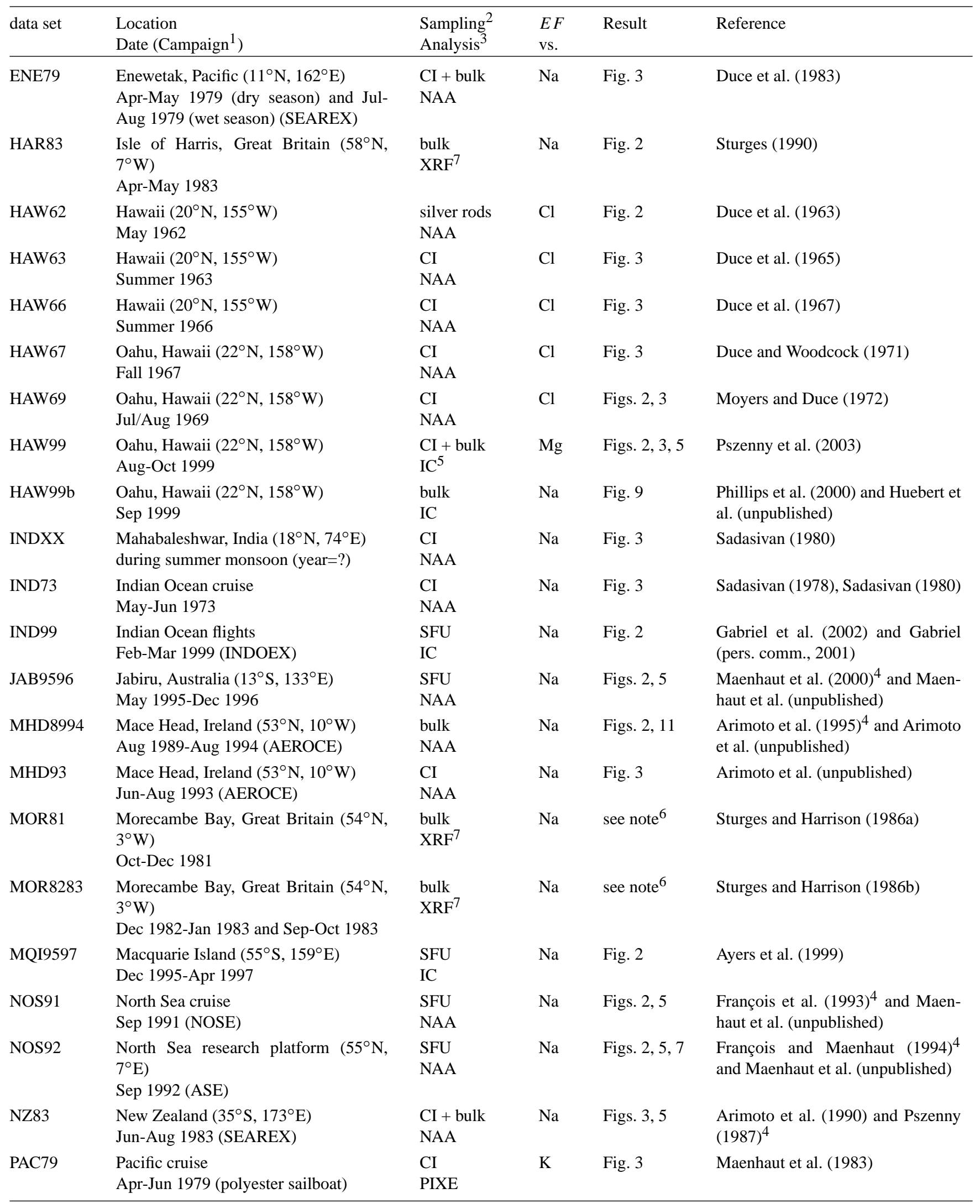


Table 2. (continued)

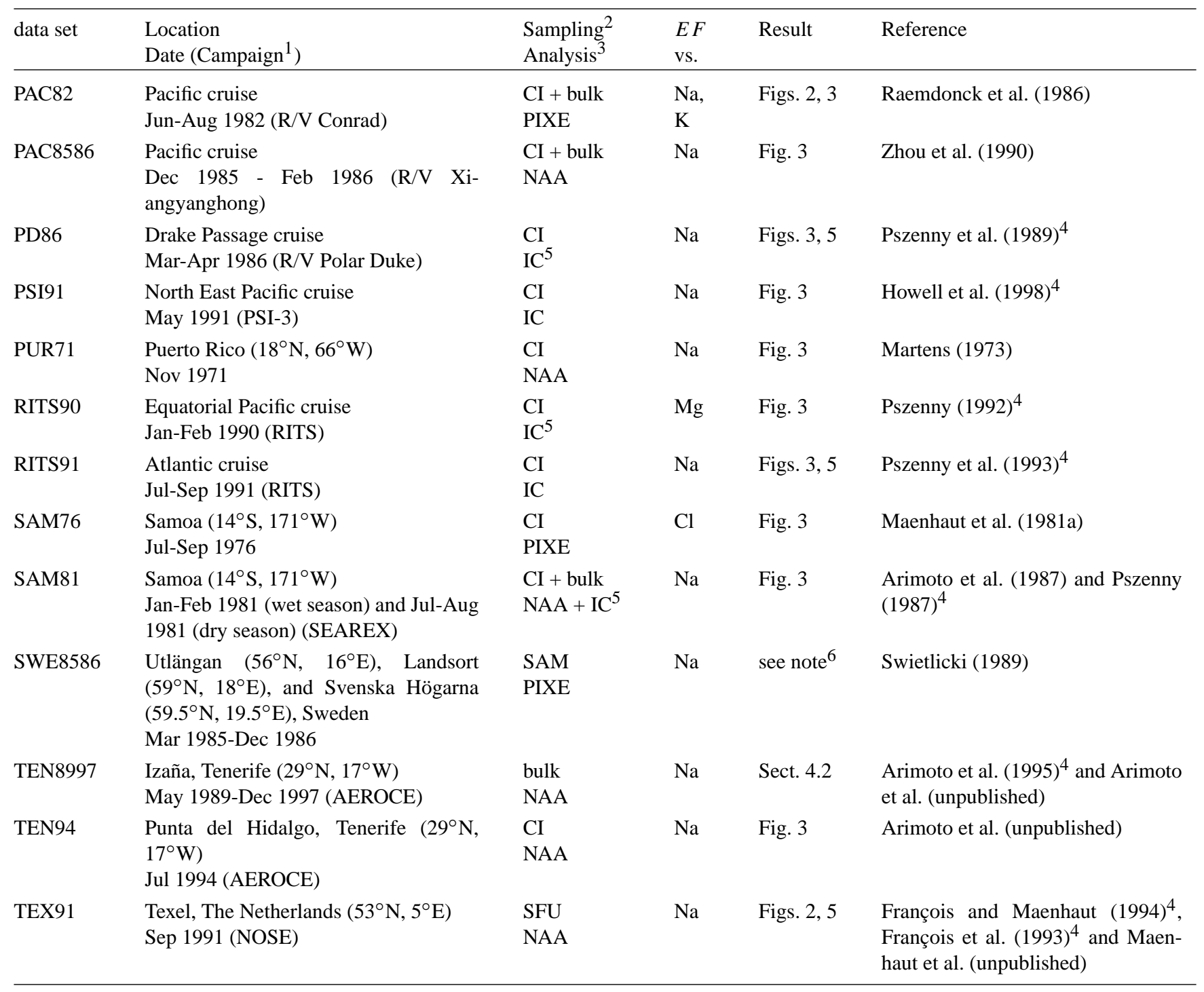

All data sets listed as unpublished are based on measurement methods presented in Sect. 2.1.

1 The acronyms of the field campaigns are: ACE-1 = First Aerosol Characterization Experiment; AEROCE = Atmosphere/Ocean Chemistry Experiment; ASE = EUROTRAC subproject Air-Sea Exchange; EUROTRAC = European Experiment on Transport and Transformation of Environmentally Relevant Trace Constituents in the Troposphere over Europe; INDOEX = Indian Ocean Experiment; NOSE = North Sea Experiment; PSI-3 = Third Pacific Sulfur/Stratus Investigation; RITS = Radiatively Important Trace Species; SEAREX = Sea/Air Exchange; SOAPEX = Southern Ocean Atmospheric Photochemistry EXperiment. For ship cruises, the name of the ship is given.

2 The sampling devices are: bulk = aerosol sampled in bulk on filters; CI = cascade impactor; HVDVI = high-volume dichotomous virtual impactor; SAM = stationary aerosol monitor as described by Hansson and Nyman (1985); SFU = 2-stage stacked filter unit.

3 The analytical methods are: IC = ion chromatography; NAA = neutron activation analysis; PIXE = particle (or 'proton') induced X-ray emission; PALMS = particle analysis by laser mass spectrometry; XRF $=$ X-ray fluorescence.

4 This reference contains general information about the field campaign. However, it does not contain the aerosol bromine data that we present here.

5 The reference element was analyzed using atomic absorption spectroscopy (AAS).

${ }^{6}$ CGR94: Tab. 4 in Ayers et al. (1999) lists a mean value of $E F=0.51$; MOR81: A good correlation between $\mathrm{Br}$ and $\mathrm{Pb}$ was found with only a small sea-salt contribution; MOR8283: $E F \approx 0$ after correction for Br from vehicles; SWE8586: $E F>1$ for submicrometer particles.

7 The reference element was analyzed using flame photometry. 
chlorine deficits are large (e.g. Keene et al., 1990; Sander and Crutzen, 1996), significant bias is associated with this approach.

For the ease of data evaluation, we define a dimensionless enrichment factor $E F(\mathrm{Br})$ for bromine, using $\mathrm{Na}$ as a reference element, as follows:

$$
E F(\mathrm{Br})=\frac{([\mathrm{Br}] /[\mathrm{Na}])_{\text {meas }}}{([\mathrm{Br}] /[\mathrm{Na}])_{\text {seawater }}}
$$

where square brackets denote concentrations and 'meas' stands for 'measured'. Analogous definitions can be made for other sea-water elements. In this paper we abbreviate $E F(\mathrm{Br})$ as $E F$. When the enrichment factor of another element (e.g. $\mathrm{Cl})$ is mentioned, it will be denoted explicitly as $E F(\mathrm{Cl})$.

Some authors report relative bromine depletions rather than enrichment factors. The simple relationship between them is:

depletion $=1-E F$

We prefer $E F$ here because it avoids the complication of 'negative depletion' in the case when the aerosol is enriched in bromine, i.e. when $E F>1$.

Available evidence suggests that fresh sea-salt aerosol has an inorganic composition indistinguishable from that of surface seawater, i.e., $E F=1$ even though the aerosol is substantially enriched in organic constituents (Duce and Woodcock, 1971; Duce and Hoffman, 1976; Turekian et al., 2003).

While the dimensionless quantities EF and 'depletion' describe the relative composition, we will use the terms 'excess' and 'deficit' to refer to absolute quantities (e.g. expressed as mass per volume of air). We define 'excess Br' as the concentration of aerosol bromine above that which originated from sea salt:

excess $\mathrm{Br}=[\mathrm{Br}]_{\text {meas }}-\left[[\mathrm{Na}]_{\text {meas }} \times\left(\frac{[\mathrm{Br}]}{[\mathrm{Na}]}\right)_{\text {seawater }}\right]$

The simple definition of the deficit is:

$\mathrm{Br}$ deficit $=-$ excess $\mathrm{Br}$

Absolute quantities are especially useful when analyzing size-segregated data as shown in Sect. 4.1. Values for different size bins can simply be added up. If the total value of 'excess Br' is negative, it yields a rough estimate of what to expect in the gas phase, assuming that bromine originates from sea salt and is just cycled between the phases. However, this estimate needs to be treated with caution because organobromine species also originate from seawater and cycling between phases does not preclude differential atmospheric lifetimes against deposition.

\subsection{Measurements of inorganic gas-phase species}

As discussed in more detail below, chemical characterization of marine aerosol often reveals substantial enrichments in submicrometer $\mathrm{Br}$ and large deficits in supermicrometer $\mathrm{Br}$ relative to sea salt. These observations indicate that $\mathrm{Br}$ actively cycles between phases. The most likely forms of inorganic gas-phase bromine involved in such transformations include $\mathrm{Br}_{2}, \mathrm{BrCl}, \mathrm{IBr}, \mathrm{Br}, \mathrm{BrO}, \mathrm{HOBr}, \mathrm{BrNO}_{2}, \mathrm{BrNO}_{3}$, $\mathrm{HBr}$, and possibly other species (e.g. Behnke et al., 1994; Sander and Crutzen, 1996; Vogt et al., 1996, 1999; Sander et al., 1999). Several techniques have been developed to quantify gas-phase Br.

The most widely used approach employs an alkalineimpregnated filter positioned downstream of a filter that removes particulate $\mathrm{Br}$ from the air stream. Available evidence suggests that such filter-pack devices efficiently sample reactive inorganic $\mathrm{Br}$ while effectively discriminating against organic Br gases (Rahn et al., 1976; Li et al., 1994). As for gas-phase Cl (Berg and Winchester, 1978), activated charcoal sampling media (Moyers and Duce, 1972) probably efficiently collect both inorganic and organic forms of gas-phase Br. Several potential artifacts are associated with the use of filter-pack samplers. Reactions on the upstream bulk filter between constituents of chemically distinct aerosols or between particulate-phase species and gases in the sample air stream could lead to positive or negative bias in volatile $\mathrm{Br}$ sampled downstream. In addition, the specificity of such samplers for most $\mathrm{Br}$ compounds has not been confirmed via testing with calibration gases.

Tandem mass spectrometry (Spicer et al., 1998) and long path differential optical absorption spectroscopy (LP-DOAS) (Hebestreit et al., 1999; Martinez et al., 1999) have been used to measure $\mathrm{Br}_{2}$ and $\mathrm{BrO}$, respectively, in Arctic marine air. Detection limits for the current generation of these instruments are near the upper limits of model-calculated mixing ratios over the open ocean. Consequently, most deployments to date do not have adequate resolution to reliably discern signal from noise in the mbl at lower latitudes. However, the development of Multi-Axis DOAS (MAX-DOAS) (Hönninger, 2002; Hönninger and Platt, 2002; Leser et al., 2003) allows very sensitive measurements of BrO in the planetary boundary layer. Recently, BrO was quantified in the mbl of the North Atlantic using this new approach (Leser et al., 2003).

Techniques have been developed to measure mixing ratios of Br-atom precursors (primarily $\mathrm{Br}_{2}$ and $\mathrm{HOBr}$ ) (Impey et al., 1997) and to infer Br-atom concentrations based on relative concentration changes in hydrocarbons (Jobson et al., 1994) under conditions of enhanced $\mathrm{Br}$ chemistry during sunrise in the Arctic. However, such approaches have so far lacked adequate sensitivity to reliably characterize these species in marine regions at lower latitudes.

\subsection{The detection limit}

Differences in methods used to address measured concentrations below the analytical detection limit (DL) are an important and often overlooked factor influencing the compa- 
rability of reported data sets. Since particulate bromine in marine air is typically present at low concentrations relative to the resolution of current analytical techniques or the blank level of the filter material, most data sets include a significant fraction of observations below the DL. Some laboratories report only detectable concentrations. Others convert measured concentrations below zero (which occasionally result from random analytical variability around low ambient concentrations) to zero. A third approach sets all values less than the DL to the DL. All of these approaches cause positive bias in resulting population statistics. Some laboratories employ an alternative approach of setting all measured concentrations less than the DL (both positive and negative) to zero, which results in negative bias in population statistics. To minimize bias of this nature, values below the DL are sometimes set to 0.5 times the DL. However, the lower limits on distributions established by this approach reflect laboratory-specific analytical resolution rather than ambient concentrations. Finally, some laboratories report concentrations as measured, including both positive and negative values less than the DL. This approach retains analytical uncertainties in the lower end of concentration distributions, which results in apparently 'noisier' data. Assuming that the measurements are unbiased, however, this latter approach yields the most representative population statistics. If the method for handling concentrations below the DL is not specified, it is impossible to explicitly evaluate the potential importance for the comparability of all data reviewed herein. Undoubtedly, however, some of the observed differences at the lower end of concentration distributions result from such effects.

\section{Compilation of measurements}

Since the early 1960s, particulate bromine has been measured in most regions of the mbl (see Fig. 1). Available data sets, many previously unpublished (but from laboratories with methodologies published in the literature cited here), are summarized in Table 2. The abbreviations shown in the first column are used throughout the text to refer to individual data sets. Readers are referred to the original publications for detailed information concerning previously reported results. Unpublished data sets are briefly described in this section.

Between 1988 and 1998, the composition of marine aerosol sampled in bulk was measured as part of the Atmosphere-Ocean Chemistry Experiment (AEROCE). Amongst other elements, the particles were analyzed for $\mathrm{Br}$, $\mathrm{Cl}$, and $\mathrm{Na}$. North Atlantic data sets are available from three mbl tower sites at Barbados (BAB8897), Bermuda (BEM8897), and Mace Head, Ireland (MHD8994), and also from one high-elevation ( $2360 \mathrm{~m}$ above sea level) site at Izaña, Tenerife (TEN8997). AEROCE-related investigations also characterized the chemical composition of sizesegregated aerosols in the mbl as part of intensive field exper- iments at Barbados (BAB94), Bermuda (BEM93, BEM96, BEM97, BEM98), Mace Head (MHD93), and Punta del Hidalgo, Tenerife (TEN94). An additional, size-segregated data set was generated at the joint Texas A\&M University - University of Hawaii tower on the windward coast of Oahu, Hawaii, in autumn 1999 (HAW99). All of these sampling campaigns employed Graseby-Andersen hi-vol cascade impactors deployed on towers and operated under similar conditions. For data sets BAB94, BEM93, BEM96, and MHD93, the impactors were configured with an upper ' 0 ' stage, Whatman 41 substrates, and backup filters as described by Keene and Savoie (1998). For BEM97 and HAW99, the impactors were also configured with an upper ' 0 ' stage but aerosols were sampled on frosted polycarbonate (Lexan) impaction substrates and quartz fiber (Pallflex 2500 QAT-UP) backup filters (Keene et al., 2002; Pszenny et al., 2003). For BEM98, the upper ' 0 ' stage was not used and the standard impactors were configured with precombusted glass fiber substrates and backup filters (Turekian et al., 2001, 2003). Data sets BAB94, BEM93, BEM98, and MHD93 correspond to 24-hour or longer sampling intervals whereas those for BEM96, BEM97, and HAW99 were discrete daytime or nighttime sampling intervals.

The experiments at Enewetak (ENE79), Samoa (SAM81), and New Zealand (NZ83) were conducted as part of the SEAREX (Sea/Air Exchange) program. The overall strategy for SEAREX was to sample the four major wind regimes, that is, the tradewinds and westerlies in both the Northern and Southern hemispheres, over the Pacific Ocean.

Maenhaut et al. (unpublished) analyzed bromine in aerosols at several locations (ATL90, BIR9196, JAB9596, NOS91, NOS92, TEX91). Most of the samples were collected either from ships (ATL90, NOS91), a platform (NOS92) or from stations near the coast (BIR9196, TEX91). Only Jabiru (JAB9596) is at $60 \mathrm{~km}$ away from the coast. However, it is only slightly above sea level, and sea salt is quite important there. The NOS91 data was obtained from the two ships Alkor (NOS91a) and Belgica (NOS91b) which were located on a circle of $200 \mathrm{~km}$ in diameter in the North Sea with Belgica always downwind of Alkor (see Fig. 1). The NOS92 data was obtained at two heights: On deck (NOS92-DECK) and from the mast of the platform (NOS92-MAST). All samples, (except for ATL90) were collected with the Gent PM10 stacked filter unit (SFU) sampler equipped with a PM10 inlet which separates the aerosol into two size fractions: Coarse ( 2 to $10 \mu \mathrm{m}$ aerodynamic diameter $(\mathrm{AD}))$ and fine $(<2 \mu \mathrm{m} A D)$. The collection surfaces were for the coarse fraction an $8 \mu \mathrm{m}$ pore size Apiezon ${ }^{\circledR}$ coated Nuclepore ${ }^{\circledR}$ polycarbonate filter and for the fine fraction a $0.4 \mu \mathrm{m}$ pore size Nuclepore ${ }^{\circledR}$ polycarbonate filter. The ATL90 samples were also collected with a SFU, but without the PM10 inlet. Here, the coarse filter was a $5 \mu \mathrm{m}$ pore size Nuclepore ${ }^{\circledR}$ polycarbonate filter.

Van Dingenen et al. (unpublished) collected aerosols during Polarstern cruise ANT XII/1 from Bremerhaven to Chile 

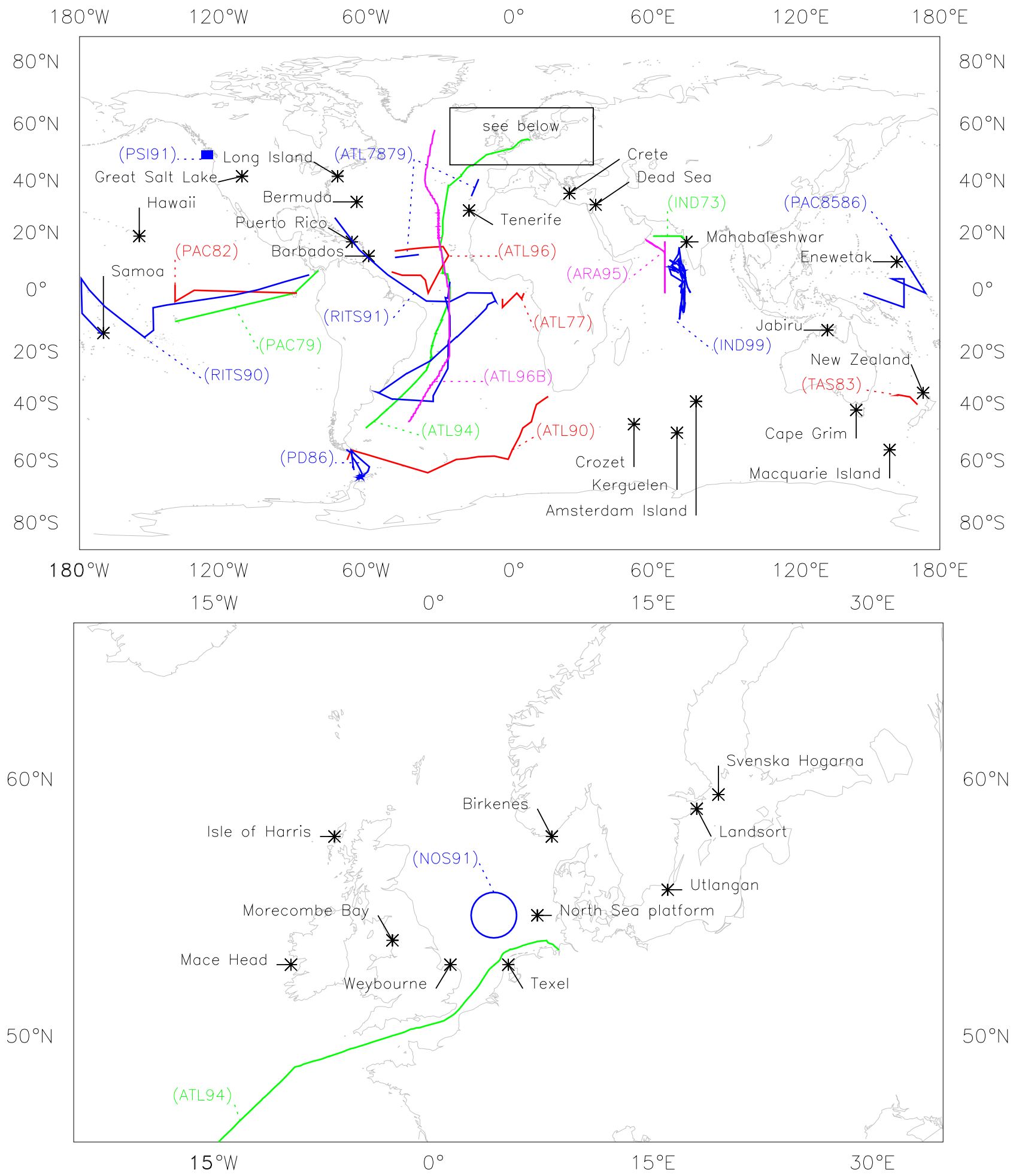

Fig. 1. Locations where atmospheric inorganic bromine has been measured in the mbl. Stationary sites are marked with asterisks. Cruise and flight tracks (colored) are labeled in parentheses using the data set names from Table 2. Some are approximate and show only the part where samples were taken. More details may be found in the original publications. 
(ATL94). Sample collection was identical to the method of Maenhaut et al. as described above but without PM10 inlet. Several elements were measured, including $\mathrm{Br}, \mathrm{Cl}, \mathrm{Ca}$, $\mathrm{K}, \mathrm{Zn}$, and $\mathrm{Fe}$. Na was not measured, so the enrichment factors are calculated using $\mathrm{Ca}$ as the sea-salt reference element. A second Atlantic cruise on the Polarstern which followed almost the same course was conducted in 1996 (ATL96b). Size-segregated aerosols were collected in six different size ranges with a Sierra-Andersen hi-vol cascade impactor and analyzed by IC.

During 20 days of the HAW99 experiment (described above), Huebert et al. (unpublished) sampled particulate bromine in bulk aerosol on PTFE filters (HAW99b). Starting each day at midnight, aerosols were sequentially sampled over approximately 3 -hour intervals (total $n=152$ ). Samples were analyzed by IC.

In the Southern Indian Ocean long-term aerosol measurements were performed at two remote islands. At Amsterdam Island (AMS9298), size-segregated aerosols were collected on Whatman 41 substrates and backup filters by means of a six-stage Sierra-Andersen hi-vol cascade impactor. The sampling was sectored based on wind direction to minimize the potential for contributions from local terrestrial sources. The sampling intervals were 24-hours or longer. At Crozet (CRO9698), aerosols were collected on PTFE filters with a sampling interval ranging between 24 and 48 hours. All samples were analyzed for major anions and cations by IC.

Available nonspecific measurements of gas-phase inorganic $\mathrm{Br}$ are summarized in Table 3 and measurements of $\mathrm{BrO}$ using the DOAS technique are summarized in Table 4. The abbreviations used to define the gas-phase data sets end with '-G'.

Bromine concentrations measured in rain are summarized in Table 5. Abbreviations for these data end with '-R'.

\section{Results and discussion}

Results of the aerosol bromine measurements mentioned above are presented in several figures. Most data sets used to produce the figures are also available in the electronic supplement (www.atmos-chem-phys.org/acp/3/1301/ acp-3-1301_supp.zip) to this paper. Figure 2 shows that bromine is depleted from most bulk samples (except for the North Sea samples). Data sets for size-segregated measurements are shown individually in Fig. 3 and in a combined plot in Fig. 4. Absolute bromine concentrations and excess bromine relative to sea water are shown in Fig. 5 separately for submicrometer (radius $r<1 \mu \mathrm{m}$ ) and supermicrometer aerosol. The size-resolved plots show that for almost all supermicrometer particles $E F<1$. Submicrometer aerosol usually shows a $\mathrm{Br} / \mathrm{Na}$ ratio higher than that of sea water. However, sea-salt concentrations in these size fractions are relatively low. In addition, the long atmospheric lifetimes for these submicrometer size fractions (5 to 10 days) increases the potential for crustal contributions from remote continental sources and thus, sea-salt reference species may not be conservative. Consequently, these enrichment factors are associated with substantially greater uncertainty and must be interpreted with caution. We return to this point in Sect. 4.1.

A few data sets were unusual in that bromine was enriched rather than depleted in samples of supermicrometer or bulk aerosol.

- Samples from the polluted North Sea (see Fig. 2) show a bulk $E F>1$. This is due to a high bromine content in the submicrometer particles (see Sect. 4.1). Supermicrometer sea salt particles show the usual bromine depletion (see Fig. 5).

- The only other outlier of the bulk data sets is HAR83. It is possible that the aerosol was influenced by Arctic air which at that time of year (spring) shows increased bromine concentrations (e.g. Berg et al., 1983).

- Two data sets corresponding to samples collected at elevated locations inland from the coast indicate significant bromine enrichments. Duce et al. (1965) (HAW63HILL) found that bromine was enriched relative to chlorine (their sea-salt reference species) in inland (approximately $16 \mathrm{~km}, 2000 \mathrm{~m}$ elevation) relative to coastal samples. Sadasivan (1980) sampled aerosol near the west coast of India at an altitude of $1380 \mathrm{~m}$ and at a distance of about $65 \mathrm{~km}$ from the coast (INDXX). However, no such bromine enrichment was observed at Jabiru (JAB9596), which is $60 \mathrm{~km}$ away from the coast but only slightly above sea level. A potential explanation for these observations is fast release of bromine to the gas phase close to the coast, followed by particle loss and readsorption of gas-phase bromine onto the remaining particles. Such an effect has also been seen in a model study by Moldanová and Ljungström (2001).

- Murphy et al. (1997) report that their measurements (CGR95) are consistent 'with a slight enrichment of bromine'. However, this conclusion was based on less than $4 \%$ of their PALMS spectra. When all spectra are used (including those with a signal to noise ratio $<1000$ ) they find that bromine is below the DL in about $85 \%$ of the particles.

- For the bromine enrichment of CGR79 we do not have a satisfactory explanation, especially since other campaigns performed at Cape Grim (CGR94, CGR9698) show bromine depletion.

\subsection{Size dependence}

Duce et al. (1967) were the first to observe that $E F$ varies as a function of particle size. Since then, many other studies have confirmed this size dependence. Figure 3 shows several data sets obtained at marine sites throughout the world. The 
Table 3. Measurements of inorganic gas-phase bromine species (other than $\mathrm{BrO}$ )

\begin{tabular}{|c|c|c|c|c|}
\hline data set & $\begin{array}{l}\text { Location } \\
\text { Date (Campaign) }\end{array}$ & $\begin{array}{l}\text { Sampling } \\
\text { Analysis }\end{array}$ & Result & Reference \\
\hline ATL77-G & $\begin{array}{l}\text { Atlantic }\left(0^{\circ} \mathrm{N}, 0^{\circ} \mathrm{W}\right) \\
\text { Jun } 1977\end{array}$ & $\begin{array}{l}\text { filter }+\mathrm{LiOH} \\
\text { NAA }\end{array}$ & $3.4 \mathrm{pmol} / \mathrm{mol}$ & Kritz and Rancher (1980) \\
\hline ATL80-G & $\begin{array}{l}\text { North and South Atlantic }\left(20^{\circ} \mathrm{N}\right. \\
\left.\text { to } 30^{\circ} \mathrm{S}\right) \\
\text { Oct-Nov } 1980\end{array}$ & $\begin{array}{l}\text { see note } \\
\text { see note }\end{array}$ & $\begin{array}{l}2.6 \pm 1.1 \mathrm{pmol} / \mathrm{mol} \text { during day } \\
3.2 \pm 1.4 \mathrm{pmol} / \mathrm{mol} \text { at night }\end{array}$ & Berg et al. (1982) \\
\hline HAR83-G & $\begin{array}{l}\text { Isle of Harris, Great Britain } \\
\left(58^{\circ} \mathrm{N}, 7^{\circ} \mathrm{W}\right) \\
\text { Apr-May } 1983\end{array}$ & $\begin{array}{l}\text { filter }+\mathrm{KOH} \\
\mathrm{XRF}\end{array}$ & $7.9 \mathrm{pmol} / \mathrm{mol}$ & Sturges (1990) \\
\hline HAW63-G & $\begin{array}{l}\text { Hawaii }\left(20^{\circ} \mathrm{N}, 155^{\circ} \mathrm{W}\right) \\
\text { summer } 1963\end{array}$ & $\begin{array}{l}\mathrm{K}_{2} \mathrm{CO}_{3} \text { impinger } \\
\text { NAA }\end{array}$ & 2 to $12 \mathrm{pmol} / \mathrm{mol}$ & Duce et al. (1965) \\
\hline HAW99-G & $\begin{array}{l}\text { Hawaii }\left(20^{\circ} \mathrm{N}, 155^{\circ} \mathrm{W}\right) \\
\text { Sep } 1999\end{array}$ & $\begin{array}{l}\text { filter }+\mathrm{K}_{2} \mathrm{CO}_{3} \\
\text { IC }\end{array}$ & $\begin{array}{l}4.9 \mathrm{pmol} / \mathrm{mol} \text { daytime average } \\
2.8 \mathrm{pmol} / \mathrm{mol} \text { nighttime aver- } \\
\text { age (Fig. } 8)\end{array}$ & $\begin{array}{l}\text { Perner et al. (2000) and } \\
\text { Pszenny et al. (2003) }\end{array}$ \\
\hline MOR8283-G & $\begin{array}{l}\text { Morecambe Bay, Great Britain } \\
\left(54^{\circ} \mathrm{N}, 3^{\circ} \mathrm{W}\right) \\
\text { Dec } 1982-\mathrm{Jan} 1983 \text { and Sep- } \\
\text { Oct } 1983\end{array}$ & $\begin{array}{l}\text { filter }+\mathrm{KOH} \\
\mathrm{XRF}\end{array}$ & $2.8 \pm 1.7 \mathrm{pmol} / \mathrm{mol}$ & $\begin{array}{l}\text { Sturges and Harrison } \\
(1986 b)\end{array}$ \\
\hline NY96-G & $\begin{array}{l}\text { Long Island, New York, USA } \\
\left(41^{\circ} \mathrm{N}, 72^{\circ} \mathrm{W}\right) \\
\text { Jun } 1996\end{array}$ & APCIMS & $\begin{array}{l}\text { small } \mathrm{Br}_{2} \text { signal detected (but } \\
\text { did not exceed detection limit } \\
\text { of } 6 \mathrm{pmol} / \mathrm{mol} \text { ) }\end{array}$ & $\begin{array}{l}\text { Spicer et al. (1998) and Fos- } \\
\text { ter et al. (2001) }\end{array}$ \\
\hline
\end{tabular}

1 APCIMS = atmospheric-pressure chemical ionization mass spectrometry; IC = ion chromatography; NAA = neutron activation analysis; $\mathrm{XRF}=\mathrm{X}$-ray fluorescence.

2 The sampling and analysis methods were not specified by Berg et al. (1982).

medians of these data sets are shown in a composite plot in Fig. 4. Most of the size distributions exhibit asymmetric $U$ shapes with three distinct regions:

1. For very large particles, the composition approaches that of sea water $(E F \approx 1)$.

2. Particles in the medium size range of a few $\mu \mathrm{m}$ diameter are depleted in bromine $(E F<1)$.

3. Very small particles often show high bromine enrichment $(E F \gg 1)$.

These three regions are discussed in detail below.

1. Compared to smaller aerosols, the largest sea-salt particles are associated with both shorter atmospheric lifetimes against deposition and smaller surface/volume ratios. Consequently, rates of chemical processing (e.g. alkalinity titration) are slower and their average age is smaller (Erickson et al., 1999). For these reasons, they deviate less from the sea-water composition than the smaller particles. However, since the largest sea-salt aerosols turn over at much faster rates (several hours versus a mass-weighted average of 1.5 to 2 days for all sea salt (Erickson et al., 1999), even relatively small bromine depletions in these size fractions reflect disproportionately greater percentages of the total $\mathrm{Br}$ flux to the gas phase. For example, applying the average dry-deposition velocities for each size fraction of the BEM98 data set (Turekian et al., 2003) to the corresponding average $\mathrm{Br}$ deficits clearly indicates that the largest aerosols often dominate this flux.

2. Medium-sized sea-salt particles between one and a few $\mu \mathrm{m}$ are usually depleted in bromine. A mechanism for the loss of bromine from marine aerosol to the gas phase has been presented by Vogt et al. (1996). They proposed a reaction cycle that releases $\mathrm{Br}_{2}$ and $\mathrm{BrCl}$ from slightly acidified sea-salt particles, as discussed in detail in Sect. 6 .

3. Submicrometer aerosol often shows very high values of $E F$. It is still an open question how the high bromine concentrations can be sustained in these particles. At first 
Table 4. DOAS Measurements of $\mathrm{BrO}$ in the $\mathrm{mbl}$ and over inland saline water bodies.

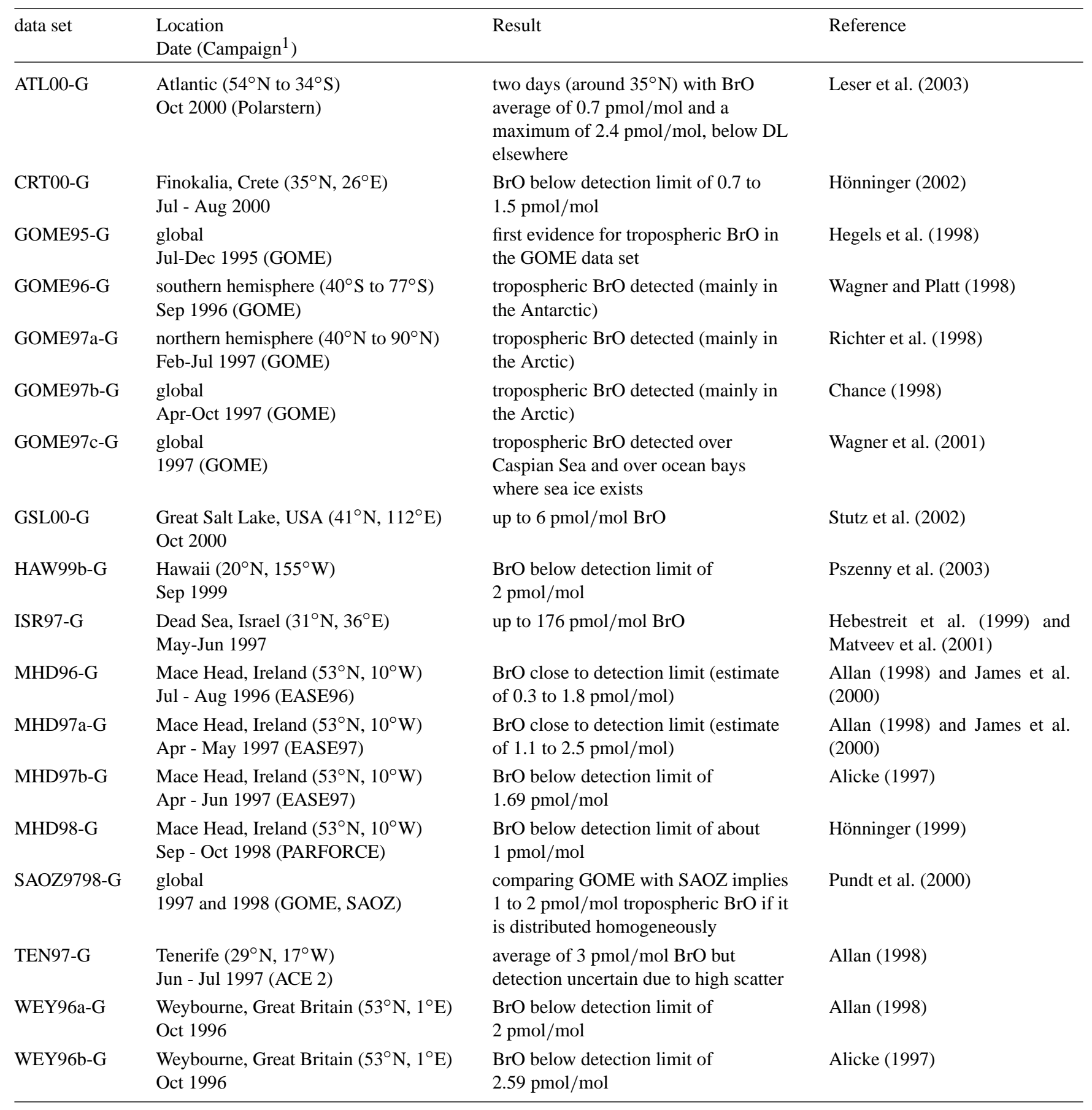

\footnotetext{
${ }^{1}$ ACE 2 = Aerosol Characterisation Experiment 2; EASE = East Atlantic Summer Experiment; GOME = Global Ozone Monitoring Experiment; PARFORCE = Particle Formation and Fate in the Coastal Environment; Polarstern = Polarstern cruise leg ANT XVIII/1; SAOZ = Systeme d'Analyse par Observation Zenitale.
}

glance, it seems logical that bromine that was previously released from sea-salt aerosol subsequently condensed onto these small particles which have a high surface/volume ratio. However, if there is a mechanism that transfers sea-salt bromine into the gas phase, why doesn't it work for submicrometer particles? The inorganic components of submicrometer marine aerosols are typically dominated by deliquesced, highly acidic sulfate compounds (Keene et al., 
Table 5. Bromine measured in marine rain samples

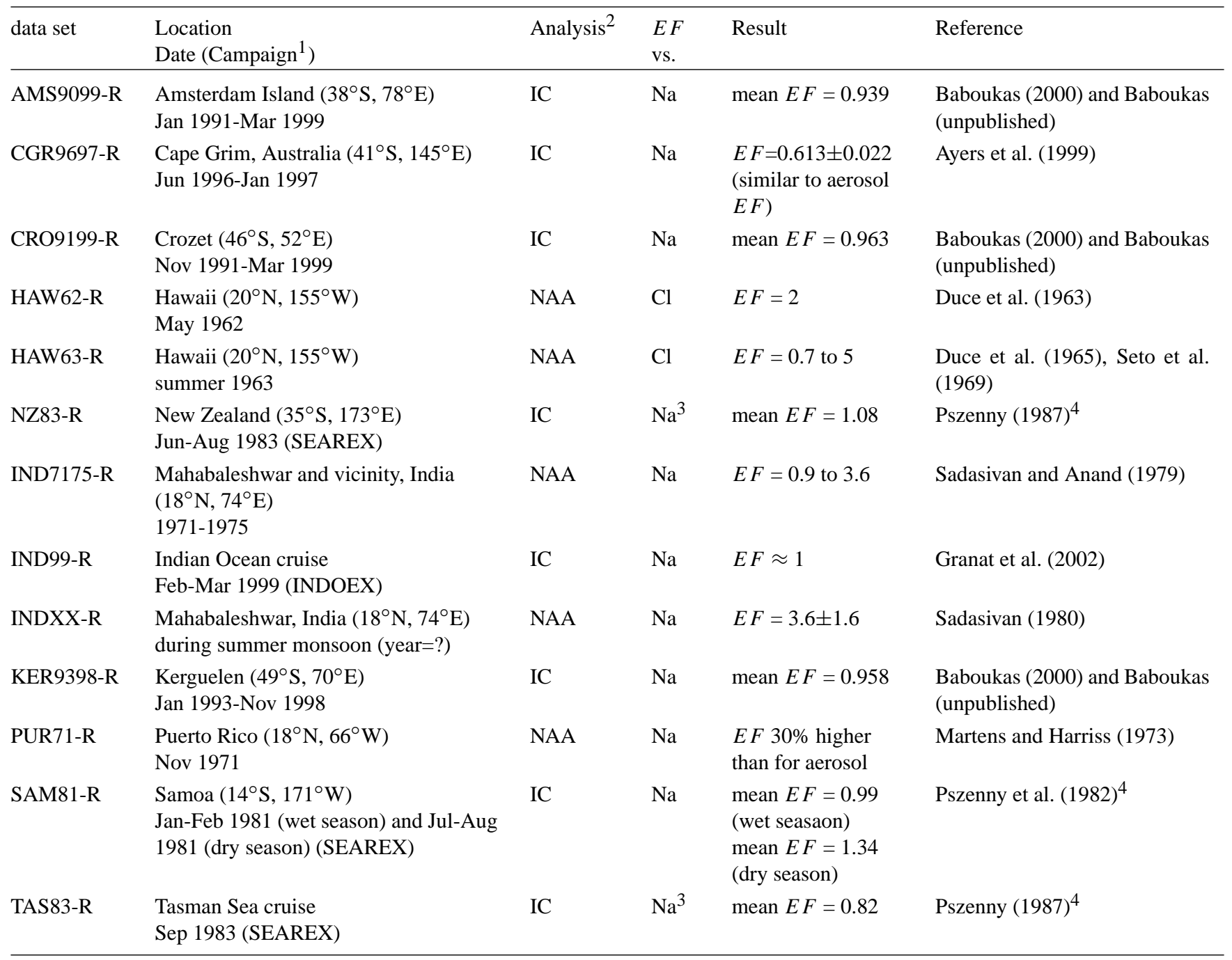

1 Campaign names are described in footnote of Table 2.

2 Analytical methods are described in footnote of Table 2.

3 The reference element was analyzed using atomic emission spectrophotometry (AES).

4 This reference contains general information about the field campaign. However, it does not contain the rainwater bromine data that we present here.

2002), which should facilitate $\mathrm{Br}$ activation. Indeed, Vogt et al. (1996) suggested that recycling through sulfate aerosol should enhance production of $\mathrm{Br}_{2}$ and $\mathrm{BrCl}$ relative to that expected based only on reactions in sea-salt solutions. There is one situation where bromide enrichment in submicrometer particles can be explained with current models: When ozone drops to almost zero during a polar ozone depletion event, the bromine activation chain (see Sect. 6) is interrupted, and bromide can accumulate in the submicrometer particles. However, there are no such extreme ozone depletion events at mid-latitudes, and therefore we must look at other potential explanations for this discrepancy.
First, it could be that submicrometer bromine exists in a form other than $\mathrm{Br}^{-}$. This bromine would have to be in a chemically inert form that cannot be converted to volatile species like $\mathrm{Br}_{2}$ and $\mathrm{BrCl}$. It would then be possible for this form of bromine to accumulate in submicrometer aerosol. A way to investigate this is to compare measurements of total bromine made by NAA (or PIXE) with specific measurements of the bromide anion made with IC. We are not aware of a campaign outside of the Arctic in which the same samples were analysed by both methods. However, Barrie et al. (1994) analyzed bromine in splits of bulk aerosol sampled on PTFE filters in the Arctic. These paired data indicated that 


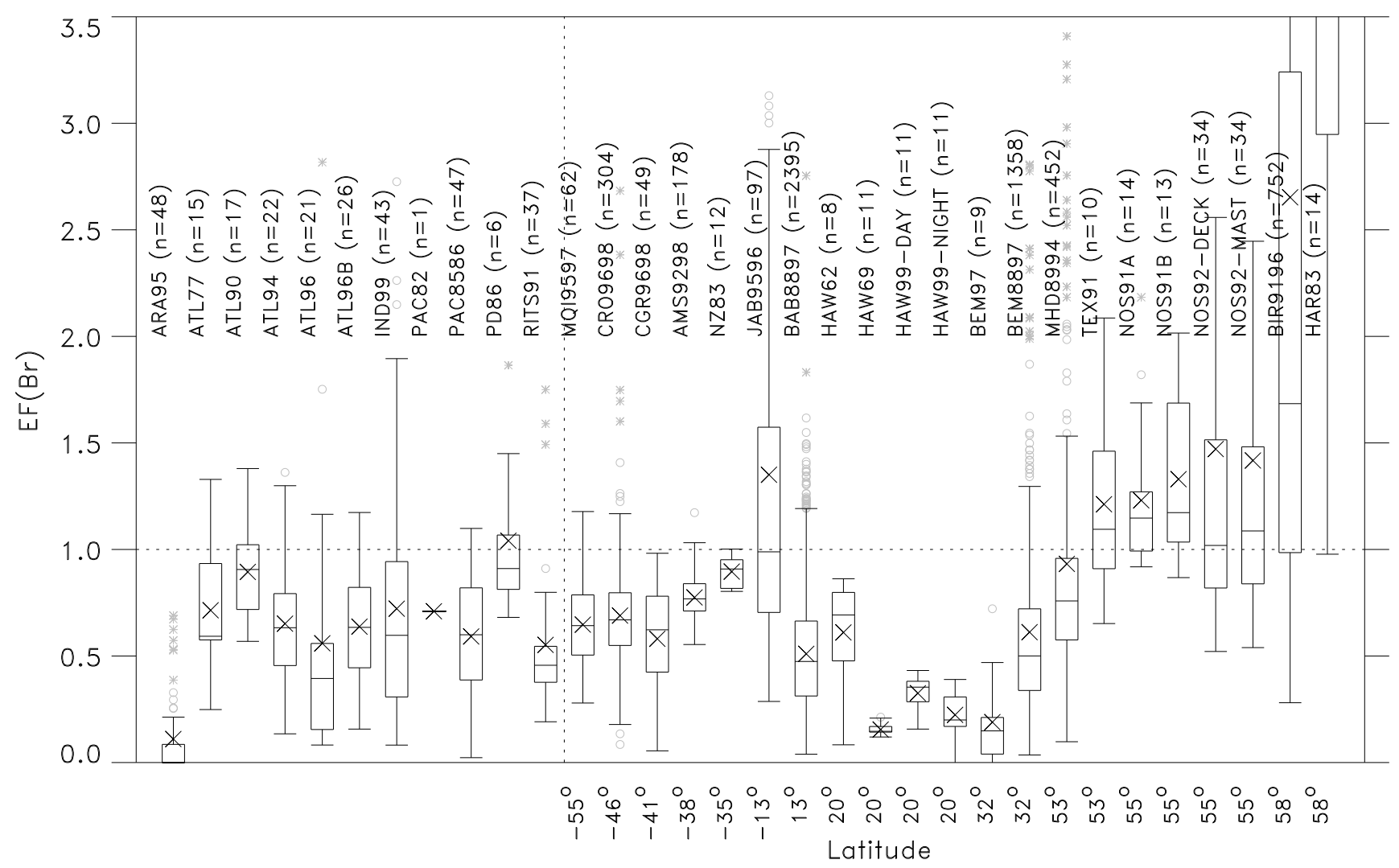

Fig. 2. Box-and-whisker plots of $E F(\mathrm{Br})$ for bulk aerosol samples. For size-segregated measurements, the sum of all sizes was used. IND99 is an exception, here only the coarse mode is available. Cruises are shown in the left part. Stationary locations (right part) are sorted by latitude. The data set names are defined in Table 2. The number of samples $n$ is given in parentheses. The plots were made following the recommodations by Frigge et al. (1989) (using their definition 6 for the quartiles): $25 \%$ of the data are below the box and $25 \%$ are above. Thus the box presents the middle 50\% (interquartile range). The horizontal line within the box is the median. A cross denotes the mean value. A 'step' is defined as 1.5 times the height of the box. The whiskers extend to the minimum and the maximum of the data set if these are within one step of the box. The maximum length of the whiskers is one step. Outliers more than one step away from the box are marked individually: A circle is used for those less than 2 steps away and an asterisk otherwise.

most particulate bromine during that experiment was in the form of soluble bromide. In addition, results from different campaigns using different analytical techniques reveal similar enrichments in submicometer aerosols (red, green, and black lines in Fig. 4). Comparisons of the data sets from Bermuda are especially useful in this regard. For BEM93 and BEM96 bromine was analyzed by NAA. The analysis method changed to IC for BEM97 and BEM98. Although substantial interannual variability is evident, mean values for all submicrometer size fractions indicate $E F>1$. This implies that the bromide ion $\mathrm{Br}^{-}$is the main chemical form of bromine in these particles.

Alternatively, some submicrometer $\mathrm{Br}^{-}$could be externally mixed with chemically distinct particles such as mineral aerosol, soot carbon, or organic carbon, which lack sufficient water and/or acidity to sustain $\mathrm{Br}$ recycling. However, available evidence based on model calculations and chem- ical analysis of single particles (e.g. Dentener et al., 1996; Anderson et al., 1996) suggests that most mineral aerosol and soot in the mbl are often coated with hygroscopic reactive surface layers, which should sustain aqueous chemical pathways. In addition, high concentrations of dust and soot in the mbl are typically limited to regions downwind of arid continents and/or extensive fossil fuel and/or biomass burning, respectively. We observe no obvious evidence for similar spatial patterns in $E F$. In contrast to dust and soot, submicrometer organic carbon is produced primarily by gasto-particle conversion. Most of it is internally mixed with inorganic constituents rather than externally mixed as isolated organic aerosols (Middlebrook et al., 1998). Consequently, it seems unlikely that external mixing with chemically distinct aerosol types could sustain substantial particulate bromine in marine air.

Finally, it is possible that some other as yet unidentified 
pathway(s) lead to the accumulation of $\mathrm{Br}^{-}$in submicrometer aerosol. Resolution of this issue remains an open question.

It should be noted, though, that $E F$ must be treated with caution here. Since sea salt occurs mainly in the supermicrometer range, there is only little $\mathrm{Na}$ and $\mathrm{Mg}$ in submicrometer aerosol. Calculating $E F$ involves dividing by the concentration of the reference element and is therefore strongly dependent on the accuracy of the measurement of that species.

\subsection{Altitudinal variation}

It is important to note that the exact location of the sampling site plays a role. Aerosol and rain samples (HAW63 and HAW63-R) collected in Hawaii by Duce et al. (1965) showed a systematic increase of $E F$ with distance from the shore and height above the sea. In general, the farther the sampling location is from the sea surface, the more the aerosol composition deviates from sea water. Duce and Woodcock (1971) compared particles taken at the top (24 m above sea level) and the bottom (4 m a.s.1.) of a sampling tower (see HAW67BOTTOM and HAW67-TOP in Fig. 3). Bromine depletion was observed only in the samples collected at the top of the tower. At the bottom EF was close to unity. This can be explained by large but short-lived sea-salt particles close to the surface that have a composition very similar to sea water.

In another study, François and Maenhaut (1994) collected samples on the deck (NOS92-DECK, $27 \mathrm{~m}$ a.s.1.) and from a mast (NOS92-MAST, $45 \mathrm{~m}$ a.s.1.) of a platform in the North Sea. Data from both altitudes are compared in Fig. 7. Coarse mode $\mathrm{Na}$ decreases with altitude simply because of the vertical gradient in sea-salt aerosol mass. Coarse mode Br shows a similar decrease and thus, a significant difference of $E F$ between these heights cannot be seen. There is almost no vertical gradient of sea-salt aerosol mass in the fine mode and a linear regression of $\mathrm{Na}_{\text {mast }}$ vs. $\mathrm{Na}_{\text {deck }}$ (Fig. 7e) yields a slope of 1.05 and a correlation coefficient of $r^{2}=0.993$ (after excluding one outlier). Bromine concentrations at both heights are also similar (Fig. 7f). However, due to a higher analytical standard deviation the correlation is not as good as for $\mathrm{Na}$.

Even though these data show no dependence of $E F$ on height up to $45 \mathrm{~m}$ a.s.l., it should be noted that model calculations by von Glasow et al. (2002a) predict that acid-catalyzed bromine activation is more efficient in higher layers of the mbl.

Sampling at even higher altitudes can change the results drastically. The station at Izaña, Tenerife is at $2360 \mathrm{~m}$ a.s.l. and often encounters free tropospheric air. The aerosol data set obtained here (TEN8997) shows little similarity with sea salt aerosol even though the site is on a small island in the Atlantic. Values of $E F$ are distributed between 0 and 40. The high variability is expected because sources of $\mathrm{Na}$ and $\mathrm{Br}$ other than sea salt are significant, e.g. crustal $\mathrm{Na}$.

\subsection{Latitudinal variation}

High concentrations of bromine are observed every spring in the Arctic (e.g. Berg et al., 1983; Sturges et al., 1993; Barrie et al., 1994; Martinez et al., 1999; Michalowski et al., 2000). A similar situation probably exists in the Antarctic (Wagner and Platt, 1998). Outside of the polar regions, there is no clear evidence for a dependence of $E F$ on latitude, except for the high bromine contents of the North Sea aerosol, which are probably due to anthropogenic influence, as discussed in Sect. 4.8. The bromine measurements plotted in Fig. 2 show no systematic variation with latitude. Data from two Atlantic cruises (ATL94 and ATL96b) are shown in Fig. 6. No clear correlation between latitude and $E F$ can be seen. If a dependence exists, it is masked by other factors. Anthropogenic pollution, aerosol acidity, biomass burning plumes, and mineral dust can all affect $E F$. However, there seems to be one indication for a latitudinal trend. As discussed below (see Sect. 4.5), the seasonal cycle of $E F$ is very pronounced in the southern hemisphere, whereas it is more difficult to see in most data sets from the northern hemisphere.

\subsection{Diurnal variation}

Very few studies have investigated the diurnal variation in gas-phase and particulate bromine. The results are inconsistent. Moyers and Duce (1972) found that the gaseous bromine concentrations did not differ in samples collected during sunlight hours versus those collected at night (HAW69). Systematic diurnal variation in particulate bromine was also examined but the limited number of samples precluded a statistically meaningful evaluation. Sizesegregated data from a more recent study at Bermuda during spring (BEM96) also reveal no discernable evidence for significant diurnal variation (Keene et al., unpublished). However, the resolution of that data set is limited by the relatively small number of samples coupled with dynamic meteorological conditions.

In contrast to the above, Rancher and Kritz (1980) measured large diurnal variabilities in both gas-phase and particulate bromine during stable meteorological conditions over the tropical South Atlantic Ocean (ATL77). Gas-phase inorganic bromine was approximately two times greater during the day relative to night. Particulate bromine varied by similar magnitudes but was anticorrelated with highest concentrations at night. Recent measurements in coastal air at Hawaii during late summer also reveal persistent, large diurnal variabilities in both gas-phase (HAW99-G, see Fig. 8) and particulate (HAW99b, see Fig. 9) bromine. Maxima in daily $E F$ values ranged from 0.22 to 1.2 and mimima from $<$ DL to 0.33 . Day-night patterns and absolute differences in concentrations were similar to those reported by Rancher and Kritz (1980). The consistency between results from these latter studies in different areas suggests that diurnal variation in gas-phase and particulate inorganic bromine is a characteris- 

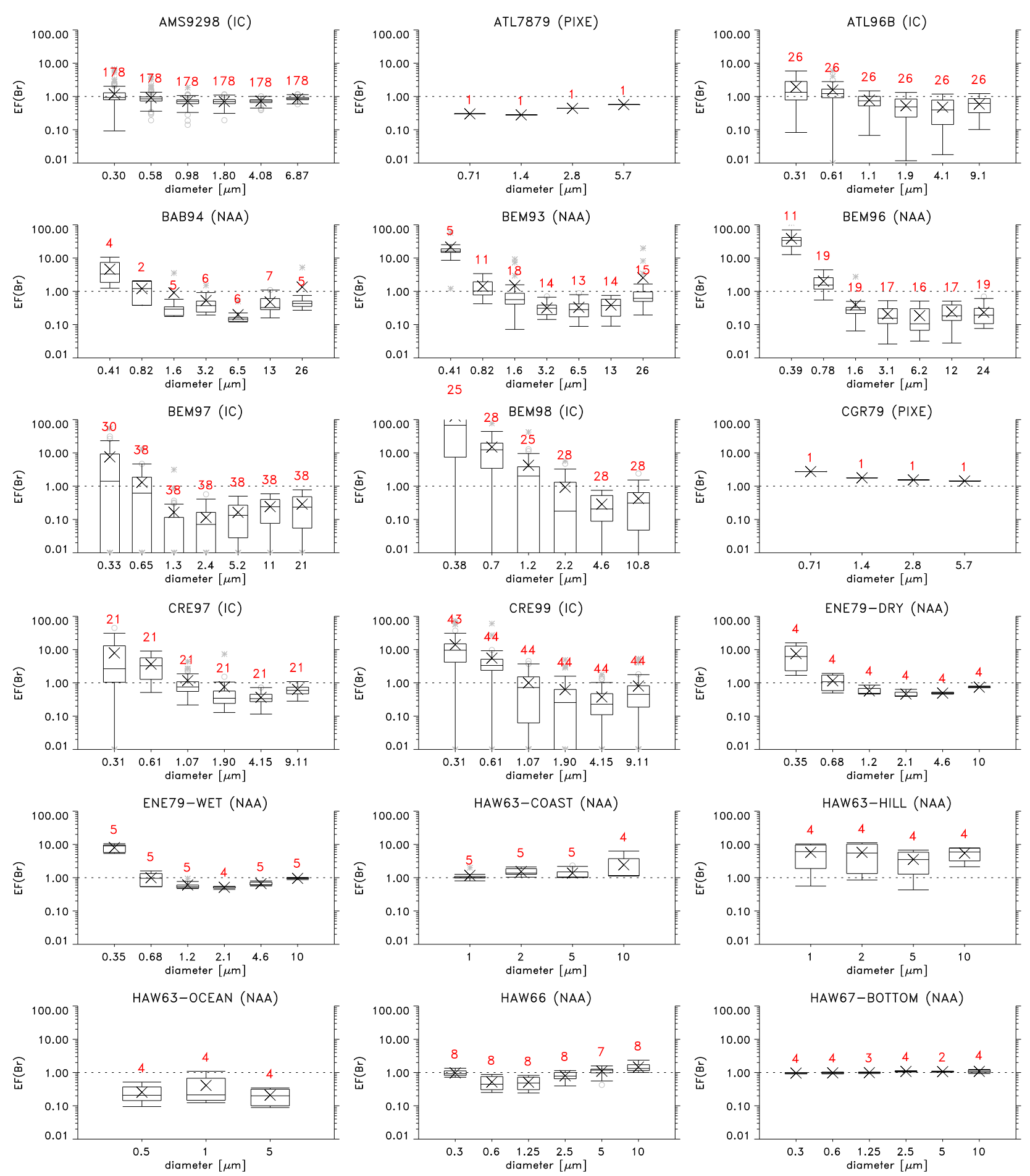

Fig. 3. Size-resolved measurements of $E F(\mathrm{Br})$. The box-and-whisker plots are defined as explained in Fig. 2. The number of samples is shown in red above each box. The $x$-axes differ between plots. The characteristic aerosol diameter at ambient relative humidity for each impactor stage was estimated as the geometric mean diameter (GMD) of the $50 \%$ cutoff diameters for that stage and for the preceding stage. For the top stage corresponding to the largest size fraction, we assume a GMD $\sqrt{2}$ times larger than the cutoff diameter of that stage. For the backup filter corresponding to the smallest size fraction, we assume a GMD $\sqrt{2}$ times smaller than the cutoff diameter of the preceding impactor stage. For INDXX, the sizes of the stages are not known. 

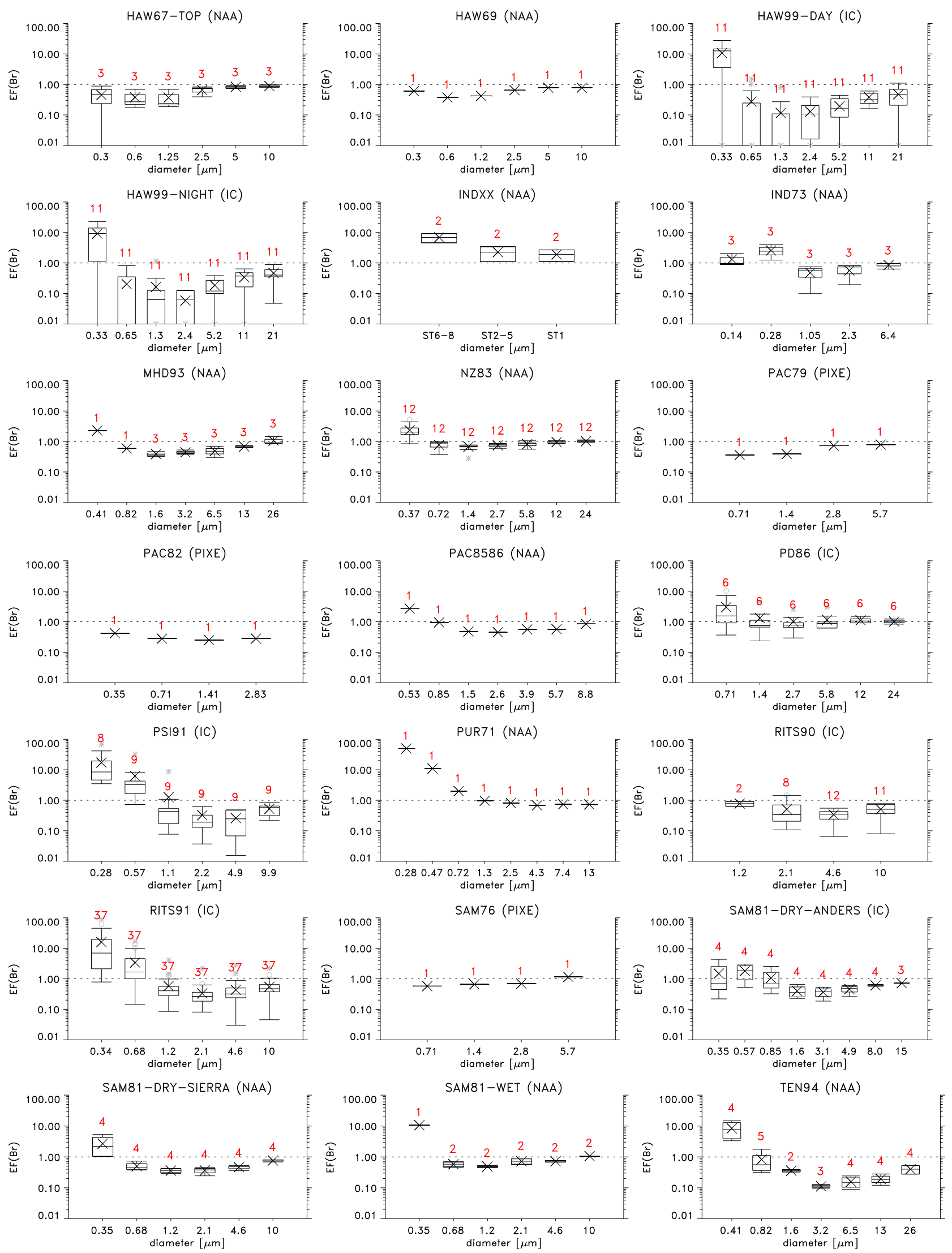

Fig. 3. (continued) 


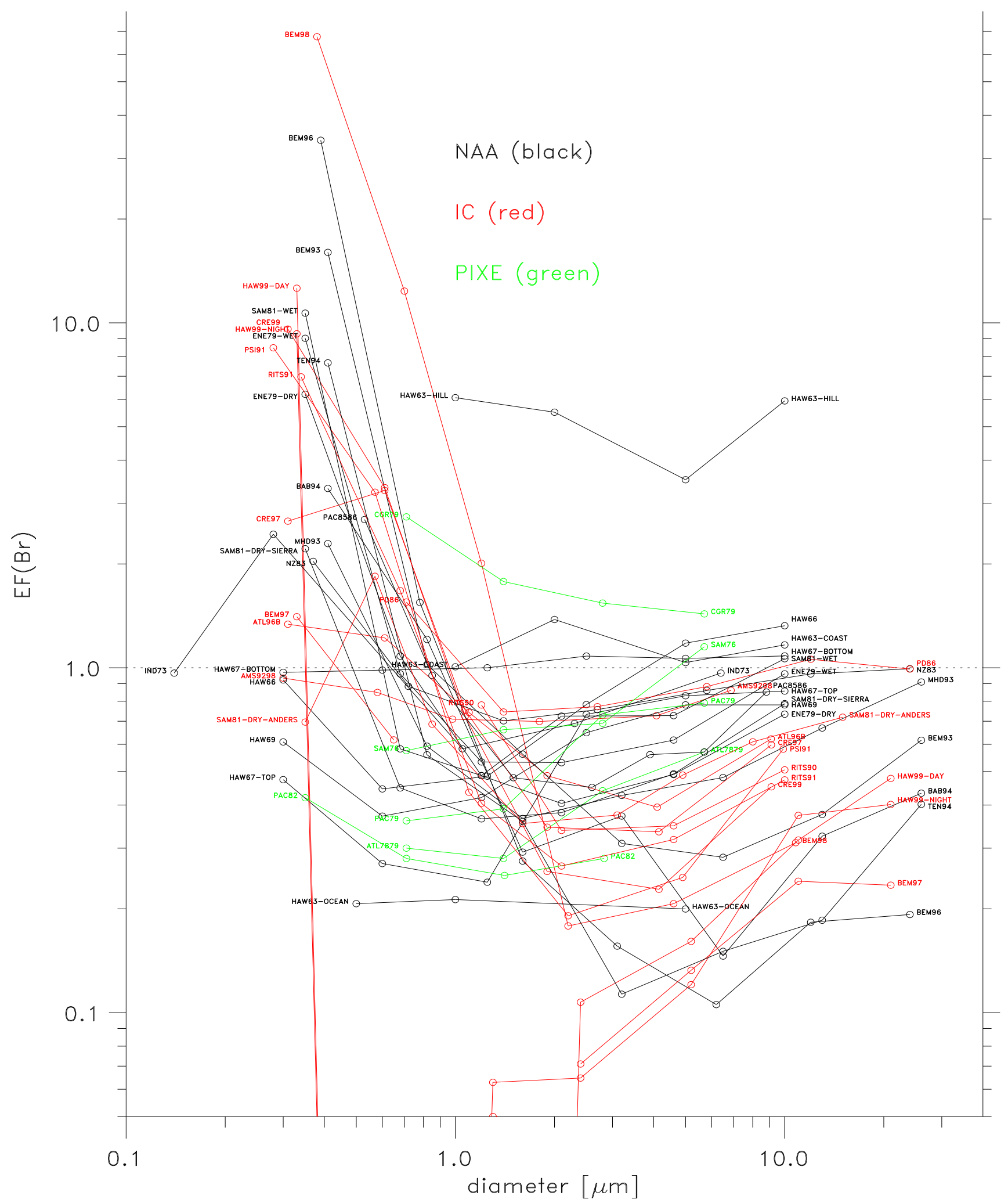

Fig. 4. Composite plot of the medians in Fig. 3. Different analytical methods are shown in different colors. 


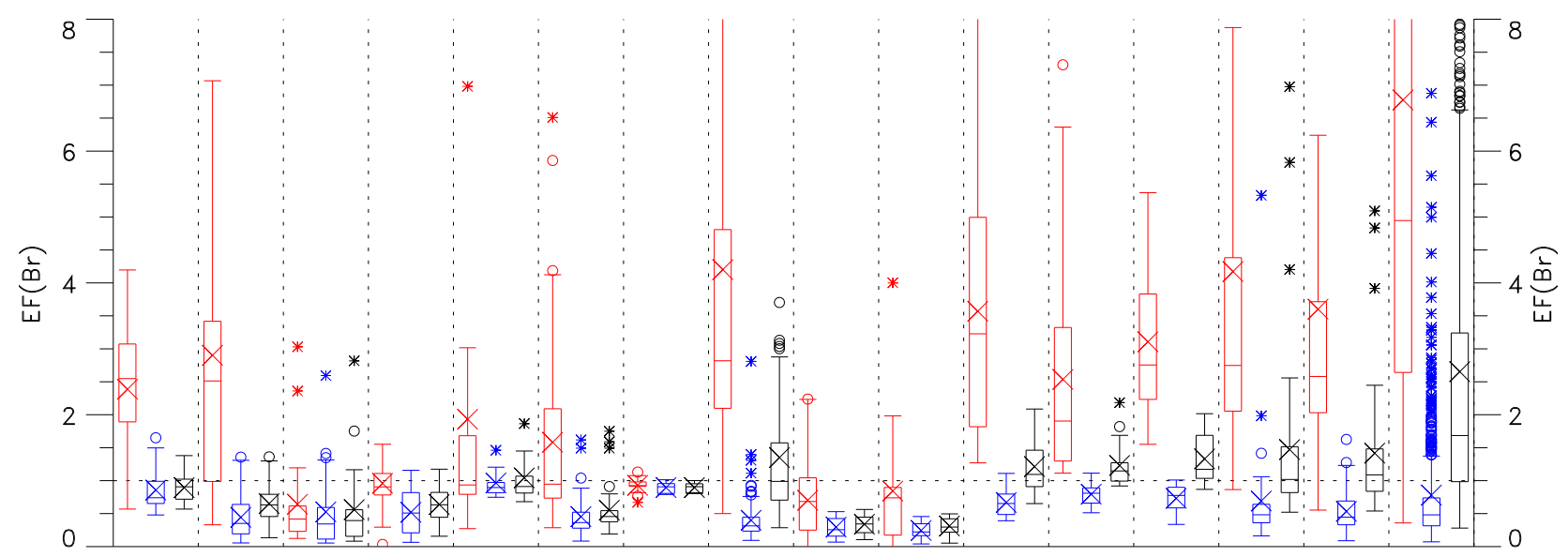

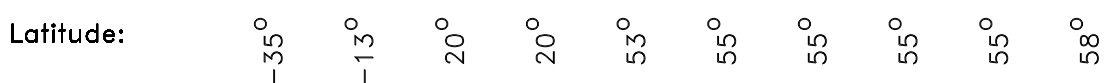
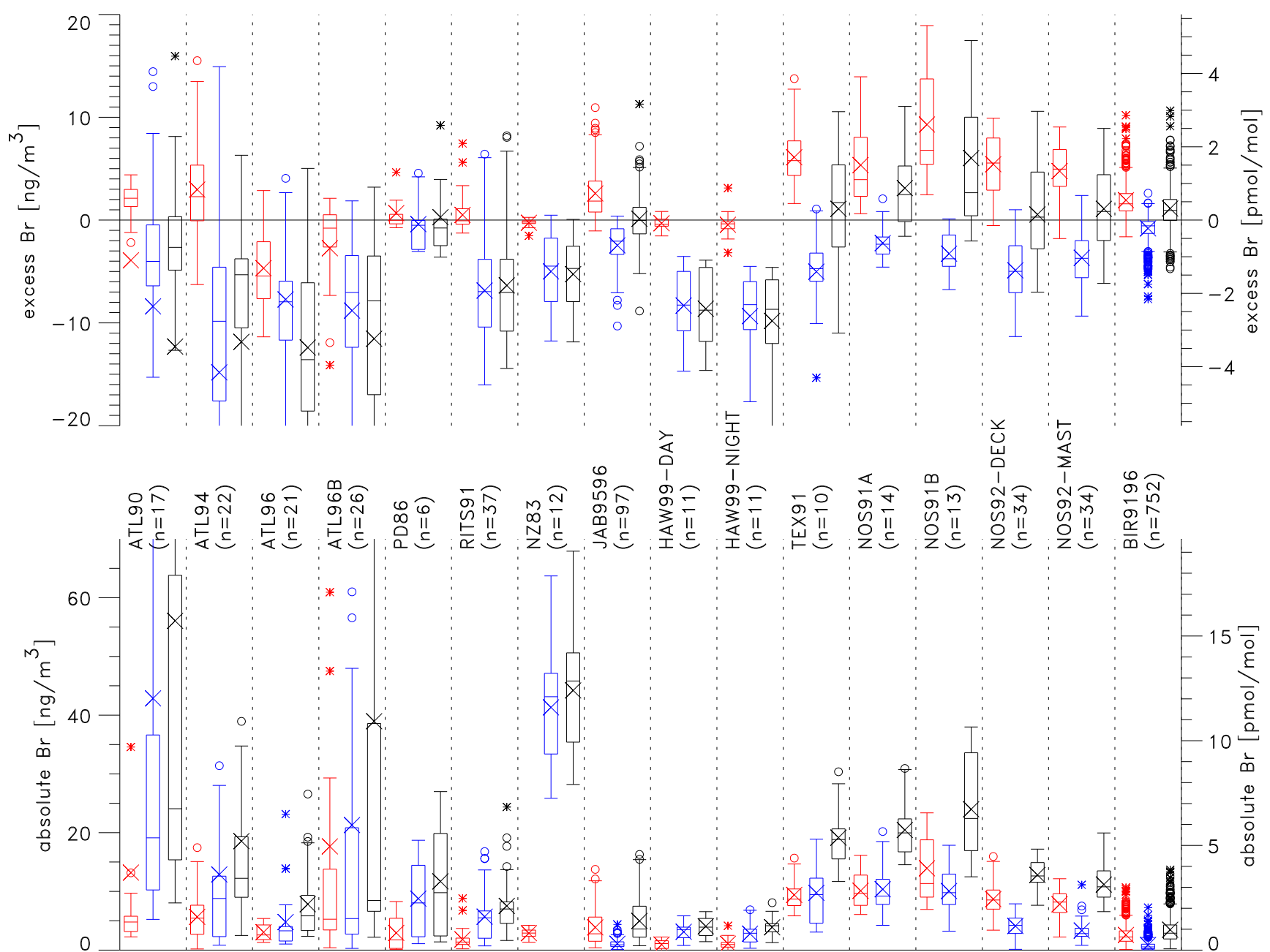

Fig. 5. EF (top), excess Br calculated using Eq. (3) (middle), and absolute bromine concentrations (bottom). The data set names are defined in Table 2. The number of samples $n$ is given in parentheses. The plots show the SFU data sets as well as those CI data sets that include all stages for all samples. The box-and-whisker plots (as defined in Fig. 2) are shown for submicrometer (red), supermicrometer (blue) and total aerosol (black). The mixing ratio plotted at the right axis was calculated at $T=273.15 \mathrm{~K}$ and $p=101325 \mathrm{~Pa}$. 

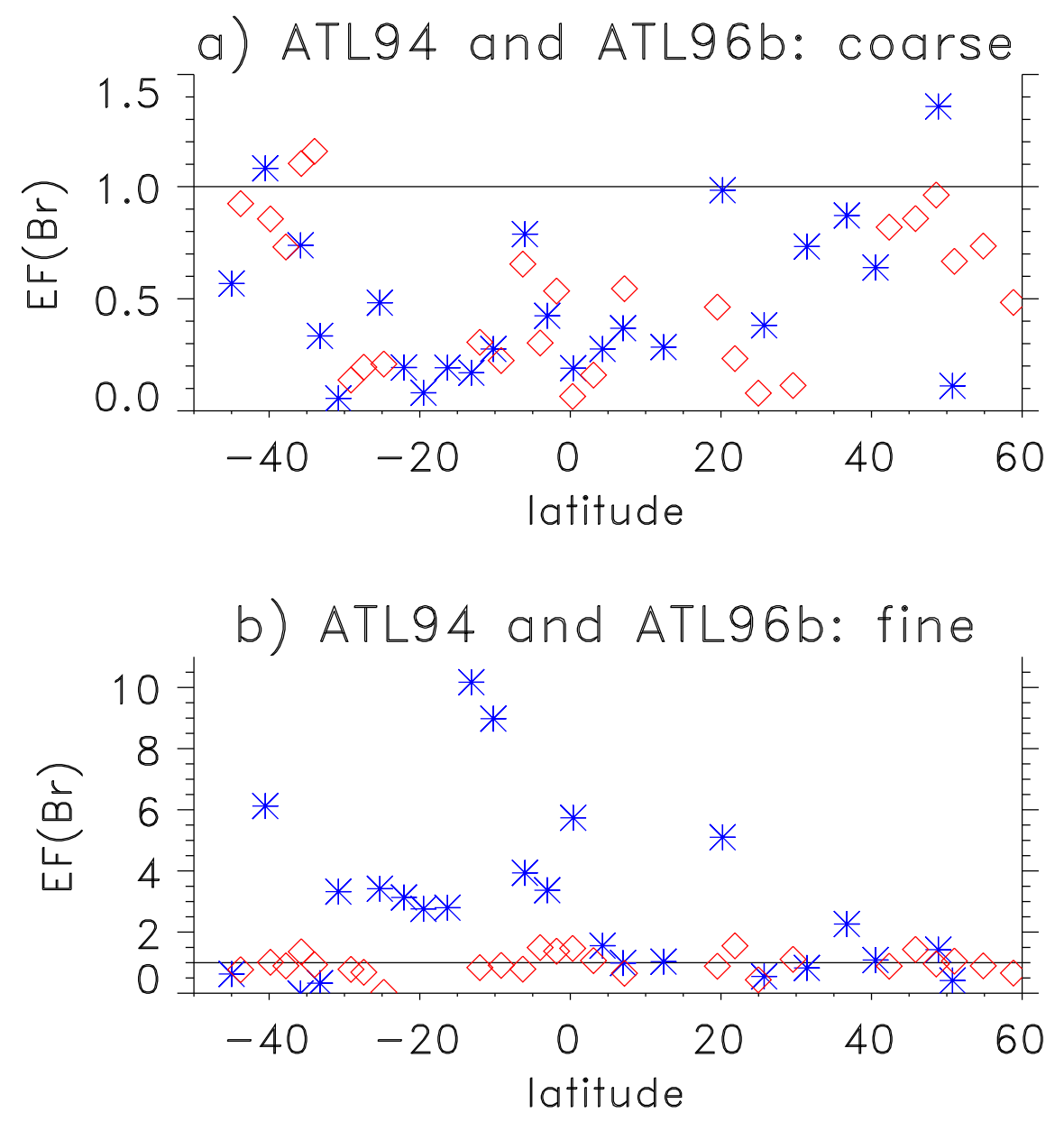

Fig. 6. Bromine enrichment factors as a function of latitude for ATL94 (blue asterisks) and ATL96b (red diamonds).

tic feature of the mbl in at least some tropical and subtropical regions. By considering the effect of stratiform clouds, von Glasow et al. (2002b) were able to reproduce this diurnal cycle with the one-dimensional column model MISTRA.

\subsection{Seasonal and long-term variation}

The seasonal variation in aerosol bromine has been investigated by Ayers et al. (1999). Bromine in particles of $<10 \mu \mathrm{m}$ diameter was measured at Cape Grim from January 1996 until May 1997. They found the highest depletions in the (austral) summer. The reason for the seasonal cycle is probably changing aerosol acidity (see Sect. 4.6). More recent data from June 1997 until July 1998 (Ayers, unpublished) show that the seasonal variation continues as predicted. The complete data set (CGR9698) is shown in Fig. 10a. Very similar seasonalities were observed at Crozet (CRO9698, Fig. 10b), Amsterdam Island (AMS9298, Baboukas (2000)), and at Macquarie Island (MQI9597) in the Southern Ocean (as shown by Ayers et al. (1999) in their Fig. 12).
The long-term measurements made as part of AEROCE are also very useful for revealing seasonal trends. Figures $11 \mathrm{a}-\mathrm{c}$ show the development of $E F$ over time for Barbados (BAB8897), Bermuda (BEM8897), and Mace Head (MHD8994). Since there were several extreme outliers in the data sets we decided to use medians and not means for our analysis. There is evidence for a seasonal variation at Barbados for the whole time and for Bermuda from 1988 to 1993. Again, $E F$ reaches a maximum in the winter and a minimum in summer. For Bermuda since 1994 and for Mace Head, the seasonal variation (if any) is much less pronounced. A longterm study in Norway (BIR9196) does not show a consistent seasonal variation (Fig. 12), either. In summary, seasonal trends are most obvious in unpolluted regions of the southern hemisphere.

In addition to seasonal trends, it is also interesting to analyze the data for long-term variations. However, we cannot see any significant difference between the data from the beginning of AEROCE in 1988 and ten years later in 1998. Similarly, the measurements at Birkenes (BIR9196) do not 

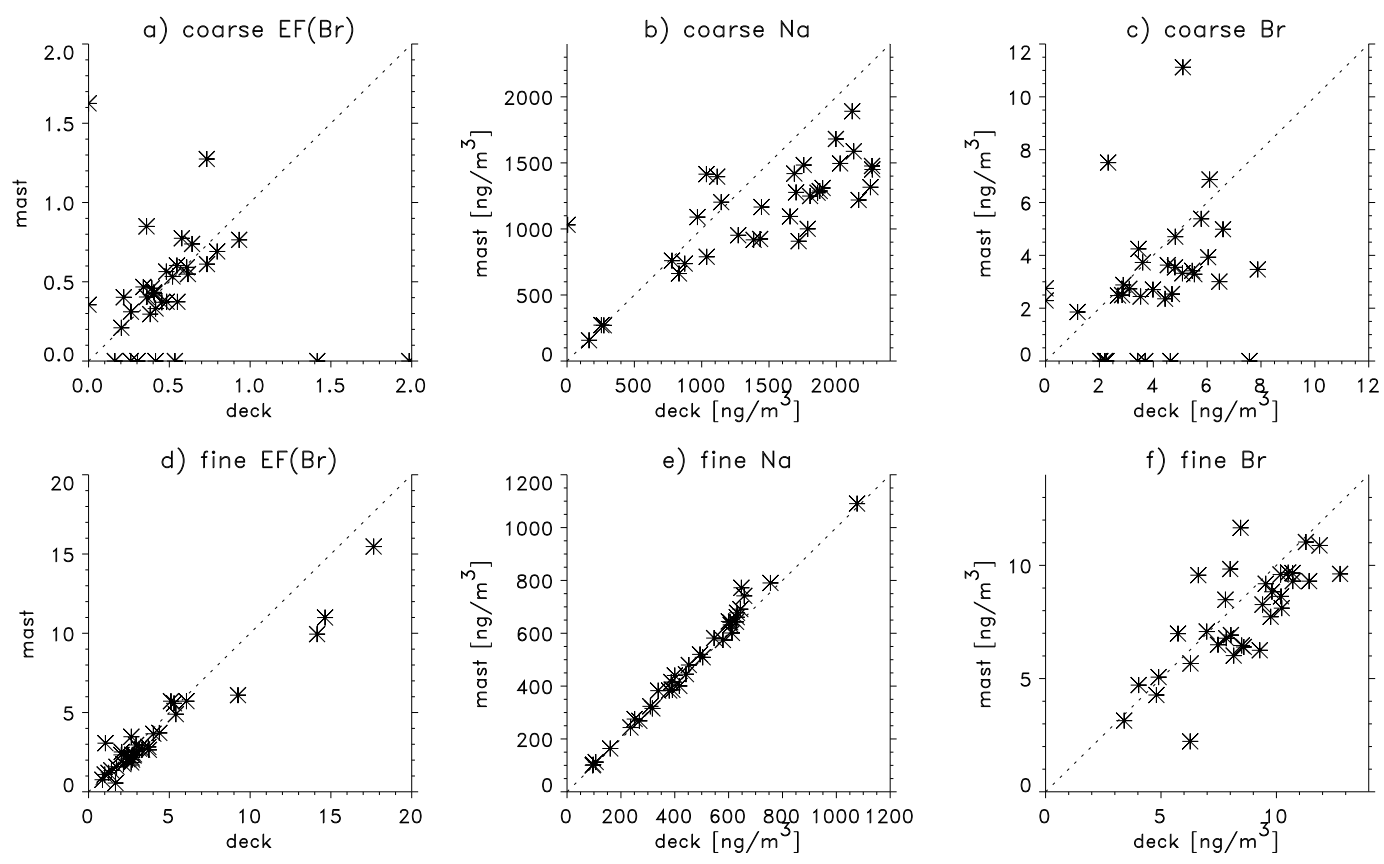

Fig. 7. Correlation between aerosol samples collected on deck (NOS92-DECK) and from the mast (NOS92-MAST) of a platform (values below the detection limit are set to zero). Data points with equal values at both heights lie on the dotted diagonal.

show a long-term trend, either (see Fig. 12).

\subsection{Correlation to acids}

Laboratory studies show that bromine release is acidcatalyzed (see Sect. 7). Thus a correlation of bromine depletions with aerosol acidity is to be expected. Three data sets can be used to directly address this topic. Murphy et al. (1997) analyzed aerosols in clean marine air at Cape Grim (CGR95). They observed an anticorrelation of bromine with sulfate. Assuming that sulfate is a tracer for aerosol acidity, this indicates enhanced loss of bromine from the aerosol when the particles are acidified. The long-term studies by Ayers et al. (1999), which was also performed at Cape Grim (CGR9698), and by Baboukas (2000) at Crozet (CRO9698) confirm this result. The monthly mean bromine depletions show a strong correlation with methane sulfonic acid (MSA), which is shown in Fig. 10. Still, the acidification is not strong enough for significant loss of chloride via acid displacement, and $E F(\mathrm{Cl})$ thus remains close to unity (also shown in Fig. 10).

Most acids in the mbl over the high-latitude southern ocean are of natural origin (Ayers et al., 1999) and consequently, loss of bromine to the gas phase reported in the above studies is a naturally occurring phenomenon that is not driven by anthropogenic pollutants. As noted by Ayers et al. (1999), however, during colder months at Cape Grim, when sea-salt concentrations are higher and ambient acids lower, bromine enrichment factors are closer to one. There- fore, it is reasonable to speculate that the enhanced fluxes of acids from anthropogenic activities to the global mbl have increased both the spatial and temporal extent of bromine depletion and related chemical processes over the world's oceans.

\subsection{Correlation to sea-salt concentration}

Another observation made by Ayers et al. (1999) was that low $E F$ values correlated well with low total concentrations of Na. A likely explanation involves acidity again. Since the $\mathrm{pH}$ of sea water is about 8 , the production of sea-salt particles is a source of atmospheric alkalinity. Higher aerosol acidities are expected when the concentrations of sea salt particles and thus $\mathrm{Na}$ are low relative to acids.

The correlation to $\mathrm{Na}$ can also be seen at Crozet (CRO9698, Fig. 10b) and in the AEROCE data sets (BAB8897, BEM8897, MHD8994), as shown in Figs. 11d-f. If $[\mathrm{Na}]>10 \mu \mathrm{g} / \mathrm{m}^{3}$, then in almost all cases $E F(\mathrm{Br})>0.3$. It is interesting to compare $E F(\mathrm{Br})$ to $E F(\mathrm{Cl})$ in Figs. 11 j1. Since dechlorination is mainly driven by acid displacement, chlorine deficits indicate acidified particles. Bermuda is often heavily impacted by anthropogenic acids transported from North America and the associated acidification of seasalt aerosol results in lower $E F(\mathrm{Cl})$ values compared to Barbados and Mace Head. The lowest $E F(\mathrm{Cl})$ are at low concentrations of Na. $E F(\mathrm{Cl})$ is never below 0.5 when the concentration of $\mathrm{Na}$ is above $5 \mu \mathrm{g} / \mathrm{m}^{3}$. For Mace Head and Barbados, $E F(\mathrm{Cl})$ is close to $1 . E F(\mathrm{Br})$ is in a similar range for 


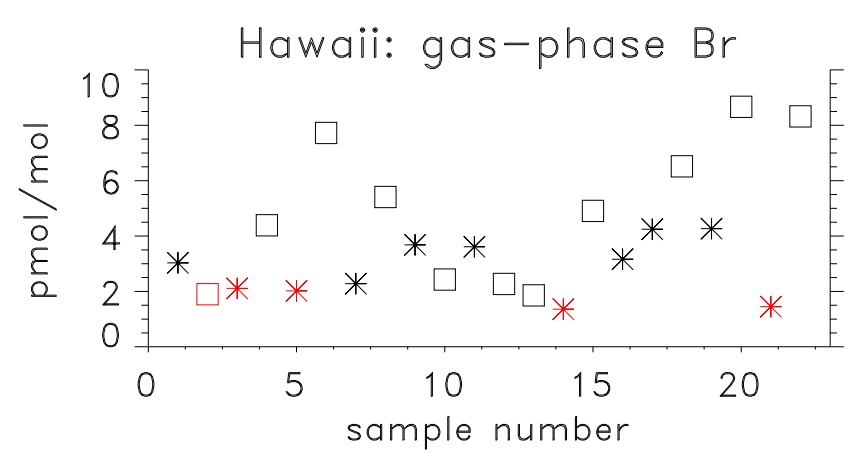

Fig. 8. Night (asterisks) and day (squares) mixing ratios of reactive gas-phase bromine compounds measured during September 1999 at Hawaii (HAW99-G). Values below DL are shown in red.

all three sites suggesting that the lack of strong aerosol acidification events at Barbados and Mace Head does not prevent debromination. This is consistent with models results (Keene et al., 1998) which show that strong acidification is necessary for chlorine release while bromine can escape from only slightly acidic solutions around $\mathrm{pH}=5.5$. It indicates that whenever substantial debromination occurs, atmospheric acidity is present at levels sufficient to titrate sea-salt alkalinity. We note in this regard that mixing chemically distinct aerosols (e.g. supermicrometer sea salt and submicrometer sulfate on bulk filters) can cause artifact acid displacement of $\mathrm{HCl}$ (e.g. Keene et al., 1990). Thus caution is warranted in interpreting chlorine deficits associated with bulk aerosol.

Wind speed directly influences these processes in several important respects. Sea-salt production increases as a power function of wind speed (Gong et al., 1997; Gong and Barrie, 2003). Increased wind velocities lead to increased production fluxes of sea-salt aerosols and associated alkalinity, higher concentrations of atmospheric sea salt, increased mean sea-salt sizes and total aerosol surface areas (but decreased mean surface/volume ratio), decreased sea-salt lifetimes, decreased rates of gaseous uptake and loss from individual particles, and increased overall scavenging and deposition of acids (e.g. Woodcock, 1953; Erickson et al., 1999). It is evident from the above discussion that all of these effects will influence the rate and degree of aerosol acidification and associated debromination.

\subsection{Correlation to anthropogenic influence}

It was shown in Sect. 4.1 that submicrometer aerosol often shows very high values of $E F$. Samples that do not show such an enrichment are mostly taken from remote regions (see AMS9298, PAC79, PAC82, and SAM76 in Fig. 3). A comparison of the Atlantic cruises ATL94 and ATL96b (Fig. 6b) shows high $E F$ for many submicrometer particles during 1994 but $E F \approx 1$ in 1996 . This may be related

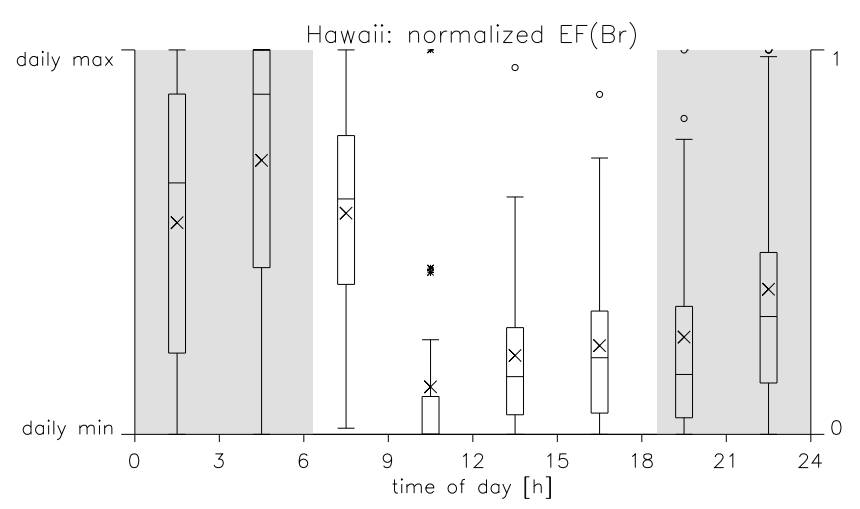

Fig. 9. Diurnal cycle of normalized $E F(\mathrm{Br})$ at Hawaii (HAW99b). To eliminate the influence of day-to-day variability, the data for each day were normalized individually, where 0 represents the daily minimum and 1 the daily maximum. The box-and-whisker-plot conventions are explained in Fig. 2. The time from sunset to sunrise is shaded in grey.

to biomass-burning plumes encountered during ATL94 (see Sect. 5.3) while low levels of CO measured in 1996 indicate clean air masses. In addition to analyzing the relative enrichment factor $E F$, it is thus also important to look at absolute concentrations of bromine and 'excess Br', as defined in Eq. (3) and plotted in Fig. 5. Since most data sets shown here are from SFU sampling, they are divided into only two size bins: submicrometer and supermicrometer aerosol. As expected, the submicrometer particles show positive excess bromine (red in Fig. 5) and the supermicrometer particles negative values (blue). For many data sets, the bromine concentration in submicrometer particles is too small to compensate for the bromine deficit in supermicrometer particles and the total excess bromine (black in Fig. 5) is thus negative. However, all data sets from the polluted North Sea (TEX91, NOS91, NOS92, BIR9196) show median excess bromine greater than zero. This suggests contributions from a non-sea-salt (possibly anthropogenic) source to submicrometer bromine in this region. Potential sources are discussed in Sect. 5. Alternatively, these enhanced enrichments may be related to physical (e.g. submicrometer volume) or other chemical (e.g. solution acidity) differences in the aerosol populations associated with relatively greater concentrations of pollutants.

Another indication for anthropogenic influence may be the fact that a seasonal cycle of $E F$ can only be seen in the remote, pristine southern hemisphere (see Sect. 4.5). If the reason is indeed changing aerosol acidity, one cannot expect such a cycle in regions where anthropogenic pollution acidifies the aerosol throughout the year. 


\subsection{Inorganic gas-phase bromine species}

Several measurements of unspecified gas-phase inorganic bromine have been made in the mbl since the 1960s (see Table 3 ). They typically show mixing ratios between 2 and $10 \mathrm{pmol} / \mathrm{mol}$. This is slightly larger than the bromine missing from the aerosol as shown in Fig. 5.

In addition to the direct measurements, there is also indirect support for the existence of inorganic gas-phase bromine compounds. Enrichment factors in rain (Table 5) range from about 0.6 to 5 . Most values are above one. In all cases the $E F$ for rain is larger than those for aerosol particles collected during the same campaign. A likely explanation is that clouds and falling rain drops scavenge not only particulate bromine, but also soluble gas-phase bromine (e.g. $\mathrm{HBr}$ ).

Ozone measurements have also been used to indirectly infer the presence of inorganic gas-phase bromine. Dickerson et al. (1999) analyzed diurnal variations of $\mathrm{O}_{3}$ in the Indian Ocean and partly attributed the changes to bromine chemistry. Nagao et al. (1999) analyzed a long-term ozone record from Ogasawara Island in the subtropical Pacific. Their data showed pronounced ozone destruction at sunrise, especially in the winter when ozone concentrations are high. Bromine chemistry was given as a potential explanation. Galbally et al. (2000) also suggested a bromine (and iodine) based mechanism to explain their observation of sunrise ozone destruction at Cape Grim. Nowak et al. (2001) speculate on the reaction of gas-phase $\mathrm{BrO}$ with dimethyl sulfide (DMS) to explain observed levels of dimethyl sulfoxide (DMSO). However, they conclude that this reaction cannot explain production of DMSO at night. Sciare et al. (2000) find that 2 to $3 \mathrm{pmol} / \mathrm{mol}$ of $\mathrm{BrO}$ can reproduce the observed daytime cycle of their DMS measurements.

Encouraged by these indications that reactive bromine exists in the mbl, there were several attempts to detect individual bromine species, especially $\mathrm{BrO}$ (see Table 4). Hebestreit et al. (1999) and Matveev et al. (2001) were able to detect very high mixing ratios of up to $176 \mathrm{pmol} / \mathrm{mol} \mathrm{BrO}$ over the Dead Sea, Israel (ISR97-G) with LP-DOAS. Compared to the open ocean, however, the Dead Sea has a much higher bromide content and is also acidic with a $\mathrm{pH}<7$ (Nishri and Stiller, 1997), which favors heterogeneous reactions releasing bromine (see also Sects. 6 and 7). Recently, Stutz et al. (2002) reported $\mathrm{BrO}$ mixing ratios up to $6 \mathrm{pmol} / \mathrm{mol}$ at the Great Salt Lake, USA (GSL00-G) even though it has bromide content lower than sea water. However, major differences between these salt lakes, which are usually surrounded by salt pans, and the open ocean are the large salt surface areas available for heterogeneous reactions on salt pans and the different ionic composition including $\mathrm{pH}$ of most salt lakes compared to standard ocean water. Therefore, these results are not representative for the mbl over the open ocean.

GOME (Global Ozone Monitoring Experiment) satellite observations of column-integrated $\mathrm{BrO}$ have been reported by several authors (Richter et al., 1998; Chance, 1998;
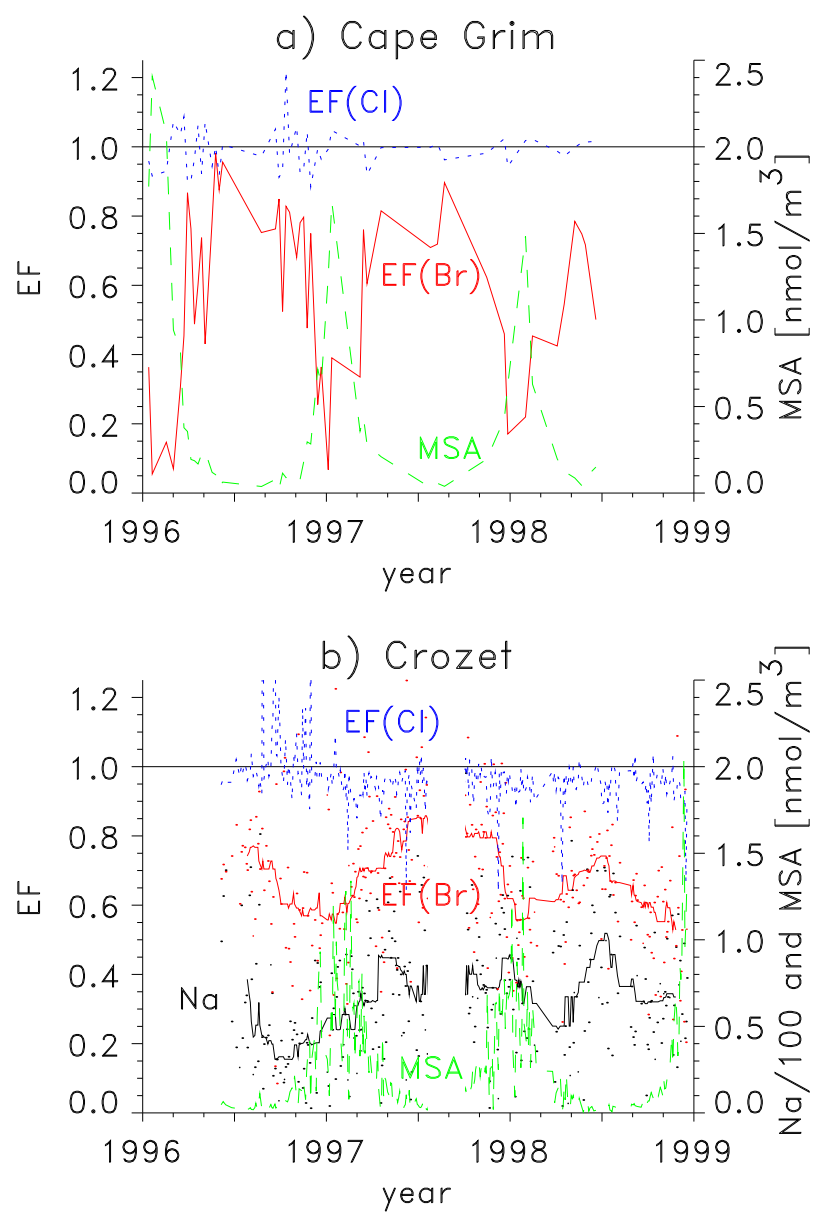

Fig. 10. Bulk $E F(\mathrm{Br})$ (red, solid), $E F(\mathrm{Cl})$ (blue, dotted), and MSA concentrations (green, dashed) at (a) Cape Grim (CGR9698) and (b) Crozet (CRO9698). For CRO9698, Na is also shown (black, solid). Since there is a lot of scatter in the $E F(\mathrm{Br})$ and $\mathrm{Na}$ data for Crozet, the individual data points are shown as dots and the solid line represents the 20-point running median.

Hegels et al., 1998; Wagner and Platt, 1998; Wagner et al., 2001). In both polar regions, enhanced $\mathrm{BrO}$ vertical column densities indicate boundary layer BrO regularly during the spring months. Except for the polar regions during springtime, however, the total $\mathrm{BrO}$ column is governed by $\mathrm{BrO}$ in the stratosphere. The relative contributions from the troposphere or even the mbl cannot be reliably separated from the total $\mathrm{BrO}$ column.

However, comparison with total column measurements from the ground (e.g. Friess et al., 1999) or with measurements of the stratospheric BrO column from balloon-borne instruments (e.g. Pundt et al., 2000; Harder et al., 2000) allow derivation of the tropospheric $\mathrm{BrO}$ fraction. If uniformly distributed over the complete altitude range of the troposphere the inferred tropospheric BrO column can be converted to a mixing ratio of 1 to $2 \mathrm{pmol} / \mathrm{mol} \mathrm{BrO}$ (SAOZ9798- 

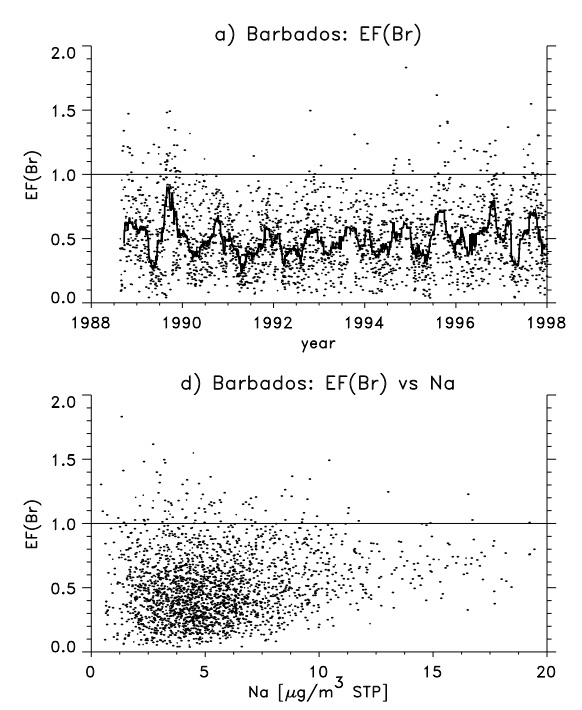

g) Barbados: $\mathrm{EF}(\mathrm{Cl})$ vs $\mathrm{Na}$

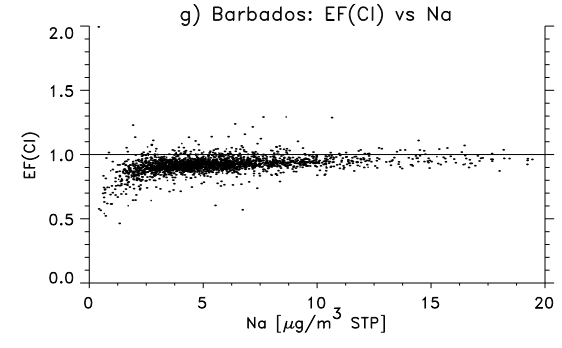

i) Barbados: $\mathrm{EF}(\mathrm{Cl})$ vs $\mathrm{EF}(\mathrm{Br})$

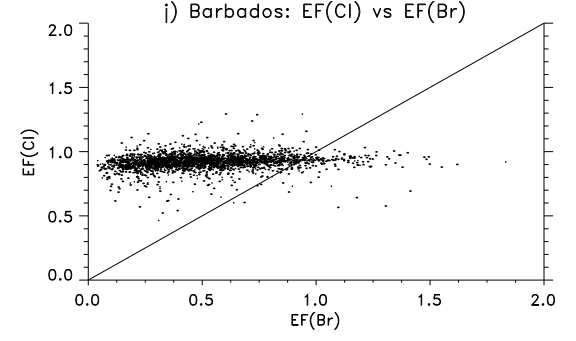

b) Bermuda: $E F(B r)$

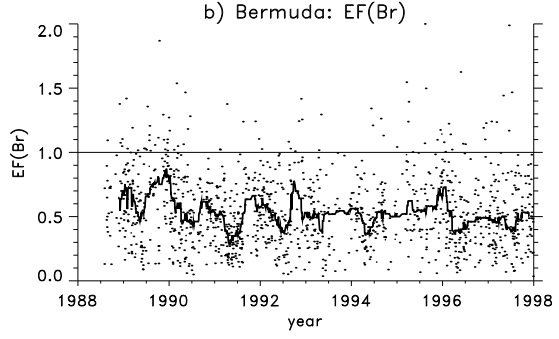

e) Bermuda: $\mathrm{EF}(\mathrm{Br})$ vs $\mathrm{Na}$

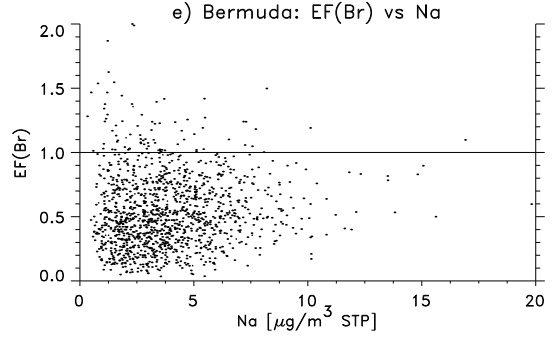

h) Bermuda: $\mathrm{EF}(\mathrm{Cl})$ vs $\mathrm{Na}$

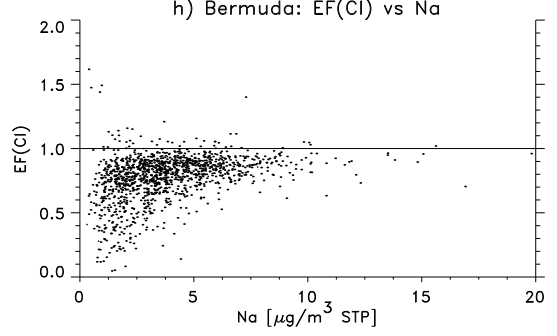

k) Bermuda: $\operatorname{EF}(\mathrm{Cl})$ vs $\mathrm{EF}(\mathrm{Br})$

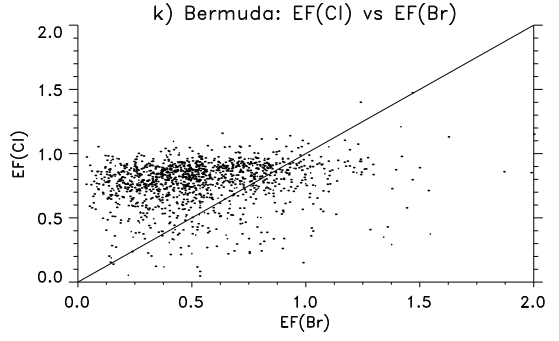

c) Mace Head: $E F(B r)$

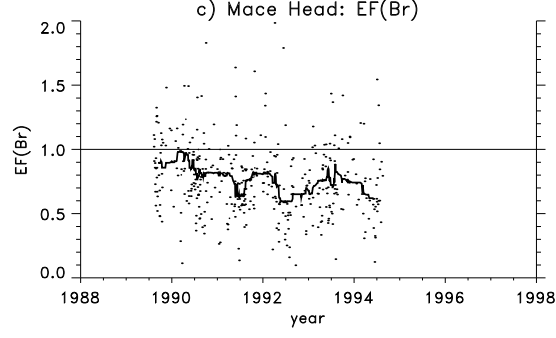

f) Mace Head: $\mathrm{EF}(\mathrm{Br})$ vs $\mathrm{Na}$

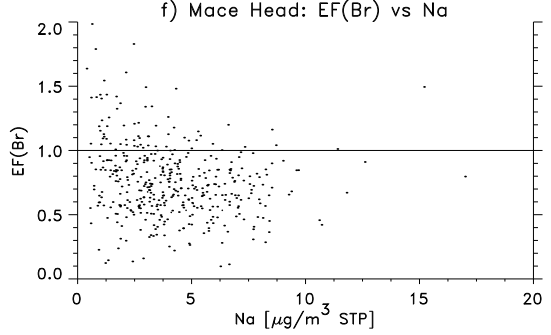

i) Mace Head: $\mathrm{EF}(\mathrm{Cl})$ vs $\mathrm{Na}$

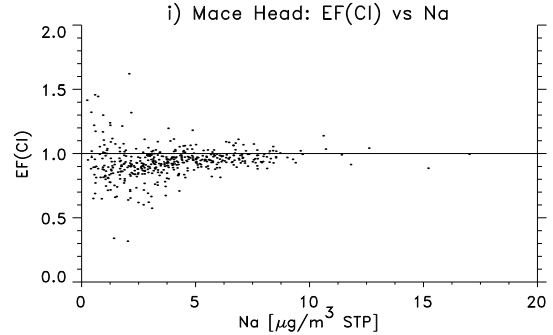

l) Mace Head: $\operatorname{EF}(\mathrm{Cl})$ vs $\operatorname{EF}(\mathrm{Br})$

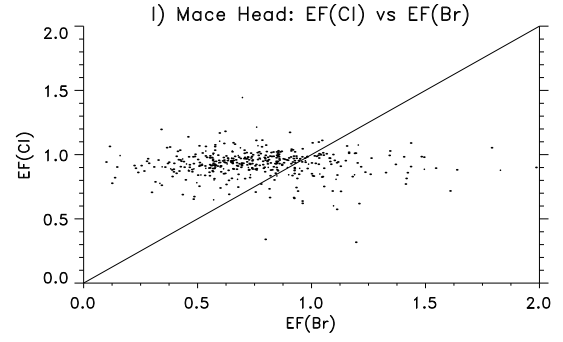

Fig. 11. Bulk AEROCE data for Barbados (BAB8897), Bermuda (BEM8897), and Mace Head (MHD8994).

(a-c) Bromine enrichment vs. time. The thick solid line is a 40-point running median. Labels for the years mark 1 January.

(d-i) Enrichment factors plotted against Na concentrations (STP refers to $T=273.15 \mathrm{~K}$ and $p=101325 \mathrm{~Pa}$ ).

(j-l) A comparison between $E F(\mathrm{Cl})$ and $E F(\mathrm{Br})$. The diagonal lines divide the regions where $E F(\mathrm{Br})<E F(\mathrm{Cl})(\mathrm{upper}$ left) and $E F(\mathrm{Br})>E F(\mathrm{Cl})$ (lower right).

G). Several attempts have been made to measure $\mathrm{BrO}$ in the mbl outside the polar regions, both at a clean remote site (HAW99b-G) and also at sites that are more polluted to varying degrees (MHD96-G, MHD97a-G, MHD97b-G, MHD98G, TEN97-G, WEY96a-G, WEY96b-G, CRT00-G). The results from these LP-DOAS measurements indicate ambient concentrations around or below the DL of the respective instruments (about 1 to $3 \mathrm{pmol} / \mathrm{mol}$ ) (Alicke, 1997; Allan, 1998; Hönninger, 1999; Hönninger, 2002).

Recently Leser et al. (2003) performed shipborne MAXDOAS measurements during an Atlantic transect from $54^{\circ} \mathrm{N}$ to $34^{\circ} \mathrm{S}$ (ATL00-G). Between $37^{\circ}$ and $30^{\circ} \mathrm{N} \mathrm{BrO}$ was observed in the $\mathrm{mbl}$ with an average of $0.7 \pm 0.2 \mathrm{pmol} / \mathrm{mol}$ and maximum values reaching up to $2.4 \pm 2.1 \mathrm{pmol} / \mathrm{mol}$. For the rest of the transect $\mathrm{BrO}$ ranged below the $\mathrm{DL}$ of 1 to $3.6 \mathrm{pmol} / \mathrm{mol}$ for individual measurements. In contrast to the LP-DOAS measurements mentioned above, which are only sensitive to the respective absorption path, MAX-DOAS provides some extent of vertical resolution with the maximum sensitivity over the lowest kilometer of the atmosphere.

In summary, except for a few data points, individual gasphase inorganic $\mathrm{Br}$ compounds have not been reliably characterized in the $\mathrm{mbl}$ at lower latitudes. Total gas-phase inorganic $\mathrm{Br}$ has been measured at several locations and typically appears to be around a few $\mathrm{pmol} / \mathrm{mol}$. 
Table 6. Elemental $\mathrm{Br} / \mathrm{Na}$ mass ratios in different materials

\begin{tabular}{|c|c|c|}
\hline Material & $m(\mathrm{Br}) / m(\mathrm{Na})$ & Reference \\
\hline continental crust & 0.000088 & Mason and Moore (1982) \\
\hline \multicolumn{3}{|l|}{ biomass-burning } \\
\hline - aerosol (South Africa) & 0.015 to 0.059 & Maenhaut et al. (1996b) \\
\hline - savanna fires (South Africa) & 0.0176 & Andreae et al. (1998) \\
\hline - wood, foliage, bark, soil, ... & see note ${ }^{1}$ & McKenzie et al. (1996) \\
\hline - wood & 0.007 to 0.01 & Slocum et al. (1978) \\
\hline - charcoal & 0.014 to 0.025 & Slocum et al. (1978) \\
\hline - rice straw & 0.028 to 0.45 & Saito et al. (1994) \\
\hline leaded petrol & (very large) & \\
\hline
\end{tabular}

${ }^{1}$ McKenzie et al. (1996) measured $\mathrm{Cl}$ but not Na. They report $m(\mathrm{Br}) / m(\mathrm{Cl})$ between $<0.0013$ and $>8.2$.
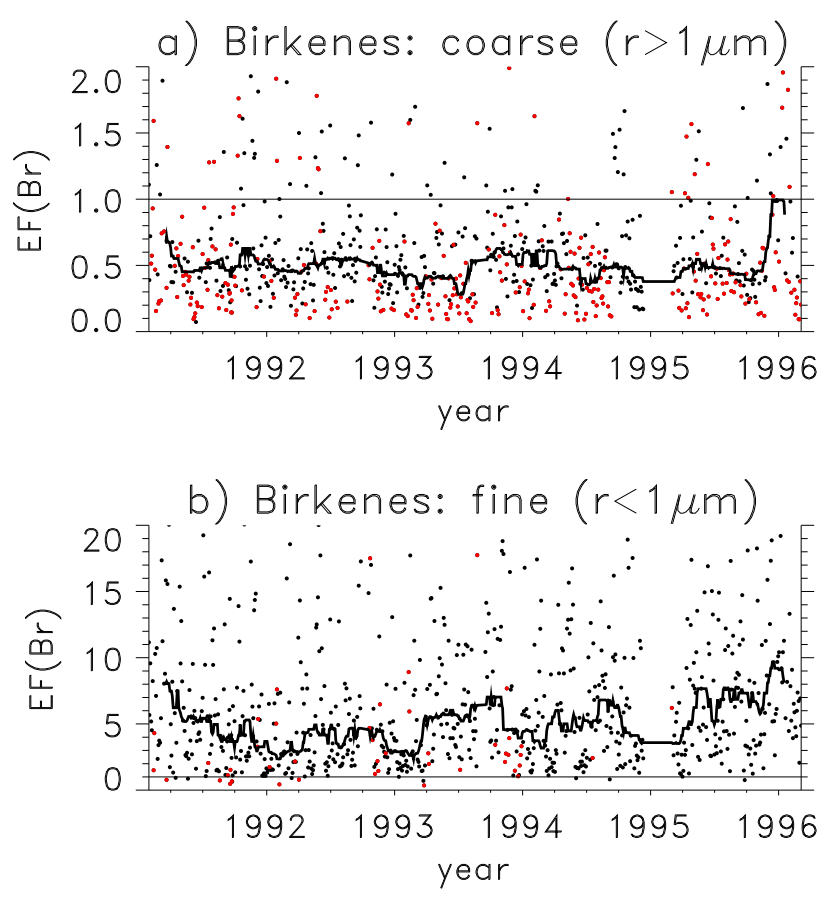

Fig. 12. Bromine enrichment measured at Birkenes (BIR9196) vs. time. The thick solid line is a 40-point running median. Labels for the years mark 1 January. In cases where measured bromine was below DL (shown in red), values were set to $50 \%$ of the DL.

\section{Primary sources of inorganic bromine}

Although most inorganic bromine in the marine troposphere is produced from the ocean surface in association with seasalt aerosol, other sources must also be considered. This is especially relevant for the high enrichment factors observed in submicrometer particles. The $\mathrm{Br} / \mathrm{Na}$ mass ratios of different materials are listed in Table 6.

\subsection{Sea-salt production}

The emission flux of particulate $\mathrm{Br}$ from the surface ocean to the atmosphere can be estimated from reported production fluxes of sea-salt aerosol and the measured composition of surface sea water. Based on the production flux of sea-salt chloride of $1785 \mathrm{Tg} / \mathrm{a}$ (Erickson et al., 1999) and the $\mathrm{Br} / \mathrm{Cl}$ mass ratio of $0.00348 \mathrm{~kg} / \mathrm{kg}$ (Table 1), we estimate a direct bromine production flux of $6.2 \mathrm{Tg} / \mathrm{a}$ from the surface ocean. This pathway is the principal global source for atmospheric $\mathrm{Br}$.

\subsection{Mineral aerosol}

Strong winds during dry seasons sporadically inject large amounts of soil dust from semi-arid regions (primarily from northern Africa and central Asia) into the middle troposphere where it can be transported long distances over oceans by prevailing winds before removal via wet and dry deposition (Swap et al., 1992; Prospero et al., 1996). A well-known example is Saharan dust which can often be seen in marine aerosol samples. The element $\mathrm{Al}$ can be used as a conservative tracer for dust. In principle, it is possible to obtain the dust-derived contribution $[\mathrm{Br}]_{\text {dust }}$ to the total bromine content:

$[\mathrm{Br}]_{\text {dust }}=[\mathrm{Al}]_{\text {meas }} \times\left(\frac{[\mathrm{Br}]}{[\mathrm{Al}]}\right)_{\text {dust }}$

where $[\mathrm{Al}]_{\text {meas }}=$ measured $\mathrm{Al}$ concentration and $([\mathrm{Br}] /[\mathrm{Al}])_{\mathrm{dust}}=$ elemental ratio typical for mineral aerosol. However, it is difficult to derive a value for the ratio $\mathrm{Br} / \mathrm{Al}$ in dust because the composition of mineral aerosol is distinct 
from that of Earth's crust (Schütz and Rahn, 1982) and also varies spatially. The bromine content of the continental crust is very low with $m(\mathrm{Br}) / m(\mathrm{Al})=2.07 \times 10^{-5} \mathrm{~kg} / \mathrm{kg}$ (Wedepohl, 1995). This value does not apply to airborne particles. Bromine concentrations in atmospheric dust near source regions are substantially greater than those in crustal rock. Since most dust originates from deflation of seasonally wetted soils (Prospero et al., 1996), this relative enrichment can be attributed in part to the dissolution, upward migration, and subsequent evaporative concentration of soluble salts near the soil surface over wet/dry cycles. Adepetu et al. (1988) analyzed dust in Nigeria that originated in the Sahara. Their 6 samples collected between 1981 and 1984 showed bromine enrichments from 10 to 300 relative to crustal rock and a mean value of $m(\mathrm{Br}) / m(\mathrm{Al})=3.19 \times 10^{-3} \mathrm{~kg} / \mathrm{kg}$. They state that this enrichment could be due to brominecontaining pesticide residues and automobile exhaust in the local environment. Consequently, the data by Adepetu et al. (1988) probably represent upper limits for the bromine content of Saharan dust.

Approximately $73 \mathrm{Tg} / \mathrm{a}$ of mineral $\mathrm{Al}$ is deposited from the atmosphere to the world's oceans (Duce et al., 1991). Adopting the $\mathrm{Br} / \mathrm{Al}$ mass ratio from Adepetu et al. (1988) as an upper limit and assuming similar atmospheric lifetimes for crustal $\mathrm{Br}$ and $\mathrm{Al}$, we estimate that an upper limit of about $0.23 \mathrm{Tg} / \mathrm{a}$ of crustal $\mathrm{Br}$ is deposited to the world's oceans. Although this flux of crustal bromine is small (about 4\%) compared to the global flux of sea-salt bromine, most crustal bromine is deposited over the equatorial Atlantic and North Pacific Oceans, which lie downwind of the major dust source regions in North Africa and central Asia, respectively. Thus, the relative contributions of crustal to total bromine in these regions are considerably greater than the global average.

The chemical evolution of mineral aerosol is poorly understood (e.g. Dentener et al., 1996) and that of crustal bromine virtually unexplored. Assuming that water and acids accumulate on aging atmospheric dust (probably as aqueous surface films) (e.g. Dentener et al., 1996; Li-Jones et al., 1998), bromine activation reactions analogous to those in sea salt aerosol should proceed. Such reactions could have important implications for the chemical evolution of dust plumes.

\subsection{Biomass burning}

Biomass contains significant $\mathrm{Br}$ which is emitted to the atmosphere during combustion (e.g. Andreae et al., 1996; McKenzie et al., 1996). Based on the few available compound specific measurements, $\mathrm{CH}_{3} \mathrm{Br}$ comprises relatively minor fractions (5\%) of the emitted Br (e.g. Andreae et al., 1996). As for $\mathrm{Cl}$ (e.g. Keene et al., 1999), it appears that most $\mathrm{Br}$ is emitted from burns in the form of volatile inorganic and particulate compounds. Particulate $\mathrm{Br}$ is enriched in biomass burning plumes, particularly from savanna fires (e.g. Echalar et al., 1995; Maenhaut et al., 1996b; Andreae et al., 1998; Kleeman et al., 1999). The relative importance of primary emissions versus secondary production cannot be reliably differentiated from such measurements. This raises the possibility that transformations involving $\mathrm{Br}$ radicals, analogous to those in marine air, may influence the chemical evolution of biomass-burning plumes. The advection of burning emissions over the ocean contributes combustion-derived $\mathrm{Br}$ to the multiphase mbl system. Particulate $\mathrm{Br} / \mathrm{Na}$ and $\mathrm{Br} / \mathrm{Ca}$ ratios in aged biomass burning plumes are greater than those in sea water (see Table 6) which complicates the interpretation of $\mathrm{Br}$ enrichment factors in marine air. Data from the experiments ATL94 and BEM98 provide context for assessing relative contributions of combustion-derived $\mathrm{Br}$ in marine regions significantly impacted by biomass-burning products.

During the ATL94 cruise between $10^{\circ} \mathrm{S}$ and $30^{\circ} \mathrm{S}$ in the Atlantic, $E F$ relative to sea-salt $\mathrm{Ca}$ for fine-fraction aerosols ranged from 3 to 10 while the coarse fractions were depleted (Fig. 6). Ratios of particulate $\mathrm{Zn} / \mathrm{Ca}$ and $\mathrm{K} / \mathrm{Ca}$ (e.g. Maenhaut et al., 1996b) indicate the presence of significant biomass-burning emissions in this region suggesting that burning-derived $\mathrm{Br}$ may have contributed to the apparent fine-fraction enrichments relative to sea salt. However, the $\mathrm{Br} / \mathrm{Zn}$ ratio characteristic of burning over southern Africa (Maenhaut et al., 1996b) suggests that $30 \%$ to $80 \%$ of the observed fine-fraction $\mathrm{Br}$ originated from sources other than biomass burning.

During BEM98, the western North Atlantic mbl was significantly impacted by emissions from extensive wildfires in Latin America and Florida that were associated with a particularly strong El Niño (Turekian, 2000). The corresponding biomass burning emissions of Br probably explain why $E F$ in the finer aerosol size fractions was higher than during other years at Bermuda (BEM93, BEM96, BEM97), as shown in Fig. 4.

\subsection{Fossil-fuel combustion}

Duce et al. (1965) suggested that bromine from automobile exhaust may also contribute to the atmospheric burden. This is especially true for a polluted atmosphere (Moyers et al., 1972). However, it can also apply to the marine environment. Martens (1973) concluded that 'leaded aerosols appear to be a major source of bromine in small particles' for marine aerosols collected in Puerto Rico. Leaded petrol contains tetraethyl lead $\left(\mathrm{Pb}\left(\mathrm{C}_{2} \mathrm{H}_{5}\right)_{4}\right)$ which is a good tracer for automobile pollution for regions where leaded petrol is still used. Leaded petrol also contains the additives 1,2-dibromoethane $\left(\mathrm{BrCH}_{2} \mathrm{CH}_{2} \mathrm{Br}\right)$ and 1,2-dichloroethane $\left(\mathrm{ClCH}_{2} \mathrm{CH}_{2} \mathrm{Cl}\right)$ (Hamilton, 1996). During the combustion process the lead and halogen compounds react and predominantly produce $\mathrm{PbBrCl}$ which is emitted into the atmosphere (Habibi, 1973). Thus a ratio $n(\mathrm{Br}) / n(\mathrm{~Pb})=1 \mathrm{~mol} / \mathrm{mol}$ is expected for freshly emitted particles. This is equivalent to a mass ratio of $m(\mathrm{Br}) / m(\mathrm{~Pb})=0.386 \mathrm{~kg} / \mathrm{kg}$ (Lininger et al., 1966; Harrison and Sturges, 1983). A study in urban Honolulu, Hawaii, by Jernigan et al. (1971) showed a strong cor- 
relation between $\mathrm{Pb}$ and $\mathrm{Br}$ in the particles. The portion of bromine resulting from sea salt was small even though the city is in the middle of the Pacific Ocean. A similar result was obtained by Sturges and Harrison (1986b): Aerosol collected at a coastal site in northwest England (MOR8283) also showed a strong correlation between $\mathrm{Pb}$ and $\mathrm{Br}$. The ratio $\mathrm{Br} / \mathrm{Pb}$ was close to that expected for petrol. To obtain the petrol-derived contribution to the bromine contents $[\mathrm{Br}]_{\text {petrol }}$, a formula similar to Eq. (5) can be applied:

$[\mathrm{Br}]_{\text {petrol }}=[\mathrm{Pb}]_{\text {meas }} \times\left(\frac{[\mathrm{Br}]}{[\mathrm{Pb}]}\right)_{\text {petrol }}$

where $[\mathrm{Pb}]_{\text {meas }}=$ measured $\mathrm{Pb}$ concentration and $([\mathrm{Br}] /[\mathrm{Pb}])_{\text {petrol }}$ is the elemental ratio typical for petrol. A very different result was obtained by Sturges (1990) at a site in Scotland (HAR83). In this case contamination from petrol could not explain the high bromine content.

The decline in the world-wide use of leaded petrol (Thomas et al., 1997) is reflected in the atmosphere. For example, at Bermuda, aerosol lead concentrations have decreased by an order of magnitude from the 1970s to the mid-1990s (Huang et al., 1996). Since unleaded petrol does not contain the additive 1,2-dibromoethane, aerosol bromine from petrol has also decreased (Thomas et al., 1997). In India, leaded petrol has only recently been phased out. During the INDOEX measurements in the Indian Ocean (IND99), a steep gradient with increasing aerosol bromide concentrations towards the Indian coast was observed (Gabriel et al., 2002).

\subsection{Other sources}

Degradation of short-lived organobromine compounds like $\mathrm{CH}_{3} \mathrm{Br}$ (e.g. Khalil et al., 1993; Yokouchi et al., 2000) and $\mathrm{CHBr}_{3}$ (Quack and Wallace, 2003) via photolysis and reaction with $\mathrm{OH}$ also represents a source of inorganic bromine in the mbl. WMO (1998) lists global fluxes of 0.043 to $0.244 \mathrm{Tg} / \mathrm{a}$ of $\mathrm{CH}_{3} \mathrm{Br}$ and $0.1965 \mathrm{Tg} / \mathrm{a}$ of $\mathrm{CHBr}_{3}$. However, these numbers are upper limits for the contribution to inorganic reactive bromine because only a part of these molecules reacts in the mbl.

Degradation of longer-lived organobromine compounds in the stratosphere and subsequent downward transport is also a potential source. Accurate data are not available but nevertheless it is possible to get a rough estimate. Schauffler et al. (1998) measured a total organic bromine content near the tropopause of about $17.4 \mathrm{pmol} / \mathrm{mol}$, i.e. a mass mixing ratio of $4.8 \times 10^{-11} \mathrm{~kg} / \mathrm{kg}$. Multiplying this with an estimated downward mass exchange through the troposphere of $7.2 \times 10^{16} \mathrm{~kg} /$ month (Grewe and Dameris, 1996) yields a source strength on the order of $0.04 \mathrm{Tg} / \mathrm{a}$.

Other sources of bromine that have been proposed in the literature are coal burning (Duce et al., 1983) and volcanic emissions (Harrison and Sturges, 1983, and references therein). Bobrowski et al. (2003) recently detected $\mathrm{BrO}$ in a volcanic plume. Swietlicki (1989) applied a principal component analysis to bromine data from 600 submicrometer aerosol samples collected at 3 Swedish sites in the Baltic Sea (SWE8586). He concluded that 'bromine is found at elevated relative amounts following transport, implying a gasto-particle conversion for this element during transportation'.

\section{Modeling the mechanism of bromine chemistry in the MBL}

From the previous sections it is clear that a substantial fraction of the bromine in sea-salt particles is transferred into the gas phase. The question is which chemical mechanism causes this.

One may think that acid displacement plays a role. Acid displacement is an important mechanism by which sea-salt particles lose chloride in polluted air, e.g.:

$$
\begin{aligned}
\mathrm{H}_{2} \mathrm{SO}_{4}+\mathrm{Cl}^{-} & \rightarrow \mathrm{HCl}_{(\mathrm{aq})}+\mathrm{HSO}_{4}^{-} \\
\mathrm{HCl}_{(\mathrm{aq})} & \rightarrow \mathrm{HCl}_{(\mathrm{g})}
\end{aligned}
$$

An analogous reaction for bromine would be:

$$
\begin{aligned}
& \mathrm{H}_{2} \mathrm{SO}_{4}+\mathrm{Br}^{-} \rightarrow \mathrm{HBr}_{(\mathrm{aq})}+\mathrm{HSO}_{4}^{-} \\
& \operatorname{HBr}_{(\mathrm{aq})} \stackrel{?}{\rightarrow} \operatorname{HBr}_{(\mathrm{g})}
\end{aligned}
$$

However, this pathway can be ruled out because $\mathrm{HBr}$ is about 600 times more soluble than $\mathrm{HCl}$ (Sander, 1999). Therefore most of the chloride would have escaped from acidified particles before evaporation of $\mathrm{HBr}$ starts. This is in contrast with measurements which show that chlorine depletions are almost always smaller than bromine depletions (see Figs. 10 and $11 \mathrm{j}-1$ ). Thus a different mechanism must be responsible for debromination.

Under polluted conditions, the nitrogen oxides $\mathrm{NO}_{2}$ and $\mathrm{N}_{2} \mathrm{O}_{5}$ can react with $\mathrm{Br}^{-}$on the surface of sea-salt particles (Finlayson-Pitts and Johnson, 1988; Finlayson-Pitts et al., 1990; Behnke et al., 1994). This forms the gas-phase species $\mathrm{BrNO}$ and $\mathrm{BrNO}_{2}$. However, in clean marine air, the concentrations of nitrogen oxides are low and thus these reactions cannot explain the large bromine deficits measured in unpolluted regions of the mbl.

The first mechanism for low- $\mathrm{NO}_{\mathrm{x}}$ conditions was proposed by Fan and Jacob (1992), though for a different environment: The reaction of $\mathrm{HOBr}$ with $\mathrm{Br}^{-}$in Arctic sulfate aerosol particles:

$\mathrm{HOBr}+\mathrm{Br}^{-}+\mathrm{H}^{+} \rightarrow \mathrm{Br}_{2}+\mathrm{H}_{2} \mathrm{O}$

Mozurkewich (1995) noticed that this reaction would also be possible in acidified Arctic sea-salt particles. Using the box model MOCCA, Sander and Crutzen (1996) applied the mechanism to polluted marine air at mid-latitudes. Vogt et al. (1996) found a synergism between bromine and chlorine chemistry which makes the release of bromine possible even under clean air conditions. They proposed the reaction 


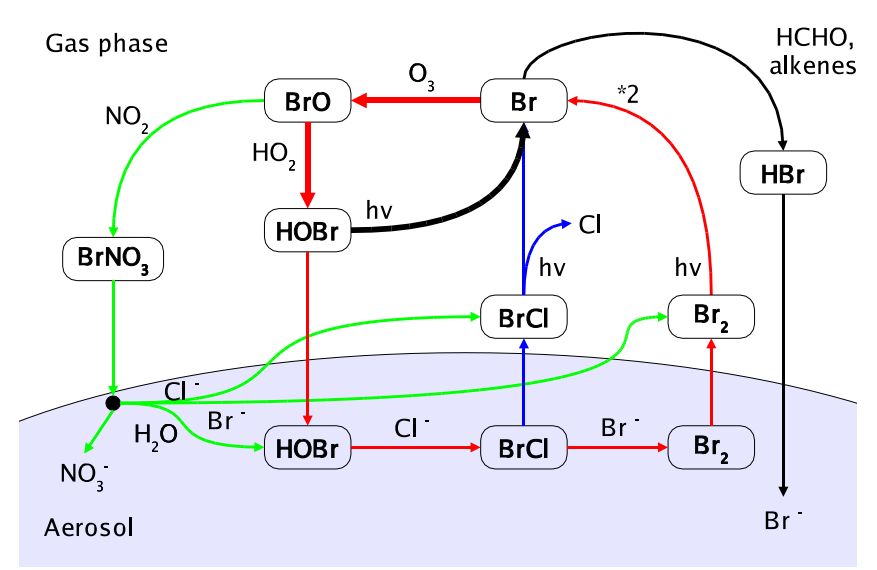

Fig. 13. Simplified reaction scheme of marine bromine chemistry.

of $\mathrm{HOBr}$ with $\mathrm{Cl}^{-}$as the key reaction of an autocatalytic cycle that converts relatively inert sea-salt bromide into reactive inorganic gas-phase bromine species. The complete cycle is:

$$
\begin{aligned}
\mathrm{HOBr}+\mathrm{Cl}^{-}+\mathrm{H}^{+} & \rightarrow \mathrm{BrCl}+\mathrm{H}_{2} \mathrm{O} \\
\mathrm{BrCl}+\mathrm{Br}^{-} & \rightarrow \mathrm{Br}_{2}+\mathrm{Cl}^{-} \\
\mathrm{Br}_{2}(\mathrm{aq}) & \rightarrow \mathrm{Br}_{2}(\mathrm{~g}) \\
\mathrm{Br}_{2} & \stackrel{h v}{\rightarrow} \mathrm{Br}+\mathrm{Br} \\
\mathrm{Br}+\mathrm{O}_{3} & \rightarrow \mathrm{BrO}+\mathrm{O}_{2} \\
\mathrm{BrO}+\mathrm{HO}_{2} & \rightarrow \mathrm{HOBr}+\mathrm{O}_{2} \\
\mathrm{HOBr}_{(\mathrm{g})} & \rightarrow \mathrm{HOBr}_{(\mathrm{aq})}
\end{aligned}
$$

$\overline{\mathrm{Br}^{-}+\mathrm{H}^{+}+\mathrm{O}_{3}+\mathrm{HO}_{2} \stackrel{h v}{\rightarrow} \mathrm{Br}+2 \mathrm{O}_{2}+\mathrm{H}_{2} \mathrm{O}}$

This cycle is shown with red lines in Fig. 13. There are several alternative pathways that may contribute as well. For example, the direct reaction of $\mathrm{HOBr}$ with $\mathrm{Br}^{-}$in Eq. (11) is equivalent to the sequence of reactions (12) and (13). If there is not enough bromide in the aerosol for reaction (13) to proceed, $\mathrm{BrCl}$ can volatilize. The photolysis of $\mathrm{BrCl}$ is a source of reactive chlorine in the gas phase (see blue lines in Fig. 13). The additional effect of $\mathrm{BrNO}_{3}$ chemistry was analyzed by Sander et al. (1999). $\mathrm{BrNO}_{3}$ can hydrolyze or react with chloride or bromide:

$$
\begin{aligned}
\mathrm{BrNO}_{3(\mathrm{~g})}+\mathrm{H}_{2} \mathrm{O} & \rightarrow \mathrm{HNO}_{3}+\mathrm{HOBr} \\
\mathrm{BrNO}_{3(\mathrm{~g})}+\mathrm{Cl}^{-} & \rightarrow \mathrm{NO}_{3}^{-}+\mathrm{BrCl} \\
\mathrm{BrNO}_{3(\mathrm{~g})}+\mathrm{Br}^{-} & \rightarrow \mathrm{NO}_{3}^{-}+\mathrm{Br}_{2}
\end{aligned}
$$

This is represented by the green lines in Fig. 13. Note that reactions (20) and (21) can produce $\mathrm{BrCl}$ and $\mathrm{Br}_{2}$ without the need of aerosol acidity.

In addition to their effect on aerosol bromide, these reaction cycles also influence ozone (thick lines in Fig. 13):

$$
\mathrm{Br}+\mathrm{O}_{3} \rightarrow \mathrm{BrO}+\mathrm{O}_{2}
$$

$$
\begin{aligned}
& \mathrm{BrO}+\mathrm{HO}_{2} \rightarrow \mathrm{HOBr}+\mathrm{O}_{2} \\
& \mathrm{HOBr} \stackrel{h v}{\rightarrow} \mathrm{Br}+\mathrm{OH} \\
& \mathrm{O}_{3}+\mathrm{HO}_{2} \stackrel{h v}{\rightarrow} 2 \mathrm{O}_{2}+\mathrm{OH}
\end{aligned}
$$

It should be noted here that the self-reaction of $\mathrm{BrO}$, which is important in the Arctic tropospheric ozone depletion events during spring (e.g. Tuckermann et al., 1997), only plays a minor role in the mbl at mid-latitudes due to the lower concentration of BrO.

Several initialization reactions can start the autocatalytic bromine activation:

$-\mathrm{Br}^{-}+\mathrm{O}_{3}$ (Oum et al., 1998; Rudich et al., 1998; Hirokawa et al., 1998; Anastasio and Mozurkewich, 2002)

$-\mathrm{Br}^{-}+\mathrm{OH}$ (Mamou et al., 1977)

$-\mathrm{Br}^{-}+\mathrm{NO}_{3}$ (Sander and Crutzen, 1996; Rudich et al., 1998)

$-\mathrm{Br}^{-}+\mathrm{N}_{2} \mathrm{O}_{5}$ (Finlayson-Pitts et al., 1990; Behnke et al., 1994)

$-\mathrm{Br}^{-}+\mathrm{HSO}_{5}^{-}$(Mozurkewich, 1995)

- photolysis of organic bromine species (Moortgat et al., 1993)

- photolysis of organic iodine species and subsequent interaction with the bromine chemistry (Vogt et al., 1999)

Once a small amount of a reactive bromine species has been produced via one of these reactions, a steady state of modeled bromine release is reached quickly.

Bromine species can also affect sulfur chemistry. The rate of scavenging of $\mathrm{SO}_{2}$ into aerosols is mainly determined by the rate at which it is oxidized in the aqueous phase. $\mathrm{HOBr}$ serves as another oxidant in addition to $\mathrm{O}_{3}$ and $\mathrm{H}_{2} \mathrm{O}_{2}$ :

$$
\begin{aligned}
\mathrm{HOBr}+\mathrm{SO}_{3}^{2-} & \rightarrow \mathrm{HBr}+\mathrm{SO}_{4}^{2-} \\
\mathrm{HOBr}+\mathrm{HSO}_{3}^{-} & \rightarrow \mathrm{HBr}+\mathrm{HSO}_{4}^{-}
\end{aligned}
$$

Only the rate constant for reaction (23a) has been measured (Troy and Margerum, 1991). Assuming that reaction (23b) proceeds at the same rate, Vogt et al. (1996) found that it can contribute about $20 \%$ to $\mathrm{S}(\mathrm{IV})$ oxidation. It will thus increase scavenging of $\mathrm{SO}_{2}$ into the particles considerably.

Another link between bromine and sulfur chemistry exists in the gas phase, as pointed out by Toumi (1994):

$\mathrm{DMS}+\mathrm{BrO} \rightarrow \mathrm{DMSO}+\mathrm{Br}$

This reaction will reduce the overall yield of $\mathrm{SO}_{2}$ resulting from DMS oxidation by the $\mathrm{OH}$ radical. Boucher et al. (2003) conclude that even $\mathrm{BrO}$ below $1 \mathrm{pmol} / \mathrm{mol}$ would be significant for DMS. Note that both reactions (23) and (24) reduce gas-phase $\mathrm{SO}_{2}$. This leads to less $\mathrm{H}_{2} \mathrm{SO}_{4}$ in the gas 
phase with possible consequences for cloud microphysics and climate (Andreae and Crutzen, 1997).

Although models are able to explain the loss of bromine from sea-salt aerosol qualitatively, model-calculated $E F$ are typically lower than those obtained from measurements. In Sect. 8, we list several ideas to improve the current models. However, in addition to model deficiencies, this discrepancy may also be caused by artificially truncated $E F$ distributions for observations where samples with bromine below DL were deleted from the data set, as explained in Sect. 2.4. In this regard, we note that some of the data sets reporting lowest median EFs for sea-salt size fractions (e.g. BEM97, HAW99, Figs. 2 and 4) correspond to those for which data below detection limits were retained without manipulation.

\section{Laboratory Studies}

Release of gas-phase bromine from aerosol is supported by several laboratory studies. Hirokawa et al. (1998) exposed ground $\mathrm{NaBr}$ salt in a reaction chamber to ozone and humidity. Using mass spectrometry they observed a release of bromine. Control experiments confirmed that both ozone and gaseous $\mathrm{H}_{2} \mathrm{O}$ are necessary for the formation of $\mathrm{Br}_{2}$. The presence or absence of irradiation (Xe arc lamp) made no difference in their study. They propose the reaction

$\mathrm{O}_{3}+\mathrm{Br}^{-} \stackrel{\mathrm{H}^{+}}{\rightarrow} \mathrm{HOBr}+\mathrm{O}_{2}$

as the first step in the formation of $\mathrm{Br}_{2}$. According to Mochida et al. (2000), bromide in sea-salt is much more reactive to ozone than pure bromide. Anastasio and Mozurkewich (2002) found evidence for a glass-surface mediated bromide oxidation in the presence of ozone.

Disselkamp et al. (1999) let ozone flow through a solution containing $\mathrm{NaBr}$ and followed the acidity (ion-sensitive electrode) and the concentration of $\mathrm{Br}^{-}$(ion chromatography). They found that $\mathrm{H}^{+}$and $\mathrm{Br}^{-}$disappear at the same rate, which is consistent with reaction (25) followed by reaction (11). An enhanced bromide oxidation rate was observed when chloride was added to the solution. In that case $\mathrm{Br}^{-}$ and $\mathrm{Cl}^{-}$disappeared at equal rates which is consistent with the formation of $\mathrm{BrCl}$ via reaction (12).

Behnke et al. (1999) generated sea-salt aerosol in a smog chamber and exposed it to ozone and light. They conclude that $\mathrm{Br}_{2}$ and $\mathrm{BrCl}$ are produced. However, in contrast to Hirokawa et al. (1998), they observed a dependence on light intensity and claim that reaction (25) cannot be the (only) initiating step.

Abbatt and Waschewsky (1998) investigated the uptake of $\mathrm{HOBr}$ on $\mathrm{NaCl}$ solution in an aerosol kinetics flow tube. They obtained an uptake coefficient of $\gamma>0.2$ for solutions of $\mathrm{pH} \leq 7.2$. For alkaline solution, the uptake was much slower. This is consistent with an acid-catalyzed reaction proceeding via Eq. (12). Using a wetted-wall flow tube,
Fickert et al. (1999) confirmed that a pH of 7 or less is necessary for uptake of $\mathrm{HOBr}$ on $\mathrm{NaCl}$ or $\mathrm{NaBr}$ solutions. Varying the composition of the solution they found, even with a molar $\left[\mathrm{Br}^{-}\right] /\left[\mathrm{Cl}^{-}\right]$ratio below $1 \times 10^{-3}$, preferential formation of $\mathrm{Br}_{2}$ relative to $\mathrm{BrCl}$. Thus in the mbl, fresh aerosol particles with the sea water composition of $\left[\mathrm{Br}^{-}\right] /\left[\mathrm{Cl}^{-}\right] \approx$ $1.5 \times 10^{-3} \mathrm{~mol} / \mathrm{mol}$ should lose $\mathrm{Br}^{-}$preferentially over $\mathrm{Cl}^{-}$ via this pathway. Wachsmuth et al. (2002) investigated uptake of $\mathrm{HOBr}$ on $\mathrm{NaBr}$ aerosol particles and found a mass accommodation coefficient of $\alpha=0.6$. Uptake of HOI on bromide has also been studied (Mössinger and Cox, 2001; Holmes et al., 2001).

\section{Future projections}

Based on current understanding of $\mathrm{Br}$ cycling through marine air, the projected increases in atmospheric acidification perhaps coupled with climatological alteration in global wind fields may lead to significant future changes in rates of $\mathrm{Br}$ activation and associated environmental impacts. Future increases in world population and per-capita energy use will almost certainly be associated with substantially increased emissions of $\mathrm{SO}_{2}, \mathrm{NO}_{\mathrm{x}}$, and other acid precursors from fossil-fuel and biomass combustion and other activities (e.g. Galloway, 1996). The transport of increasing concentrations of these compounds and their reaction products over the oceans will in turn increase the rates and spatial extent of sea-salt aerosol acidification. Since ships emit substantial amounts of unregulated exhaust directly into the mbl (e.g. Capaldo et al., 1999), increasing ship traffic will likely contribute disproportionately to aerosol acidification of more remote regions of the mbl. Substantial bromine activation is limited to acidic aerosol solutions and, consequently, increased acidification of marine air will lead to increased rates of $\mathrm{Br}$ cycling. Since $\mathrm{Br}$ activation is relatively insensitive to $\mathrm{pH}$ variability in acidic aerosol, small to negligible influences are expected in polluted regions (such as the western North Atlantic Ocean) where most sea-salt aerosols are currently acidified within seconds to minutes anyway (e.g. Erickson et al., 1999). However, in more remote regions such as the high latitude southern oceans where $\mathrm{Br}$ activation may be limited by available acidity (e.g. Ayers et al., 1999), modest increases in acidification could lead to substantial increases in the rates, spatial extent, and seasonal duration of $\mathrm{Br}$ activation and cycling.

Potential modification in global wind fields associated with changes in Earth's climate would influence the distributions of atmospheric acidity via controls on long-distance transport as well as rates of air-sea exchange of both acid precursors (e.g. DMS) and bases (sea-salt alkalinity and $\mathrm{NH}_{3}$ ). Changes in wind velocity would also alter the production fluxes, atmospheric concentrations, size distributions, and associated rates of multiphase transformations involving seasalt $\mathrm{Br}$. Since sea-salt production is a power function of wind 
Table 7. Acronyms used in the text

\begin{tabular}{ll}
\hline AA & atomic absorption \\
AAS & atomic absorption spectroscopy \\
AD & aerodynamic diameter \\
AES & atomic emission spectrophotometry \\
AMS & aerosol mass spectrometry \\
APCIMS & atmospheric-pressure chemical \\
& ionization mass spectrometry \\
ATOFMS & aerosol time-of-flight mass spectrometry \\
CI & cascade impactor \\
DL & detection limit \\
DOAS & differential optical absorption spectroscopy \\
EF & enrichment factor \\
GMD & geometric mean diameter \\
IC & ion chromatography \\
LP-DOAS & long path DOAS \\
MAX-DOAS & Multi-Axis DOAS \\
MBL & marine boundary layer \\
NAA & neutron activation analysis \\
PALMS & particle analysis by laser mass spectrometry \\
PIXE & particle-induced X-ray emission \\
PTFE & poly tetra fluoro ethylene \\
SFU & stacked filter unit \\
XRF & X-ray fluorescence \\
\hline
\end{tabular}

velocity, relatively small changes in wind speed would have disproportionately large influences on sea-salt fluxes. Despite the dynamic and highly non-linear nature of the underlying processes, available evidence suggests that the temporal and spatial extent of active $\mathrm{Br}$ cycling will probably increase, particularly in more remote regions.

We thus see the need for additional field experiments, model studies, and laboratory investigations in the future. Simultaneous measurements of inorganic bromine in both phases, using all available techniques in one campaign (as well as obtaining auxiliary data like aerosol $\mathrm{pH}$ ) would enhance our understanding a great deal. In particular, paired analyses of splits from size-segregated aerosol samples for total bromine (NAA or PIXE) and bromide (IC) would help elucidate the nature of bromine enrichments in submicrometer particles. A higher time resolution of the aerosol measurements is needed for a better analysis of the diurnal cycles. Developing improved techniques to lower the DL for $\mathrm{BrO}$ would be particularly useful because the current DL is close to model-predicted concentrations. More measurements of bromine in mineral dust will help to better quantify its relevance as a source of bromine.

Future computer simulations should move from current box and one-dimensional (1D) to three-dimensional (3D) models. However, computing limitations do not allow the direct inclusion of full scale chemical mechanisms from the box models into global models. Therefore, a robust parameterisation of the halogen chemistry must be developed. An- other aspect of future models will be explicit treatment of chemistry in size-resolved aerosols. In addition to sulfate and sea-salt aerosol, it will be necessary to consider the effect of other aerosol types like dust and soot on halogen chemistry.

Future laboratory studies are needed for the reaction of $\mathrm{BrNO}_{3}$ with aerosol particles under conditions relevant to the mbl. Also, the conditions under which the slow aqueousphase reaction of $\mathrm{O}_{3}+\mathrm{Br}^{-}$is accelerated in/on sea-salt aerosol (surface effects, light, catalysts, ...) should be investigated further.

\section{Conclusions}

Based upon a large number of observations, we come to the following conclusions:

- The main source of bromine in the mbl is sea salt. Other sources may contribute locally in some regions.

- Relative to seawater, supermicrometer sea-salt aerosol is substantially depleted in bromine (often exceeding $50 \%)$.

- Bromine depletions occur naturally in clean marine air as well as in anthropogenically influenced air.

- Acidity promotes aerosol debromination. However, the degree of debromination appears to be relatively insensitive to variability in the $\mathrm{pH}$ of acidic aerosol solutions.

- Marine submicrometer aerosol is often enriched in bromine, especially in polluted regions.

- Bromine from automobile petrol or biomass burning contributes in some regions to enrichment in submicrometer particles.

- A diurnal variation (with increased gas-phase concentrations and aerosol depletion during the day) has been observed at some, but not at all sites.

- Seasonal variation of $E F$ is most pronounced in the cleaner southern hemisphere.

- Inorganic bromine species exist in the gas phase at several $\mathrm{pmol} / \mathrm{mol}$ but the speciation has not been reliably measured.

- EF in rain is higher than in aerosol particles, possibly because clouds and rain drops scavenge bromine species from the gas phase.

- Laboratory results show that aerosol bromide can be transformed into volatile, reactive forms of bromine.

Several questions remain:

- Which species comprise 'volatile inorganic bromine'? 
- Why do some sites show a diurnal or seasonal variation of $E F$ whereas others don't?

- Is there a vertical gradient of $E F$ in the mbl?

- How can bromine accumulate in submicrometer particles instead of being recycled back into the gas phase?

Acknowledgements. For helpful discussions and for providing data we would like to thank Anne M. Johansen, Barbara J. Ray, Henning Rodhe, and Bill Sturges. Financial support for the University of Virginia was provided by the U.S. National Science Foundation (NSF) through grants ATM-9414293, ATM-941559, ATM-9634129, and ATM-9902077, the European Chemical Industry Council via Euro Chlor, and the Chemical Manufacturers' Association via the Chlorine Chemical Council. Financial support for the Massachusetts Institute of Technology was provided by NSF grants ATM-9634129 and ATM-9902077 and NOAA award No. NA87RJ0445 via the Cooperative Institute for Climate and Ocean Research at the Woods Hole Oceanographic Institution. Financial support for Ghent University came from the Belgian Federal Office of Scientific, Technical and Cultural Affairs and the 'Fonds voor Wetenschappelijk Onderzoek - Vlaanderen'. N. Mihalopoulos and E. Baboukas wish to thank B. C. Nguyen and J. Sciare for providing the aerosol and rainwater samples and IPEV for logistical support. Financial support for the University of Hawaii was provided by US NSF grant ATM-9909099.

\section{References}

Abbatt, J. P. D. and Waschewsky, G. C. G.: Heterogeneous interactions of $\mathrm{HOBr}, \mathrm{HNO}_{3}, \mathrm{O}_{3}$, and $\mathrm{NO}_{2}$ with deliquescent $\mathrm{NaCl}$ aerosols at room temperature, J. Phys. Chem. A, 102, 37193725, 1998.

Adepetu, J. A., Asubiojo, O. I., Iskander, F. Y., and Bauer, T. L.: Elemental composition of Nigerian harmattan dust, J. Radioanal. Nucl. Chem., 121, 141-147, 1988.

Alicke, B.: Messung von troposphärischen Halogenoxidradikalen in mittleren Breiten, Diplomarbeit, Ruprecht-Karls-Universität Heidelberg, Germany, 1997.

Allan, B. J.: A spectroscopic study of radical chemistry in the troposphere, Ph.D. thesis, University of East Anglia, Great Britain, 1998.

Anastasio, C. and Mozurkewich, M.: Laboratory studies of bromide oxidation in the presence of ozone: Evidence for a glass-surface mediated reaction, J. Atmos. Chem., 41, 135-162, 2002.

Anderson, J. P., Buseck, P. R., Patterson, T. L., and Arimoto, R.: Characterization of the Bermuda tropospheric aerosol by combined individual-particle and bulk-aerosol analysis, Atmos. Environ., 30, 319-338, 1996.

Andreae, M. O.: Marine aerosol chemistry at Cape Grim, Tasmania, and Townsville, Queensland, J. Geophys. Res., 87C, 8875-8885, 1982.

Andreae, M. O.: Climatic effects of changing atmospheric aerosol levels, in: World Survey of Climatology, Vol. 16, Future Climates of the World, edited by Henderson-Sellers, A., pp. 347398, Elsevier, New York, 1995.

Andreae, M. O. and Crutzen, P. J.: Atmospheric aerosols: Biogeochemical sources and role in atmospheric chemistry, Science, 276, 1052-1058, 1997.
Andreae, M. O., Atlas, E., Harris, G. W., Helas, G., de Kock, A., Koppmann, R., Maenhaut, W., Mano, S., Pollock, W. H., Rudolph, J., Scharffe, D., Schebeske, G., and Welling, M.: Methyl halide emissions from savanna fires in southern Africa, J. Geophys. Res., 101D, 23 603-23 613, 1996.

Andreae, M. O., Andreae, T. W., Annegarn, H., Beer, J., Cachier, H., le Canut, P., Elbert, W., Maenhaut, W., Salma, I., Wienhold, F. G., and Zenker, T.: Airborne studies of aerosol emissions from savanna fires in southern Africa: 2. Aerosol chemical composition, J. Geophys. Res., 103D, 32 119-32 128, 1998.

Arimoto, R., Duce, R. A., Ray, B. J., Hewitt, A. D., and Williams, J.: Trace elements in the atmosphere of American Samoa: Concentrations and deposition to the tropical South Pacific, J. Geophys. Res., 92D, 8465-8479, 1987.

Arimoto, R., Ray, B. J., Duce, R. A., Hewitt, A. D., Boldi, R., and Hudson, A.: Concentrations, sources, and fluxes of trace elements in the remote marine atmosphere of New Zealand, J. Geophys. Res., 95D, 22 389-22 405, 1990.

Arimoto, R., Duce, R. A., Ellis, Jr., W. G., Cullen, J. D., and Merrill, J. T.: Trace elements in the atmosphere over the North Atlantic, J. Geophys. Res., 100D, 1199-1213, 1995.

Ayers, G. P., Gillett, R. W., Cainey, J. M., and Dick, A. L.: Chloride and bromide loss from sea-salt particles in southern ocean air, J. Atmos. Chem., 33, 299-319, 1999.

Baboukas, E.: X

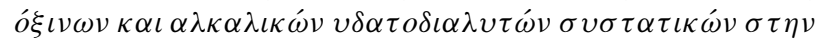

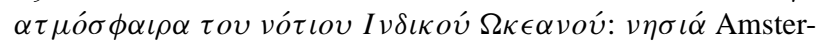
dam, Crozet $\kappa \alpha \iota$ Kerguelen (Spatial, temporal, and interannual variability of water soluble species in aerosols, gases and precipitation in the Southern Indian Ocean: Amsterdam, Crozet and Kerguelen islands), Ph.D. thesis, University of Crete, Greece, 2000.

Baboukas, E. D., Kanakidou, M., and Mihalopoulos, N.: Carboxylic acids in gas and particulate phase above the Atlantic Ocean, J. Geophys. Res., 105D, 14 459-14 471, 2000.

Barrie, L. A., Bottenheim, J. W., Schnell, R. C., Crutzen, P. J., and Rasmussen, R. A.: Ozone destruction and photochemical reactions at polar sunrise in the lower Arctic atmosphere, Nature, 334, 138-141, 1988.

Barrie, L. A., Li, S.-M., Toom, D. L., Landsberger, S., and Sturges, W.: Lower tropospheric measurements of halogens, nitrates, and sulphur oxides during Polar Sunrise Experiment 1992, J. Geophys. Res., 99D, 25 453-25 467, 1994.

Behne, W.: Untersuchungen zur Geochemie des Chlor und Brom, Geochim. Cosmochim. Acta, 3, 186-214, 1953.

Behnke, W., Scheer, V., and Zetzsch, C.: Production of $\mathrm{BrNO}_{2}$, $\mathrm{Br}_{2}$ and $\mathrm{ClNO}_{2}$ from the reaction between sea spray aerosol and $\mathrm{N}_{2} \mathrm{O}_{5}$, J. Aerosol Sci., 25, S277-S278, 1994.

Behnke, W., Elend, M., Krüger, U., and Zetzsch, C.: The influence of $\mathrm{NaBr} / \mathrm{NaCl}$ ratio on the $\mathrm{Br}^{-}$-catalyzed production of halogenated radicals, J. Atmos. Chem., 34, 87-99, 1999.

Berg, W. W. and Winchester, J. W.: Aerosol chemistry of the marine atmosphere, in: Chemical Oceanography, Vol. 7, 2nd Ed., edited by Riley, J. P. and Chester, R., pp. 173-231, Academic Press, 1978.

Berg, W. W., Grahek, F. E., Gladney, E. S., and Sedlacek, W. A.: The global bromine budget: Recent measurements and theories, in: Proc. 2nd Symposium on the Nonurban Atmosphere, pp. 72 75, American Meteorological Society, Williamsburg, 1982. 
Berg, W. W., Sperry, P. D., Rahn, K. A., and Gladney, E. S.: Atmospheric bromine in the Arctic, J. Geophys. Res., 88C, 67196736, 1983.

Blanchard, D. C., Woodward, A. H., and Cipriano, R. J.: The vertical distribution of the concentration of sea salt in the marine atmosphere near Hawaii, Tellus, 36B, 118-125, 1984.

Bobrowski, N., Hönninger, G., Galle, B., and Platt, U.: Detection of bromine monoxide in a volcanic plume, Nature, 423, 273-276, 2003.

Boucher, O., Moulin, C., Belviso, S., Aumont, O., Bopp, L., Cosme, E., von Kuhlmann, R., Lawrence, M. G., Pham, M., Reddy, M. S., Sciare, J., and Venkataraman, C.: DMS atmospheric concentrations and sulphate aerosol indirect radiative forcing: a sensitivity study to the DMS source representation and oxidation, Atmos. Chem. Phys., 3, 49-65, 2003.

Capaldo, K., Corbett, J. J., Kasibhatla, P., Fischbeck, P., and Pandis, S. N.: Effects of ship emissions on sulphur cycling and radiative climate forcing over the ocean, Nature, 400, 743-746, 1999.

Chance, K.: Analysis of $\mathrm{BrO}$ measurements from the global ozone monitoring experiment, Geophys. Res. Lett., 25, 3335-3338, 1998.

Cicerone, R. J.: Halogens in the atmosphere, Rev. Geophys. Space Phys., 19, 123-139, 1981.

Dentener, F. J., Carmichael, G. R., Zhang, Y., Lelieveld, J., and Crutzen, P. J.: Role of mineral aerosol as a reactive surface in the global troposphere, J. Geophys. Res., 101D, 22 869-22 889, 1996.

Dickerson, R. R., Rhoads, K. P., Carsey, T. P., Oltmans, S. J., Burrows, J. P., and Crutzen, P. J.: Ozone in the remote marine boundary layer: A possible role for halogens, J. Geophys. Res., 104D, $21385-21395,1999$.

Disselkamp, R. S., Chapman, E. G., Barchet, W. R., Colson, S. D., and Howd, C. D.: $\mathrm{BrCl}$ production in $\mathrm{NaBr} / \mathrm{NaCl} / \mathrm{HNO}_{3} / \mathrm{O}_{3}$ solutions representative of sea-salt aerosols in the marine boundary layer, Geophys. Res. Lett., 26, 2183-2186, 1999.

Duce, R. A. and Hoffman, E.: Chemical fractionation at the air/sea interface, Annu. Rev. Earth Planet. Sci., 4, 187-228, 1976.

Duce, R. A. and Woodcock, A. H.: Difference in chemical composition of atmospheric sea salt particles produced in the surf zone and on the open sea in Hawaii, Tellus, 23, 427-435, 1971.

Duce, R. A., Wasson, J. T., Winchester, J. W., and Burns, F.: Atmospheric iodine, bromine, and chlorine, J. Geophys. Res., 68, 3943-3947, 1963.

Duce, R. A., Winchester, J. W., and van Nahl, T. W.: Iodine, bromine, and chlorine in the Hawaiian marine atmosphere, J. Geophys. Res., 70, 1775-1799, 1965.

Duce, R. A., Woodcock, A. H., and Moyers, J. L.: Variation of ion ratios with size among particles in tropical oceanic air, Tellus, 19, 369-379, 1967.

Duce, R. A., Arimoto, R., Ray, B. J., Unni, C. K., and Harder, P. J.: Atmospheric trace elements at Enewetak Atoll: 1, Concentrations, sources, and temporal variability, J. Geophys. Res., 88C, 5321-5342, 1983.

Duce, R. A., Liss, P. S., Merrill, J. T., Atlas, E. L., Buat-Menard, P., Hicks, B. B., Miller, J. M., Prospero, J. M., Arimoto, R., Church, T. M., Ellis, W., Galloway, J. N., Hansen, L., Jickells, T. D., Knap, A. H., Reinhardt, K. H., Schneider, B., Soudine, A., Tokos, J. J., Tsunogai, S., Wollast, R., and Zhao, M.: The atmospheric input of trace species to the world oceans, Global
Biogeochem. Cycles, 5, 193-259, 1991.

Echalar, F., Gaudichet, F., Cachier, H., and Artaxo, P.: Aerosol emissions by tropical forest and savanna biomass burning: Characteristic trace elements and fluxes, Geophys. Res. Lett., 22, 3039-3042, 1995.

Erickson, III, D. J., Seuzaret, C., Keene, W. C., and Gong, S. L.: A general circulation model based calculation of $\mathrm{HCl}$ and $\mathrm{ClNO}_{2}$ production from sea-salt dechlorination: Reactive chlorine emissions inventory, J. Geophys. Res., 104D, 8347-8372, 1999.

Fan, S.-M. and Jacob, D. J.: Surface ozone depletion in Arctic spring sustained by bromine reactions on aerosols, Nature, 359, 522-524, 1992.

Fickert, S., Adams, J. W., and Crowley, J. N.: Activation of $\mathrm{Br}_{2}$ and $\mathrm{BrCl}$ via uptake of $\mathrm{HOBr}$ onto aqueous salt solutions, J. Geophys. Res., 104D, 23 719-23 727, 1999.

Finlayson-Pitts, B. J. and Johnson, S. N.: The reaction of $\mathrm{NO}_{2}$ with $\mathrm{NaBr}$ : Possible source of $\mathrm{BrNO}$ in polluted marine atmospheres, Atmos. Environ., 22, 1107-1112, 1988.

Finlayson-Pitts, B. J., Livingston, F. E., and Berko, H. N.: Ozone destruction and bromine photochemistry at ground level in the Arctic spring, Nature, 343, 622-625, 1990.

Foster, K. L., Plastridge, R. A., Bottenheim, J. W., Shepson, P. B., Finlayson-Pitts, B. J., and Spicer, C. W.: The role of $\mathrm{Br}_{2}$ and $\mathrm{BrCl}$ in surface ozone destruction at polar sunrise, Science, 291, 471-474, 2001.

François, F. and Maenhaut, W.: Chemical composition and sources of the size-fractionated atmospheric aerosol collected at the research platform Nordsee, in: Proceedings of EUROTRAC Symposium '94, edited by Borrell, P. M., Borrell, P., Cvitaš, T., and Seiler, W., pp. 472-476, SPB Academic Publishing bv, The Hague, 1994.

François, F., Cafmeyer, J., Gilot, C., and Maenhaut, W.: Chemical composition of size-fractionated atmospheric aerosols at some coastal stations and over the North Sea, in: Proceedings of EUROTRAC Symposium '92, edited by Borrell, P. M., Borrell, P., Cvitaš, T., and Seiler, W., pp. 788-791, SPB Academic Publishing bv, The Hague, 1993.

Friess, U., Otten, C., Chipperfield, M., Wagner, T., Pfeilsticker, K., and Platt, U.: Intercomparison of measured and modelled $\mathrm{BrO}$ slant column amounts for the Arctic winter and spring 1994/95, Geophys. Res. Lett., 26, 1861-1864, 1999.

Frigge, M., Hoaglin, D. C., and Iglewicz, B.: Some implementations of the boxplot, Am. Stat., 43, 50-54, 1989.

Gabriel, R., von Glasow, R., Sander, R., Andreae, M. O., and Crutzen, P. J.: Bromide content of sea-salt aerosol particles collected over the Indian Ocean during INDOEX 1999, J. Geophys. Res., 107D, 8032, 10.1029/2001JD001 133, 2002.

Galbally, I. E., Bentley, S. T., and Meyer, C. P.: Mid-latitude marine boundary-layer ozone destruction at visible sunrise observed at Cape Grim, Tasmania, $41^{\circ} \mathrm{S}$, Geophys. Res. Lett., 27, 38413844, 2000.

Galloway, J. N.: Anthropogenic mobilization of sulphur and nitrogen: Immediate and delayed consequences, Annu. Rev. Energy Environ., 21, 261-292, 1996.

Galloway, J. N., Likens, G. E., Keene, W. C., and Miller, J. M.: The composition of precipitation in remote areas of the world, J. Geophys. Res., 87C, 8771-8786, 1982.

Gard, E. E., Kleeman, M. J., Gross, D. S., Hughes, L. S., Allen, J. O., Morrical, B. D., Fergenson, D. P., Dienes, T., Gälli, M. E., 
Johnson, R. J., Cass, G. R., and Prather, K. A.: Direct observation of heterogeneous chemistry in the atmosphere, Science, 279, 1184-1187, 1998.

Gong, S. L. and Barrie, L. A.: Simulating the impact of sea salt on global nss sulphate aerosols, J. Geophys. Res., 108D, 10.1029/2002JD003 181, 2003.

Gong, S. L., Barrie, L. A., and Blanchet, J.-P.: Modeling sea-salt aerosols in the atmosphere: 1. Model development, J. Geophys. Res., 102D, 3805-3818, 1997.

Gong, S. L., Barrie, L. A., and Lazare, M.: Canadian Aerosol Module (CAM): A size-segregated simulation of atmospheric aerosol processes for climate and air quality models 2 . Global sea-salt aerosol and its budgets, J. Geophys. Res., 107D, 10.1029/2001JD002 004, 2002.

Graedel, T. E. and Keene, W. C.: The tropospheric budget of reactive chlorine, Global Biogeochem. Cycles, 9, 47-77, 1995.

Granat, L., Norman, M., Leck, C., Kulshrestha, U. C., and Rodhe, H.: Wet scavenging of sulfur compounds and other constituents during the Indian Ocean Experiment (INDOEX), J. Geophys. Res., 107D, 10.1029/2001JD000 499, 2002.

Grewe, V. and Dameris, M.: Calculating the global mass exchange between stratosphere and troposphere, Ann. Geophys., 14, 431442, 1996.

Habibi, K.: Characterization of particulate matter in vehicle exhaust, Environ. Sci. Technol., 7, 223-234, 1973.

Hamilton, B.: Gasoline FAQ, http://www.faqs.org/faqs/autos/ gasoline-faq/, 1996.

Hansson, H.-C. and Nyman, S.: Microcomputer-controlled two size fractionating aerosol sampler for outdoor environments, Environ. Sci. Technol., 19, 1110-1115, 1985.

Harder, H., Bösch, H., Camy-Peyret, C., Chipperfield, M. P., Fitzenberger, R., Payan, S., Perner, D., Platt, U., Sinnhuber, B.-M., and Pfeilsticker, K.: Comparison of measured and modeled stratospheric BrO: Implications for the total amount of stratospheric bromine, Geophys. Res. Lett., 27, 3695-3698, 2000.

Harrison, R. M. and Sturges, W. T.: The measurement and interpretation of $\mathrm{Br} / \mathrm{Pb}$ ratios in airborne particles, Atmos. Environ., 17, 311-328, 1983.

Hebestreit, K., Stutz, J., Rosen, D., Matveiv, V., Luria, M., and Platt, U.: DOAS measurements of tropospheric bromine oxide in mid-latitudes, Science, 283, 55-57, 1999.

Hegels, E., Crutzen, P. J., Klüpfel, T., and Perner, D.: Global distribution of atmospheric bromine-monoxide from GOME on earth observing satellite ERS-2, Geophys. Res. Lett., 25, 3127-3130, 1998.

Hirokawa, J., Onaka, K., Kajii, Y., and Akimoto, H.: Heterogeneous processes involving sodium halide particles and ozone: Molecular bromine release in the marine boundary layer in the absence of nitrogen oxides, Geophys. Res. Lett., 25, 2449-2452, 1998.

Holmes, N. S., Adams, J. W., and Crowley, J. N.: Uptake and reaction of $\mathrm{HOI}$ and $\mathrm{IONO}_{2}$ on frozen and dry $\mathrm{NaCl} / \mathrm{NaBr}$ surfaces and $\mathrm{H}_{2} \mathrm{SO}_{4}$, Phys. Chem. Chem. Phys., 3, 1679-1687, 2001.

Hönninger, G.: Referenzspektren reaktiver Halogenverbindungen für DOAS-Messungen, Diplomarbeit, Ruprecht-Karls-Universität Heidelberg, Germany, http: //www.iup.uni-heidelberg.de/urmel/abstracts/tit2hg.html, 1999.

Hönninger, G.: Halogen Oxide Studies in the Boundary Layer by Multi Axis Differential Optical Absorption Spectroscopy and Active Longpath-DOAS, Ph.D. thesis, Universität Heidel- berg, Institut für Umweltphysik, http://www.ub.uni-heidelberg. de/archiv/1940, 2002.

Hönninger, G. and Platt, U.: Observations of $\mathrm{BrO}$ and its vertical distribution during surface ozone depletion at Alert, Atmos. Environ., 36, 2481-2489, 2002.

Howell, S., Pszenny, A. A. P., Quinn, P., and Huebert, B. J.: A field intercomparison of three cascade impactors, Aerosol Sci. Technol., 29, 475-492, 1998.

Huang, S., Arimoto, R., and Rahn, K. A.: Changes in atmospheric lead and other pollution elements at Bermuda, J. Geophys. Res., 101D, 21 033-21 040, 1996.

Huebert, B. J., Lee, G., and Warren, W. L.: Airborne aerosol inlet passing efficiency measurement, J. Geophys. Res., 95D, 16369$16381,1990$.

Impey, G. A., Shepson, P. B., Hastie, D. R., Barrie, L. A., and Anlauf, K. G.: Measurements of photolyzable chlorine and bromine during the Polar Sunrise Experiment 1995, J. Geophys. Res., 102D, 16 005-16010, 1997.

James, J. D., Harrison, R. M., Savage, N. H., Allen, A. G., Grenfell, J. L., Allan, B. J., Plane, J. M. C., Hewitt, C. N., Davison, B., and Robertson, L.: Quasi-Lagrangian investigation into dimethyl sulfide oxidation in maritime air using a combination of measurements and model, J. Geophys. Res., 105D, 26 379-26 392, 2000.

Jayne, J. T., Leard, D. C., Zhang, X., Davidovits, P., Smith, K. A., Kolb, C., and Worsnop, D. R.: Development of an aerosol mass spectrometer for size and composition analysis of submicron particles, Aerosol Sci. Technol., 33, 49-70, 2000.

Jernigan, E. L., Ray, B. J., and Duce, R. A.: Lead and bromine in atmospheric particulate matter on Oahu, Hawaii, Atmos. Environ., 5, 881-886, 1971.

Jobson, B. T., Niki, H., Yokouchi, Y., Bottenheim, J., Hopper, F., and Leaitch, R.: Measurements of $\mathrm{C}_{2}-\mathrm{C}_{6}$ hydrocarbons during the polar sunrise 92 experiment: Evidence for $\mathrm{Cl}$-atom and $\mathrm{Br}$ atom chemistry, J. Geophys. Res., 99D, 25 355-25 368, 1994.

Johansen, A. M., Siefert, R. L., and Hoffmann, M. R.: Chemical characterization of ambient aerosol collected during the southwest monsoon and intermonsoon seasons over the Arabian Sea: Anions and cations, J. Geophys. Res., 104D, 26325-26347, 1999.

Johansen, A. M., Siefert, R. L., and Hoffmann, M. R.: Chemical composition of aerosols collected over the tropical North Atlantic Ocean, J. Geophys. Res., 105D, 15 277-15 312, 2000.

Keene, W. C. and Savoie, D. L.: The $\mathrm{pH}$ of deliquesced sea-salt aerosol in polluted marine air, Geophys. Res. Lett., 25, 21812184, 1998.

Keene, W. C. and Savoie, D. L.: Correction to "The pH of deliquesced sea-salt aerosol in polluted marine air", Geophys. Res. Lett., 26, 1315-1316, 1999.

Keene, W. C., Pszenny, A. A. P., Galloway, J. N., and Hawley, M. E.: Sea-salt corrections and interpretation of constituent ratios in marine precipitation, J. Geophys. Res., 91D, 6647-6658, 1986.

Keene, W. C., Pszenny, A. A. P., Jacob, D. J., Duce, R. A., Galloway, J. N., Schultz-Tokos, J. J., Sievering, H., and Boatman, J. F.: The geochemical cycle of reactive chlorine through the marine troposphere, Global Biogeochem. Cycles, 4, 407-430, 1990.

Keene, W. C., Sander, R., Pszenny, A. A. P., Vogt, R., Crutzen, P. J., and Galloway, J. N.: Aerosol pH in the marine boundary layer: A review and model evaluation, J. Aerosol Sci., 29, 339-356, 1998. 
Keene, W. C., Khalil, M. A. K., Erickson, III, D. J., McCulloch, A., Graedel, T. E., Lobert, J. M., Aucott, M. L., Gong, S. L., Harper, D. B., Kleiman, G., Midgley, P., Moore, R. M., Seuzaret, C., Sturges, W. T., Benkovitz, C. M., Koropalov, V., Barrie, L. A., and $\mathrm{Li}$, Y. F.: Composite global emissions of reactive chlorine from anthropogenic and natural sources: Reactive chlorine emissions inventory, J. Geophys. Res., 104D, 8429-8440, 1999.

Keene, W. C., Pszenny, A. A. P., Maben, J. R., and Sander, R.: Variation of marine aerosol acidity with particle size, Geophys. Res. Lett., 29, 10.1029/2001GL013 881, 2002.

Khalil, M. A. K., Rasmussen, R. A., and Gunawardena, R.: Atmospheric methyl bromide: Trends and global mass balance, J. Geophys. Res., 98D, 2887-2896, 1993.

Kleeman, M. J., Schauer, J. J., and Cass, G. R.: Size and composition distribution of fine particulate matter emitted from wood burning, meat charbroiling, and cigarettes, Environ. Sci. Technol., 33, 3516-3523, 1999.

Kouvarakis, G., Doukelis, Y., Mihalopoulos, N., Rapsomanikis, S., Sciare, J., and Blumthaler, M.: Chemical, physical and optical characterization of aerosols during PAUR II experiment, J. Geophys. Res., 107D, 10.1029/2000JD000 291, 2002.

Kritz, M. A. and Rancher, J.: Circulation of $\mathrm{Na}, \mathrm{Cl}$, and $\mathrm{Br}$ in the tropical marine atmosphere, J. Geophys. Res., 85C, 1633-1639, 1980.

Leser, H., Hönninger, G., and Platt, U.: MAX-DOAS measurements of $\mathrm{BrO}$ and $\mathrm{NO}_{2}$ in the marine boundary layer, Geophys. Res. Lett., 30, 10.1029/2002GL015 811, 2003.

Li, S.-M., Yokouchi, Y., Barrie, L. A., Muthuramu, K., Shepson, P. B., Bottenheim, J. W., Sturges, W. T., and Landsberger, S.: Organic and inorganic bromine compounds and their composition in the Arctic troposphere during polar sunrise, J. Geophys. Res., 99D, 25 415-25 428, 1994.

Li-Jones, X., Maring, H. B., and Prospero, J. M.: Effect of relative humidity on light scattering by mineral dust aerosol as measured in the marine boundary layer over the tropical Atlantic Ocean, J. Geophys. Res., 103D, 31 113-31 121, 1998.

Lininger, R. L., Duce, R. A., Winchester, J. W., and Matson, W. R.: Chlorine, bromine, iodine, and lead in aerosols from Cambridge, Massachusetts, J. Geophys. Res., 71, 2457-2463, 1966.

Maenhaut, W., Darzi, M., and Winchester, J. W.: Seawater and nonseawater aerosol components in the marine atmosphere of Samoa, J. Geophys. Res., 86C, 3187-3193, 1981a.

Maenhaut, W., Selen, A., van Espen, P., van Grieken, R., and Winchester, J. W.: PIXE analysis of aerosol samples collected over the Atlantic Ocean from a sailboat, Nucl. Instrum. Methods, 181, 399-405, 1981b.

Maenhaut, W., Raemdonck, H., Selen, A., van Grieken, R., and Winchester, J. W.: Characterization of the atmospheric aerosol over the eastern equatorial Pacific, J. Geophys. Res., 88C, 53535364, 1983.

Maenhaut, W., François, F., Cafmeyer, J., Gilot, C., and Hanssen, J. E.: Long-term aerosol study in southern Norway, and the relationship of aerosol components to source regions, in: Proceedings of EUROTRAC Symposium '96, edited by Borrell, P. M., Borrell, P., Kelly, K., and Seiler, W., pp. 277-280, SPB Academic Publishing bv, The Hague, 1996a.

Maenhaut, W., Salma, I., Cafmeyer, J., Annegarn, H. J., and Andreae, M. O.: Regional atmospheric aerosol composition and sources in the eastern Transvaal, South Africa, and impact of biomass burning, J. Geophys. Res., 101D, 23 631-23 650, $1996 \mathrm{~b}$.

Maenhaut, W., Fernández-Jiménez, M.-T., Vanderzalm, J. L., Hooper, B., Hooper, M. A., and Tapper, N. J.: Aerosol composition at Jabiru, Australia, and impact of biomass burning, J. Aerosol Sci., 31, S745-S746, 2000.

Mamou, A., Rabani, J., and Behar, D.: On the oxidation of aqueous $\mathrm{Br}^{-}$by $\mathrm{OH}$ radicals, studied by pulse radiolysis, J. Phys. Chem., 81, 1447-1448, 1977.

Marchand, M. E.: Sur la constitution physique et chimique des eaux naturelles, C. R. Hebd. Seances Acad. Sci., 34, 54-56, 1852.

Martens, C. S.: Ion ratio variations with particle size in Puerto Rican aerosols, J. Geophys. Res., 78, 8867-8871, 1973.

Martens, C. S. and Harriss, R. C.: Chemistry of aerosols, cloud droplets, and rain in the Puerto Rican marine atmosphere, J. Geophys. Res., 78, 949-957, 1973.

Martinez, M., Arnold, T., and Perner, D.: The role of bromine and chlorine chemistry for Arctic ozone depletion events in $\mathrm{Ny}$ Ålesund and comparison with model calculations, Ann. Geophys., 17, 941-956, 1999.

Mason, B. and Moore, C. B.: Principles of Geochemistry, fourth edition, John Wiley \& Sons, Inc., 1982.

Matveev, V., Peleg, M., Rosen, D., Tov-Alper, D. S., Hebestreit, K., Stutz, J., Platt, U., Blake, D., and Luria, M.: Bromine oxide - ozone interaction over the Dead Sea, J. Geophys. Res., 106D, 10375-10387, 2001.

McKenzie, L. M., Ward, D. E., and Hao, W. M.: Chlorine and bromine in the biomass of tropical and temperate ecosystems, in: Biomass Burning and Global Change, Vol. 1, Remote Sensing, Modeling and Inventory Development, and Biomass Burning in Africa, edited by Levine, J. S., pp. 241-248, The MIT press, Cambridge, Massachusetts, USA, 1996.

Michalowski, B. A., Francisco, J. S., Li, S.-M., Barrie, L. A., Bottenheim, J. W., and Shepson, P. B.: A computer model study of multiphase chemistry in the Arctic boundary layer during polar sunrise, J. Geophys. Res., 105D, 15 131-15 145, 2000.

Middlebrook, A. M., Murphy, D. M., and Thomson, D. S.: Observations of organic material in individual marine particles at Cape Grim during the first Aerosol Characterization Experiment (ACE 1), J. Geophys. Res., 103D, 16475-16483, 1998.

Mihalopoulos, N., Stephanou, E., Kanakidou, M., Pilitsidis, S., and Bousquet, P.: Tropospheric aerosol ionic composition in the Eastern Mediterranean region, Tellus, 49B, 314-326, 1997.

Mochida, M., Hirokawa, J., and Akimoto, H.: Unexpected large uptake of $\mathrm{O}_{3}$ on sea salts and the observed $\mathrm{Br}_{2}$ formation, Geophys. Res. Lett., 27, 2629-2632, 2000.

Moldanová, J. and Ljungström, E.: Sea-salt aerosol chemistry in coastal areas: A model study, J. Geophys. Res., 106D, 12711296, 2001.

Moortgat, G. K., Meller, R., and Schneider, W.: Temperature dependence (256-296 K) of the absorption cross-sections of bromoform in the wavelength range $285-360 \mathrm{~nm}$, in: The Tropospheric Chemistry of Ozone in the Polar Regions, NATO ASI Series, Vol. I7, edited by Niki, H. and Becker, K. H., pp. 359-369, Springer Verlag, Berlin, 1993.

Mössinger, J. C. and Cox, R. A.: Heterogeneous reaction of HOI with sodium halide salts, J. Phys. Chem. A, 105, 5165-5177, 2001.

Moyers, J. L. and Duce, R. A.: Gaseous and particulate bromine in the marine atmosphere, J. Geophys. Res., 77, 5330-5338, 1972. 
Moyers, J. L., Zoller, W. H., Duce, R. A., and Hoffman, G. L.: Gaseous bromine and particulate lead, vanadium, and bromine in a polluted atmosphere, Environ. Sci. Technol., 6, 68-71, 1972.

Mozurkewich, M.: Mechanisms for the release of halogens from sea-salt particles by free radical reactions, J. Geophys. Res., 100D, 14 199-14 207, 1995.

Murphy, D. M., Thomson, D. S., and Middlebrook, A. M.: Bromine, iodine, and chlorine in single aerosol particles at Cape Grim, Geophys. Res. Lett., 24, 3197-3200, 1997.

Nagao, I., Matsumoto, K., and Tanaka, H.: Sunrise ozone destruction found in the sub-tropical marine boundary layer, Geophys. Res. Lett., 26, 3377-3380, 1999.

Nishri, A. and Stiller, M.: Iron, Magnesese, and Trace Elements in the Dead Sea, in: The Dead Sea and its Setting, edited by T.M. Niemi, Z. Ben-Avraham and J.R. Gat, pp. 199-204, Oxford University Press, New York, Oxford, 1997.

Nowak, J. B., Davis, D. D., Chen, G., Eisele, F. L., Mauldin III, R. L., Tanner, D. J., Cantrell, C., Kosciuch, E., Bandy, A., Thornton, D., and Clarke, A.: Airborne observations of DMSO, DMS, and $\mathrm{OH}$ at marine tropical latitudes, Geophys. Res. Lett., 28, 2201-2204, 2001.

Oum, K. W., Lakin, M. J., and Finlayson-Pitts, B. J.: Bromine activation in the troposphere by the dark reaction of $\mathrm{O}_{3}$ with seawater ice, Geophys. Res. Lett., 25, 3923-3926, 1998.

Perner, D., Crutzen, P. J., von Glasow, R., Klüpfel, T., Martinez, M., Sander, R., and Keene, W. C.: Halogen oxides above the Pacific Ocean, Eos, Trans. AGU (Abstract Supplement), 81/48, F165, 2000.

Phillips, C. A., Howell, S. G., Huebert, B. J., and Zhuang, L.: Bromide in the remote marine boundary layer, Eos, Trans. AGU (Abstract Supplement), 81/48, F151, 2000.

Prospero, J. M., Barrett, K., Church, T., Dentener, F., Duce, R. A., Galloway, J. N., Levy II, H., Moody, J., and Quinn, P.: Atmospheric deposition of nutrients to the North Atlantic basin, Biogeochem., 35, 27-73, 1996.

Pszenny, A., Fischer, C., Mendez, A., and Zetwo, M.: Direct comparison of cellulose and quartz fiber filters for sampling submicrometer aerosols in the marine boundary layer, Atmos. Environ., 27A, 281-284, 1993.

Pszenny, A. A. P.: Atmospheric deposition of nitrate to the ocean surface, Ph.D. thesis, University of Rhode Island, Kingston, 1987.

Pszenny, A. A. P.: Particle size distributions of methanesulfonate in the tropical Pacific marine boundary layer, J. Atmos. Chem., 14, 273-284, 1992.

Pszenny, A. A. P., MacIntyre, F., and Duce, R. A.: Sea-salt and the acidity of marine rain on the windward coast of Samoa, Geophys. Res. Lett., 9, 751-754, 1982.

Pszenny, A. A. P., Castelle, A. J., Galloway, J. N., and Duce, R. A.: A study of the sulfur cycle in the Antarctic marine boundary layer, J. Geophys. Res., 94, 9818-9830, 1989.

Pszenny, A. A. P., Moldanová, J., Keene, W. C., Sander, R., Maben, J. R., Martinez, M., Crutzen, P. J., Perner, D., and Prinn, R. G.: Halogen cycling and aerosol $\mathrm{pH}$ in the Hawaiian marine boundary layer, Atmos. Chem. Phys. Discuss., 3, 4701-4753, 2003.

Pundt, I., van Roozendael, M., Wagner, T., Richter, A., Chipperfield, M. P., Burrows, J. P., Fayt, C., Hendrick, F., Pfeilsticker, K., Platt, U., and Pommereau, J. P.: Simultaneous UV-vis Measurements of $\mathrm{BrO}$ from Balloon, Satellite and Ground: Impli- cations for Tropospheric BrO, in: Air Pollution Research Report 73, Proc. 5th European Symposium on Polar Stratospheric Ozone 1999, CEC, edited by Harris, N. R. P., Guirlet, M., and Amanatis, G. T., pp. 316-319, 2000.

Quack, B. and Wallace, D. W. R.: Air-sea flux of bromoform: Controls, rates, and implications, Global Biogeochem. Cycles, 17, 10.1029/2002GB001 890, 2003.

Rader, D. J. and Marple, V. A.: A study of the effects of anisokinetic sampling, Aerosol Sci. Technol., 8, 283-299, 1988.

Raemdonck, H., Maenhaut, W., and Andreae, M. O.: Chemistry of marine aerosol over the tropical and equatorial Pacific, J. Geophys. Res., 91D, 8623-8636, 1986.

Rahn, K. A., Borys, R. D., and Duce, R. A.: Tropospheric halogen gases: Inorganic and organic components, Science, 192, 549550, 1976.

Rancher, J. and Kritz, M. A.: Diurnal fluctuations of Br and I in the tropical marine atmosphere, J. Geophys. Res., 85C, 5581-5587, 1980.

Richter, A., Wittrock, F., Eisinger, M., and Burrows, J. P.: GOME observations of tropospheric $\mathrm{BrO}$ in northern hemispheric spring and summer 1997, Geophys. Res. Lett., 25, 2683-2686, 1998.

Rudich, Y., Talukdar, R. K., and Ravishankara, A. R.: Multiphase chemistry of $\mathrm{NO}_{3}$ in the remote troposphere, J. Geophys. Res., 103D, 16 133-16 143, 1998.

Sadasivan, S.: Trace elements in size separated aerosols over sea, Atmos. Environ., 12, 1677-1683, 1978.

Sadasivan, S.: Trace constituents in cloud water, rainwater and aerosol samples collected near the west coast of India during the southwest monsoon, Atmos. Environ., 14, 33-38, 1980.

Sadasivan, S. and Anand, S. J. S.: Chlorine, bromine and iodine in monsoon rains in India, Tellus, 31, 290-294, 1979.

Saito, K., Muto, H., Takizama, Y., and Kodama, M.: Concentrations of various elements and inorganic ions in rice straw and ash, Toxicol. Environ. Chem., 41, 15-20, 1994.

Sander, R.: Compilation of Henry's law constants for inorganic and organic species of potential importance in environmental chemistry (version 3), http://www.mpch-mainz.mpg.de/ $\sim_{\text {sander/res/ }}$ henry.html, 1999.

Sander, R. and Crutzen, P. J.: Model study indicating halogen activation and ozone destruction in polluted air masses transported to the sea, J. Geophys. Res., 101D, 9121-9138, 1996.

Sander, R., Rudich, Y., von Glasow, R., and Crutzen, P. J.: The role of $\mathrm{BrNO}_{3}$ in marine tropospheric chemistry: A model study, Geophys. Res. Lett., 26, 2857-2860, 1999.

Schauffler, S. M., Atlas, E. L., Flocke, F., Leub, R. A., Stroud, V., and Travnicek, W.: Measurements of bromine-containing organic compounds at the tropical tropopause, Geophys. Res. Lett., 25, 317-320, 1998.

Schütz, L. and Rahn, K.: Trace-element concentrations in erodible soils, Atmos. Environ., 16, 171-176, 1982.

Sciare, J., Baboukas, E., Kanakidou, M., Krischke, U., Belviso, S., Bardouki, H., and Mihalopoulos, N.: Spatial and temporal variability of atmospheric sulfur-containing gases and particles during the Albatross campaign, J. Geophys. Res., 105D, $14433-$ $14448,2000$.

Seto, Y.-B., Duce, R. A., and Woodcock, A. H.: Sodium-to-chlorine ratio in Hawaiian rains as a function of distance inland and of elevation, J. Geophys. Res., 74, 1101-1103, 1969.

Slocum, D. H., McGinnes, Jr., E. A., and McKown, D. M.: Elemen- 
tal analysis of oak and hickory charcoal using neutron activation analysis, Wood Fiber, 10, 200-209, 1978.

Spicer, C. W., Chapman, E. G., Finlayson-Pitts, B. J., Plastridge, R. A., Hubbe, J. M., Fast, J. D., and Berkowitz, C. M.: Unexpectedly high concentrations of molecular chlorine in coastal air, Nature, 394, 353-356, 1998.

Stumm, W. and Brauner, P. A.: Chemical Speciation, in: Chemical Oceanography, Vol. 1, 2nd Ed., edited by Riley, J. P. and Skirrow, G., pp. 173-239, Academic Press, 1975.

Sturges, W. T.: Excess particulate and gaseous bromine at a remote coastal location, Atmos. Environ., 24A, 167-171, 1990.

Sturges, W. T. and Harrison, R. M.: Bromine:lead ratios in airborne particles from urban and rural sites, Atmos. Environ., 20, 577588, 1986a.

Sturges, W. T. and Harrison, R. M.: Bromine in marine aerosols and the origin, nature and quantity of natural atmospheric bromine, Atmos. Environ., 20, 1485-1496, 1986b.

Sturges, W. T., Harrison, R. M., and Dams, R.: Development of a technique for the determination of lead and bromine in atmospheric particles by X-ray fluorescence, Atmos. Environ., 19, 1495-1502, 1985.

Sturges, W. T., Schnell, R. C., Dutton, G. S., Garcia, S. R., and Lind, J. A.: Spring measurements of tropospheric bromine at Barrow, Alaska, Geophys. Res. Lett., 20, 201-204, 1993.

Stutz, J., Ackermann, R., Fast, J. D., and Barrie, L.: Atmospheric reactive chlorine and bromine at the Great Salt Lake, Utah, Geophys. Res. Lett., 29, 10.1029/2002GL014 812, 2002.

Swap, R., Garstang, M., Greco, S., Talbot, R., and Kallberg, P.: Saharan dust in the Amazon basin, Tellus, 44B, 133-149, 1992.

Swietlicki, E.: European source region identification of long range transported ambient aerosol based on PIXE analysis and related techniques, Ph.D. thesis, Lund University, Sweden, 1989.

Thomas, V. M., Bedford, J. A., and Cicerone, R. J.: Bromine emissions from leaded gasoline, Geophys. Res. Lett., 24, 1371-1374, 1997.

Toumi, R.: BrO as a sink for dimethylsulphide in the marine atmosphere, Geophys. Res. Lett., 21, 117-120, 1994.

Troy, R. C. and Margerum, D. W.: Non-metal redox kinetics: Hypobromite and hypobromous acid reactions with iodide and with sulfite and the hydrolysis of bromosulfate, Inorg. Chem., 30, 3538-3543, 1991.

Tuckermann, M., Ackermann, R., Gölz, C., Lorenzen-Schmidt, H., Senne, T., Stutz, J., Trost, B., Unold, W., and Platt, U.: DOASobservation of halogen radical-catalysed arctic boundary layer ozone destruction during the ARCTOC campaign 1995 and 1996 in Ny-Ålesund, Spitzbergen, Tellus, 49B, 533-555, 1997.

Turekian, V. C.: The application of chemical and isotopic tracers to characterize aerosol sources and processing in marine air, Ph.D. thesis, University of Virginia, 2000.

Turekian, V. C., Macko, S. A., and Keene, W. C.: Application of stable sulfur isotopes to differentiate sources of size-resolved particulate sulfate in polluted marine air at Bermuda during spring, Geophys. Res. Lett., 28, 1491-1494, 2001.

Turekian, V. C., Macko, S. A., and Keene, W. C.: Concentrations, isotopic compositions, and sources of size-resolved, particulate organic carbon and oxalate in near-surface marine air at Bermuda during spring, J. Geophys. Res., 108D, 4157, 10.1029/2002JD002 053, 2003.

Turn, S. Q., Jenkins, B. M., Chow, J. C., Pritchett, L. C., Campbell, D., Cahill, T., and Whalen, S. A.: Elemental characterization of particulate matter emitted from biomass burning: Wind tunnel derived source profiles for herbaceous and wood fuels, J. Geophys. Res., 102D, 3683-3699, 1997.

Vogt, R., Crutzen, P. J., and Sander, R.: A mechanism for halogen release from sea-salt aerosol in the remote marine boundary layer, Nature, 383, 327-330, 1996.

Vogt, R., Sander, R., von Glasow, R., and Crutzen, P. J.: Iodine chemistry and its role in halogen activation and ozone loss in the marine boundary layer: A model study, J. Atmos. Chem., 32, 375-395, 1999.

von Glasow, R., Sander, R., Bott, A., and Crutzen, P. J.: Modeling halogen chemistry in the marine boundary layer. 1 . Cloud-free MBL, J. Geophys. Res., 107D, 4341, 10.1029/2001JD000 942, 2002a.

von Glasow, R., Sander, R., Bott, A., and Crutzen, P. J.: Modeling halogen chemistry in the marine boundary layer. 2. Interactions with sulfur and the cloud-covered MBL, J. Geophys. Res., 107D, 4323, 10.1029/2001JD000 943, 2002 b.

Wachsmuth, M., Gäggeler, H. W., von Glasow, R., and Ammann, M.: Accommodation coefficient of $\mathrm{HOBr}$ on deliquescent sodium bromide aerosol particles, Atmos. Chem. Phys., 2, 121131, 2002.

Wagner, T. and Platt, U.: Satellite mapping of enhanced BrO concentrations in the troposphere, Nature, 395, 486-490, 1998.

Wagner, T., Leue, C., Wenig, M., Pfeilsticker, K., and Platt, U.: Spatial and temporal distribution of enhanced boundary layer BrO concentrations measured by the GOME instrument aboard ERS2, J. Geophys. Res., 106D, 24 225-24 235, 2001.

Wedepohl, K. H.: The composition of the continental crust, Geochim. Cosmochim. Acta, 59, 1217-1232, 1995.

Willeke, K.: Performance of the slotted impactor, Am. Ind. Hyg. Assoc. J., 36, 683-691, 1975.

Wilson, T. R. S.: Salinity and the major elements of sea water, in: Chemical Oceanography, Vol. 1, 2nd Ed., edited by Riley, J. P. and Skirrow, G., pp. 365-413, Academic Press, 1975.

WMO: Scientific Assessment of Ozone Depletion: 1998, Global Ozone Research and Monitoring Project, Report no. 44, World Meteorological Organization, Geneva, 1998.

Woodcock, A. H.: Salt nuclei in marine air as a function of altitude and wind force, J. Meteorol., 10, 362-371, 1953.

Yokouchi, Y., Machida, T., Barrie, L. A., Toom-Sauntry, D., Nojiri, Y., Fujinuma, Y., Inuzuka, Y., Li, H.-J., Akimoto, H., and Aoki, S.: Latitudinal distribution of atmospheric methyl bromide: measurements and modeling, Geophys. Res. Lett., 27, 697-700, 2000.

Zafiriou, O. C.: Photochemistry of halogens in the marine atmosphere, J. Geophys. Res., 79, 2730-2732, 1974.

Zhou, M. Y., Yang, S. J., Parungo, F. P., and Harris, J. M.: Chemistry of marine aerosols over the western Pacific Ocean, J. Geophys. Res., 95D, 1779-1787, 1990. 